\title{
Representação Compressiva de Malhas
}

\author{
Mesh Compressive Representation
}

\author{
SÃO PAULO \\ 2014
}




\section{Representação Compressiva de Malhas}

Dissertação apresentada à Escola de Artes, Ciências e Humanidades da Universidade de São Paulo para obtenção do título de Mestre em Ciências do Programa de Pós-Graduação em Sistemas de Informação

Versão corrigida contendo as alterações solicitadas pela comissão julgadora em 17 de fevereiro de 2014 . A versão original encontra-se em acervo reservado na Biblioteca da EACH/USP e na Biblioteca Digital de Teses e Dissertações da USP (BDTD), de acordo com a Resolução CoPGr 6018, de 13 de outubro de 2011.

Área de Concentração: Ciência da Computação

Orientador(a): Prof. Dr. Helton Hideraldo Bíscaro 
Autorizo a reprodução e divulgação total ou parcial deste trabalho, por qualquer meio convencional ou eletrônico, para fins de estudo e pesquisa, desde que citada a fonte.

\section{CATALOGAÇÃO-NA-PUBLICAÇÃO}

Biblioteca

Escola de Artes, Ciências e Humanidades da Universidade de São Paulo

Lima, José Paulo Rodrigues de

Representação compressiva de malhas / José Paulo Rodrigues de

Lima ; orientador, Helton Hideraldo Bíscaro. - São Paulo, 2014.

xvi, 85 f. : il.

Dissertação (Mestrado em Ciências) - Programa de Pós-

Graduação em Sistemas de Informação, Escola de Artes, Ciências e Humanidades, Universidade de São Paulo, em 2014.

Versão corrigida.

1. Processamento de imagens. 2. Algoritmos para imagens. 3. Algoritmos e estrutura de dados.. I. Bíscaro, Helton Hideraldo, orient. II. Título.

CDD 22.ed. -621.367 
Folha de Aprovação

Dissertação sob o título "Representação Compressiva de Malhas", defendida por José Paulo Rodrigues de Lima e aprovada em 17 de fevereiro de 2014, em São Paulo, Estado de São Paulo, pela banca examinadora constituída pelos doutores:

Prof. Dr. Helton Hideraldo Bíscaro Orientador

Prof. Dr. João Paulo Gois Universidade Federal do ABC

Prof. ${ }^{a}$ Dr. ${ }^{a}$ Fátima L. S. Nunes Marques Universidade de São Paulo 
Para meu amor, Nara Escarabelin Martins.

Em memória de Sebastião Rodrigues de Lima e Carmela Canale Rodrigues de Lima. 
Um agradecimento especial para aquele sem o qual este trabalho não seria possível: Dr. Helton Bíscaro. Sua orientação foi ímpar.

Agradeço à minha esposa Nara e minha família por me acompanhar nesta jornada. Obrigado pela paciência. Uma lembrança especial para Maria Aparecida, Pedro Luiz Martins, Marlene Escarabelin Martins, Pedro Henrique Escarabelin Martins, Juliana Escarabelin Martins, Sílvio Custódio, Anderson Pereira, Rafael Angelo, Luis Marsoti, Ariane Marsoti, Paulo Eduardo e Leandro da Silva. Obrigado por entenderem minha ausência em vários momentos. 
Isso aqui é trabalho, meu filho!

(Muricy Ramalho, 2013) 


\section{Resumo}

LIMA, José Paulo Rodrigues de. Representação Compressiva de Malhas. 2014. 101 f. Dissertação (Mestrado em Ciências pelo Programa de Pós-Graduação em Sistemas de Informação) - Escola de Artes, Ciências e Humanidades, Universidade de São Paulo, São Paulo, 2014

A compressão de dados é uma área de muito interesse em termos computacionais devido à necessidade de armazená-los e transmiti-los. Em particular, a compressão de malhas possui grande interesse em função do crescimento de sua utilização em jogos tridimensionais e modelagens diversas. Nos últimos anos, uma nova teoria de aquisição e reconstrução de sinais foi desenvolvida, baseada no conceito de esparsidade na minimização da norma $L_{1}$ e na incoerência do sinal, chamada Compressive Sensing (CS). Essa teoria possui algumas características marcantes, como a aleatoriedade de amostragem e a reconstrução via minimização, de modo que a própria aquisição do sinal é feita considerando somente os coeficientes significativos. Qualquer objeto que possa ser interpretado como um sinal esparso, permite sua utilização. Assim, ao se representar esparsamente um objeto (sons, imagens) é possível aplicar a técnica de CS. Este trabalho verifica a viabilidade da aplicação da teoria de CS na compressão de malhas, de modo que seja possível um sensoreamento e representação compressivos na geometria de uma malha. Nos experimentos realizados, foram utilizadas variações dos parâmetros de entrada e técnicas de minimização da Norma $L_{1}$. Os resultados obtidos mostram que a técnica de CS pode ser utilizada como estratégia de compressão da geometria das malhas.

Palavras-chave: compressão de malhas, Compressive Sensing, minimização norma $L_{1}$. 


\section{Abstract}

LIMA, José Paulo Rodrigues de. Mesh Compressive Representation. 2014. 101 p. Master Thesis (Master in Sciences by Systems Information Program) - School of Arts, Sciences and Humanities, University of São Paulo, São Paulo, 2014.

Data compression is an area of a major interest in computational terms due to the issues on storage and transmission. Particulary, mesh compression has wide usage due to the increase of its application in games and three-dimensional modeling. In recent years, a new theory of acquisition and reconstruction of signals was developed, based on the concept of sparsity and in the minimization of the $L_{1}$ norm and the incoherency of the signal, called Compressive Sensing (CS). This theory has some remarkable features, such as random sampling and reconstruction by minimization, in a way that the signal acquisition is done by considering only its significant coefficients. Any object that can be interpreted as a sparse sign allows its use. Thus, representing an object sparsely (sounds, images), you can apply the technique of CS. This work explores the viability of CS theory on mesh compression, so that it is possible a representative and compressive sensing on the mesh geometry. In the performed experiments, different parameters and $L_{1}$ Norm minimization strategies were used. The results show that CS can be used as a mesh geometry compression strategy.

Keywords: mesh compression, Compressive Sensing, $L_{1}$ norm minimization 


\section{Lista de Figuras}

1 Representação da estruturação de uma malha de um cogumelo. . . . . . . . . 5

$2 \quad$ Variação de planificação de malhas. . . . . . . . . . . . . . . . . 7

$3 \quad$ Árvore topológica da malha e grafo correspondente. . . . . . . . . . . . . . 7

4 Reconstrução da malha a partir da planificação. . . . . . . . . . . . . . . . 8

5 Representação do algoritmo de criação de patches a partir dos vértices. . . 9

$6 \quad$ Exemplo de reconstrução de geometria da malha via algoritmo de flipping. $\quad 10$

$7 \quad$ Particionamento da malha para aplicação de métodos espectrais. . . . . . . . 10

$8 \quad$ Grids de quantização. . . . . . . . . . . . . . . . . . . . . . 11

$9 \quad$ Resultado de compressão progressiva com árvore binária. . . . . . . . . . . . 12

10 Esquematização visual do algoritmo de compressão baseado em malhas triangulares. . . . . . . . . . . . . . . . . . . . . . 13

11 Esquema de reconstrução de malhas por Wavelets. . . . . . . . . . . . . . . 14

12 Representação gráfica do problema algébrico . . . . . . . . . . . . . . . . . 18

13 Esparsidade e Norma $L_{1} \ldots \ldots \ldots \ldots \ldots$. . . . . . . . . . . . 25

14 Exemplo Ilustrativo - Sinal Original. . . . . . . . . . . . . . . . . . . 28

$15 \quad$ Exemplo Ilustrativo - Sinal Reconstruído $m=8$. . . . . . . . . . . . . . . 29

$16 \quad$ Exemplo Ilustrativo - Sinal Reconstruído $m=6 . \ldots \ldots$. . . . . . . . . . . 29

17 Exemplo Ilustrativo - Sinal Reconstruído $m=4$. . . . . . . . . . . . . . . 30

18 Compressão de Imagem e reconstrução a partir de coeficientes de matriz Wavelet. . . . . . . . . . . . . . . . . . . . . 31

19 Exemplo de reconstrução de imagem com CS com árvore estruturada e técnica CoSaMP. . . . . . . . . . . . . . . . . . . . . . . . . 31 
20 Diagrama de câmera de um pixel. . . . . . . . . . . . . . . . . 32

21 Modelo de gráfico de mapa de cores. . . . . . . . . . . . . . . . . . . . . . 40

22 Modelo gráfico Hausdorff X BPV. . . . . . . . . . . . . . . . . . . . . 41

23 Modelo gráfico PSNR X BPV. . . . . . . . . . . . . . . . . . . . . 41

24 Resultados Experimento - Cogumelo. . . . . . . . . . . . . . . . . . 43

25 Resultados Experimento - Manequim. . . . . . . . . . . . . . . . 45

26 Resultados Experimento - Cavalo. . . . . . . . . . . . . . . . . . . 47

27 Resultados Experimento - Vaca. . . . . . . . . . . . . . . . . . . . . 49

28 Resultados Experimento - Cabeça de Davi. . . . . . . . . . . . . . . . . . . 51

29 Resultados Experimento - Homem. . . . . . . . . . . . . . . . . . 53

30 Resultados Experimento - Fandisk . . . . . . . . . . . . . . 55

31 Resultados Experimento - Elefante. . . . . . . . . . . . . . . . . . . . 57

32 Resultados Experimento - Coelho. . . . . . . . . . . . . . . . . . . 59

33 Resultados Experimento - Dragão. . . . . . . . . . . . . . . . . . . 60 


\section{Lista de Tabelas}

$1 \quad$ Exemplos de Aplicações de CS em Diferentes Áreas. . . . . . . . . . . . . . . . 32

2 Relação de Malhas Utilizadas nos Experimentos. . . . . . . . . . . . . . . . 42

3 Resumo das Variações dos Experimentos. . . . . . . . . . . . . . . . . . . . 61

4 Comparativo de Taxas de BPV em alguns algoritmos. . . . . . . . . . . . . 62

$5 \quad$ Bibliotecas Utilizadas nos Experimentos $\ldots \ldots \ldots$. . . . . . . . . . . 79 


\section{Lista de Abreviaturas e Siglas}

BPV Bits por Vértice,

p. 38

HD Distância de Hausdorff,

p. 37

MRI Magnetic Resonance Images,

p. 32

PSNR Peak Signal to Noise Ratio,

p. 37

REQM Raiz do Erro Quadrático Médio,

p. 38

SVD Single Value Decomposition,

p. 21

TV Total Variation,

p. 23 


\section{Sumário}

\begin{tabular}{lll}
\hline 1 & Introdução & 1
\end{tabular}

1.1 Apresentação $\ldots \ldots \ldots \ldots \ldots$. . . . . . . . . . . . . . . . . . . . 1

1.2 Objetivo . . . . . . . . . . . . . . . . . . . . . . . 2

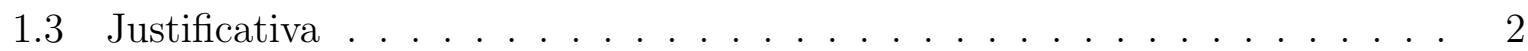

1.4 Materiais e Métodos . . . . . . . . . . . . . . . . . . . . . . 2

1.5 Organização do Trabalho . . . . . . . . . . . . . . . . . . . . . . . . . . . . 3

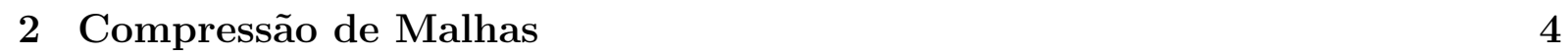

2.1 Introdução $\ldots \ldots \ldots \ldots \ldots \ldots$. . . . . . . . . . . . . . . . . . . 4

2.2 Geometria, Conectividade e Compressão $\ldots \ldots \ldots \ldots$

2.2 .1 Compressão de Conectividade . . . . . . . . . . . . . . . . 6

$2.2 .2 \quad$ Compressão de Geometria $\ldots \ldots \ldots$. . . . . . . . . . . . . . . . . 9

$2.2 .3 \quad$ Triangle Mesh . . . . . . . . . . . . . . . . . . . . . . . . . 11

2.2 .4 Wavemesh . . . . . . . . . . . . . . . . . . . . 14

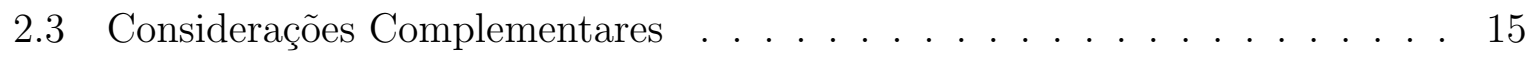

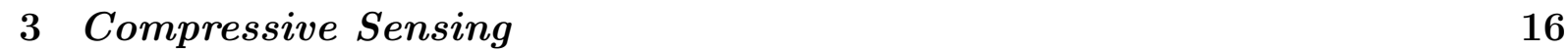

3.1 Introdução $\ldots \ldots \ldots \ldots \ldots \ldots$

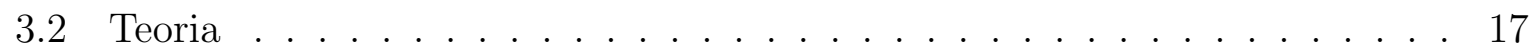

$3.3 \quad$ Esparsidade, Isotropia e Incoerência . . . . . . . . . . . . . . . . . . . . . . 18

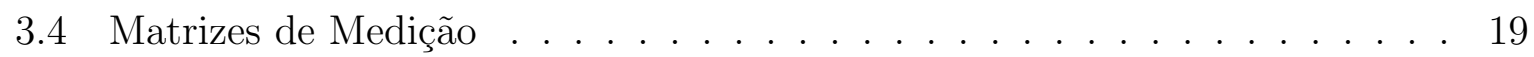

3.4 .1 Matriz Gaussiana . . . . . . . . . . . . . . . . . . . . 20 
3.4 .2 Matriz Wavelet . . . . . . . . . . . . . . . . . . 21

3.4 .3 Matriz Noiselet . . . . . . . . . . . . . . . . . . . . . 22

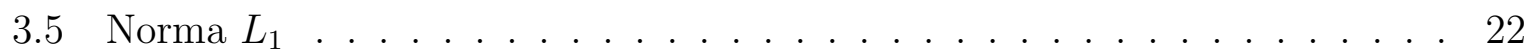

3.6 Total Variation . . . . . . . . . . . . . . . . . . . . 23

3.7 Minimização da Norma $L_{1} \ldots \ldots \ldots \ldots \ldots \ldots \ldots \ldots \ldots \ldots$

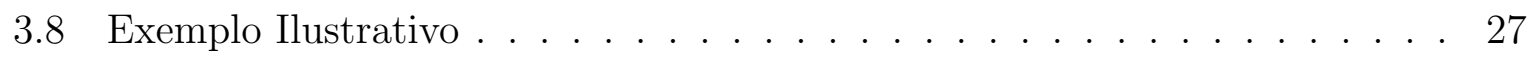

3.9 Aplicações $\ldots \ldots \ldots \ldots \ldots \ldots$

4 Compressive Sensing aplicado em Malhas 33

4.1 Introdução . . . . . . . . . . . . . . . . . . . . . . . . . . 33

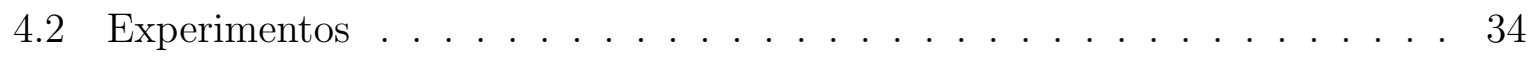

4.2 .1 Métricas de Avaliação . . . . . . . . . . . . . . . . . . 37

4.2 .2 Distância de Hausdorff $\ldots \ldots \ldots$. . . . . . . . . . . . . . 37

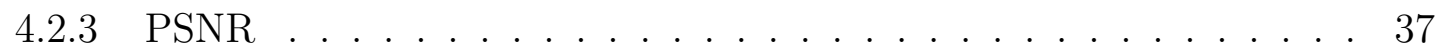

$4.2 .4 \quad$ Bits Por Vértice $(\mathrm{BPV}) \quad \ldots \ldots \ldots \ldots \ldots \ldots$

4.2 .5 Variações do Experimento . . . . . . . . . . . . . . . . . . . . 39

\begin{tabular}{lll}
\hline 5 & Resultados & 42
\end{tabular}

5.1 Cogumelo $\ldots \ldots \ldots \ldots \ldots \ldots \ldots \ldots \ldots \ldots \ldots \ldots \ldots \ldots$

$5.1 .1 \quad$ Análise dos Resultados do Cogumelo . . . . . . . . . . . . . 44

5.2 Manequim $\ldots \ldots \ldots \ldots \ldots \ldots \ldots \ldots \ldots \ldots \ldots$

$5.2 .1 \quad$ Análise dos Resultados do Manequim . . . . . . . . . . . . . 46

5.3 Cavalo . . . . . . . . . . . . . . . . . . . . . . . 47

5.3 .1 Análise dos Resultados do Cavalo . . . . . . . . . . . . . . . 47

5.4 Vaca $\ldots \ldots \ldots \ldots \ldots \ldots \ldots \ldots$

5.4 .1 Análise dos Resultados da Vaca . . . . . . . . . . . . . . . . 49

5.5 Cabeça de Davi $\ldots \ldots \ldots \ldots \ldots \ldots \ldots$ 
5.5 .1 Análise dos Resultados da Cabeça de Davi . . . . . . . . . . . . . . 52

5.6 Homem . . . . . . . . . . . . . . . . . . . . . . . 53

5.6 .1 Análise dos Resultados do Homem . . . . . . . . . . . . . . . . . . 54

5.7 Fandisk . . . . . . . . . . . . . . . . . . . . 55

5.7 .1 Análise dos Resultados do Fandisk . . . . . . . . . . . . . . . . 55

5.8 Elefante . . . . . . . . . . . . . . . . . . . . . . . . . 57

5.8 .1 Análise dos Resultados do Elefante . . . . . . . . . . . . . . . . . . 58

5.9 Coelho . . . . . . . . . . . . . . . . . . . . . . . . . . . . . . 59

$5.9 .1 \quad$ Análise dos Resultados do Coelho . . . . . . . . . . . . . . . . . . . 59

5.10 Dragão . . . . . . . . . . . . . . . . . . . . . 60

5.10 .1 Análise dos Resultados do Dragão . . . . . . . . . . . . . . . . . . . 61

5.11 Análise Complementar . . . . . . . . . . . . . . . . . . . . . 61

5.12 Discussão $\ldots \ldots \ldots \ldots$. . . . . . . . . . . . . . . . . . 62

\begin{tabular}{lll}
\hline 6 & Conclusão & 64
\end{tabular}

6.1 Contribuições . . . . . . . . . . . . . . . . . . . . 65

6.2 Trabalhos Futuros . . . . . . . . . . . . . . . . . . . 65

\begin{tabular}{|ll|}
\hline Apêndice A & Biblioteca de Códigos \\
\hline
\end{tabular}

A.1 Arquivo de Controle . . . . . . . . . . . . . . . . . 67

A.2 Processamento Noiselet. . . . . . . . . . . . . . . . . . . . . . . . . . . 71

A.3 Parametrização dos Experimentos . . . . . . . . . . . . . . . . . . . . 79

\begin{tabular}{lr}
\hline Referências & 81
\end{tabular} 


\section{Introdução}

\subsection{Apresentação}

Nos últimos anos, a compressão de dados tem sido importante para seu armazenamento e sua transmissão em diversos meios (rádio, internet, wireless, etc.). Em função do crescimento da utilização de malhas tridimensionais em aplicações como jogos e modelagens diversas, o tratamento compressivo dessas malhas ganhou relevância e se tornou objeto de estudo ((BOUZIDI et al., 2013), (LUFFEL et al., 2013), (YOON; KUIJPER, 2011), LEE et al., 2010)).

Paralelamente, uma nova teoria foi desenvolvida para realizar sensoreamento compressivo de sinais, chamada Compressive Sensing (CS) (CANDÈS; WAKIN, 2007). Essa teoria introduziu um novo ponto de vista para reconstrução de sinais, além de reduzir alguns limites teóricos bem consolidados, como a Taxa de Nyquist de compressão de sinais, de forma que um valor mínimo estipulado em função da frequência do sinal estabelecia uma barreira intransponível. A teoria de CS conseguiu provar que a Taxa de Nyquist pode ser reduzida consideravelmente e a amostragem do sinal para sua reconstrução pode ser realizada de forma aleatória, desde que o sinal seja esparso (CANDèS et al., 2006). Além de reduzir a Taxa de Nyquist, o novo paradigma introduzido permite realizar a aquisição de dados de forma compressiva, o que proporciona um ganho computacional deveras considerável (DUARTE; ELDAR, 2011)

A característica técnica da CS de realizar a aquisição compressiva dos dados, tornou-se importante também como técnica compressiva. Essa característica incentivou experimentos com utilização de CS em diversos campos, em especial no tratamento de imagens. O processamento gráfico mostrou particular interesse na amostragem compressiva e na posterior reconstrução da imagem, de modo que os resultados obtidos nada devem para as técnicas de compressão clássicas (SCHULZ, 2008).

Nesse contexto, este trabalho tem por objetivo adaptar a técnica de CS para malhas, 
de modo a explorar as características peculiares dessa teoria em modelos tridimensionais. Primeiramente, deseja-se realizar uma prova de conceito para determinar se a teoria de CS é aplicável em malhas. Conforme apresentado nos capítulos seguintes, houve sucesso nessa etapa, de modo que a pesquisa se mostra viável. Na sequência deste trabalho, serão analisados dados comparativos entre as diferentes variações de CS utilizadas no experimento inicial.

\subsection{Objetivo}

O objetivo desta dissertação é avaliar a utilização da teoria de Compressive Sensing como técnica de compressão de malhas.

\subsection{Justificativa}

A utilização de modelos tridimensionais tem sido importante em diversas áreas da computação. Uma vez que a transmissão via redes e armazenagem desses modelos em diversas mídias ganham importância, a utilização de métodos de compressão torna-se pertinente para reduzir os custos dessa necessidade (tempo de transmissão e espaço de armazenamento).

Nesse sentido, várias técnicas de compressão têm sido utilizadas para compactação de modelos tridimensionais ( ALLIEZ; DESBRUN, 2001), (MAMOU et al., 2010), (HONGNIAN et al. 2009)). A aplicação de Compressive Sensing como técnica de compressão torna-se pertinente para adicionar uma nova abordagem ao assunto.

Dessa maneira, justifica-se uma pesquisa para avaliação de viabilidade da técnica e apresentação de resultados preliminares.

\subsection{Materiais e Métodos}

Para alcançar o objetivo descrito na Seção 1.2 , foi realizada uma pesquisa em revisão sistemática nas bibliotecas digitais a fim de encontrar referências que sustentem este trabalho.

O protocolo de pesquisa utilizado buscou palavras-chave (mesh compression, compressive sensing, 3D models) nas bases digitais IEEE Xplore, ACM Digital Library e Teses da 
USP. Inicialmente, foi feito um filtro com período de 2 anos, para obtenção dos trabalhos mais recentes. As teorias gerais básicas foram extraídas de artigos mais antigos, por se tratarem de teoria clássica do assunto.

Um algoritmo, implementado no software Matlab (MATLAB, 2010) foi desenvolvido, para aplicar a técnica de Compressive Sensing em um conjunto de malhas para teste.

Os resultados dos experimentos foram registrados em gráficos para análise dos dados.

\subsection{Organização do Trabalho}

Este trabalho está organizado de forma a definir e contextualizar os conceitos necessários para compressão de malhas, apresentados no Capítulo 2. Na sequência, é apresentada a teoria da Compressive Sensing, presente no Capítulo 3 . No Capítulo 4, é apresentada a aplicação da teoria de CS dentro do universo das malhas e o experimento realizado como prova de conceito. No Capítulo 5 são demonstrados os resultados alcançados com os experimentos. Finalmente, no Capítulo 6 são apresentadas as conclusões desta pequisa. 


\section{Compressão de Malhas}

\subsection{Introdução}

Técnicas de compressão são largamente utilizadas em vários tipos de estruturas de dados (SCHULZ, 2008). Tais técnicas têm como objetivo reduzir o máximo possível a representação binária da estrutura de modo que possa ser armazenada ou transmitida e reconstruída à forma original posteriormente.

A compressão de malhas possui o mesmo objetivo: reduzir o espaço necessário para a representação de uma determinada malha e permitir o caminho inverso, retornando à malha original após o processo compressivo (PENG et al., 2005).

As malhas são formadas por três componentes básicas: conectividade, geometria e propriedades. A conectividade descreve o relacionamento de adjacência entre os vértices. A geometria define a posição dos vértices no espaço (coordenadas $x, y, z)$. As propriedades definem diversos aspectos da malha, como textura e reflectância (PENG et al., 2005).

Malhas poligonais são representadas por polígonos geométricos. Dependendo da aplicação, malhas poligonais triangulares são as mais eficientes. (PENG et al., 2005). Em alguns casos, a representação de malhas por quadrados tem melhor aplicação, conforme apresentado no trabalho de Daniels (2010). As malhas triangulares são muito estudadas (LUFFEL et al., 2013), (YU et al., 2012), (CHEN et al., 2005). Do ponto de vista compressivo, existem trabalhos relacionando compressão da conectividade e da geometria JONG et al. 2005), (VALETTE; PROST, 2004b), (KARNI; GOTSMAN, 2001), (ALLIEZ; DESBRUN, 2001).

Na sequência, serão analisados com mais detalhes os componentes necessários para a compressão de malhas. 


\subsection{Geometria, Conectividade e Compressão}

A constituição de malhas obedece dois parâmetros necessários para sua representação: geometria e conectividade. A geometria da malha trata da localização espacial dos vértices que a compõem e a conectividade trata da relação entre esses pontos, especificando as arestas e faces da malha. CHEN et al. 2005).

Na Figura 1, são apresentados os elementos que compõem uma malha. O modelo representado do cogumelo possui 226 vértices, representados em (a). As faces representadas em (b) são a representação da conectividade da malha. Nessa figura, são 448 faces que constituem a malha. Por fim, em (c) é exibida a malha preenchida com uma possível colorização. É importante observar que o preenchimento e texturização da malha são representados pelas propriedades da malha, que forma a terceira componente de sua estrutura.

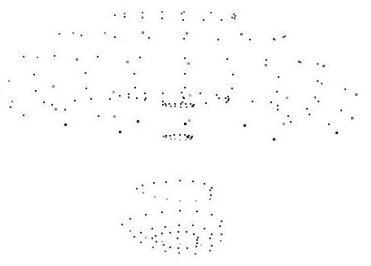

(a)

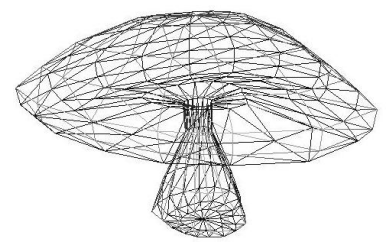

(b)

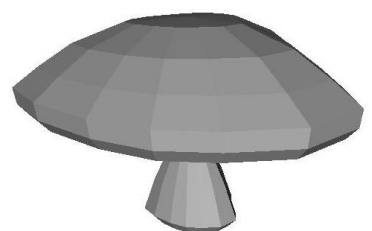

(c)

Figura 1 - Representação da estruturação de uma malha de um cogumelo: (a) Nuvem de pontos (geometria) representando a topologia; (b) Representação da conectividade e (c) Texturização da malha.

Conforme a demanda por malhas complexas torna-se maior, é necessária a utilização de mais memória para processamento, mais espaço para armazenamento e mais velocidade para transmissão dessas malhas ( $\mathrm{CHOW}, 1997)$. Dessa forma, as técnicas de compressão são utilizadas para otimizar o processamento, armazenamento e transmissão das malhas KHODAKOVSKY et al., 2000).

Métodos de compressão para objetos tridimensionais surgiram inicialmente em meados dos anos noventas e vêm evoluindo desde então (LEWINER, 2005). Essa evolução foi necessária em função da necessidade de transmissão e armazenamento crescente, além da criação de modelos de complexidade crescente. A compressão é uma negociação entre definir detalhamento e informação armazenada por bit. A medida de erro entre a malha original e a malha reconstruída pós-compressão é mais complicada de se calcular do que o erro em uma compressão de imagens (KHODAKOVSKY et al., 2000). Uma vez que não há uma correspondência imediata entre a superfície original e a superfície comprimida, 
não é possível simplesmente subtrair uma superfície da outra para encontrar o erro. Tal situação torna-se ainda mais problemática quando se trata de malhas muito densas.

Os conceitos de source (fonte) e code (codificado) é muito utilizado para tratar a compressão de forma geral. O processo de codificação trata da transformação de símbolos de um conjunto code para source. A codificação pode ser aplicada no sentido oposto, retornando o codificado ao fonte. O objetivo é representar o fonte de maneira mais conveniente, que basicamente é utilizada em armazenamento ou transmissão de dados LEWINER, 2005).

Dois aspectos que podem ser utilizados para a compressão de malhas são justamente a conectividade e a geometria.

\subsubsection{Compressão de Conectividade}

Também conhecida como topologia da malha, a conectividade é um dos aspectos que podem ser comprimidos na malha para reduzir o tamanho de armazenamento e transmissão (COHEN-OR et al., 1999). Uma das técnicas de compressão da conectividade foi desenvolvida por Rossignac (1998). A ideia básica consiste em utilizar a informação de arestas vizinhas de modo que a malha seja planificada e a informação de adjacência entre os polígonos é utilizada para realizar a compressão. A Figura 2 apresenta duas formas de planificação da malha, de modo que a partir dessa planificação, é realizado o encoding (compressão). Em (a) e (b) são apresentadas as malhas originais. Em (c) e (d), o recorte a partir dos polígonos. Em (e) e (f), a planificação. A partir disto, são criadas as árvores topológicas que contém a informação de conectividade necessária para recriar a malha após a compressão.

As árvores topológicas são formadas a partir de grafos de vértices e arestas da malha. Uma vez que a proximidade de vértices da árvore topológica implica em proximidade geométrica, os nós antecessores da árvore podem ser utilizados para realizar a predição da posição dos vértices seguintes e comprimir somente a diferença entre o vértice previsto e o vértice atual (TAUBIN; ROSSIGNAC, 1998). A Figura 3 apresenta o modelo esquemático de como é realizada a construção da árvore topológica e seu respectivo grafo. A partir da malha em (a), é criada a árvore de vértices (b). A planificação da malha em (c) a partir de (d) permite encaixar o grafo na figura planificada (f). Em (e), é apresentada a iteração necessária para percorrer toda a malha. A partir do polígono raiz em (g), o algoritmo segue com a busca, conforme (h) e (i). 


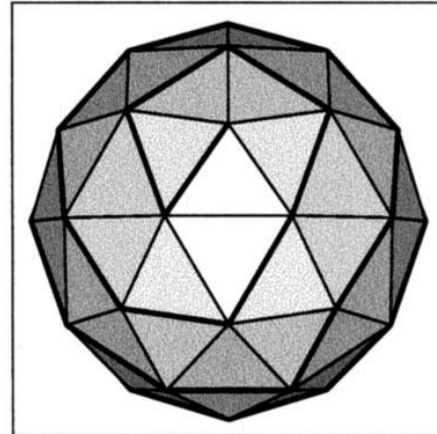

(a)

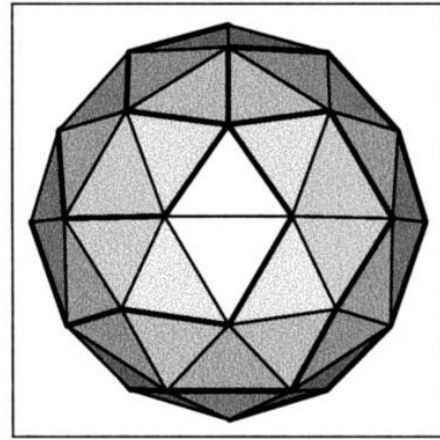

(b)

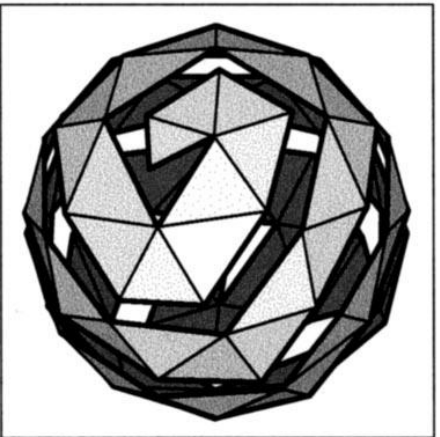

(c)

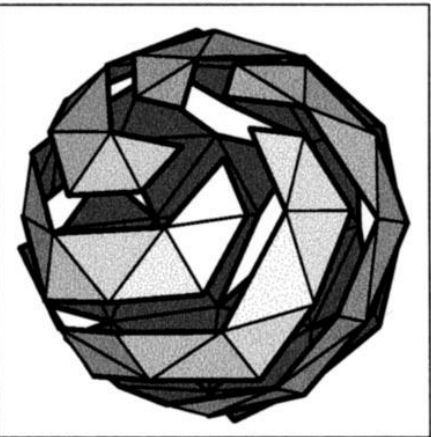

(d)

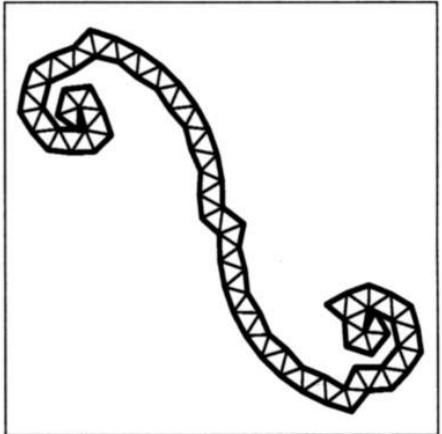

(e)

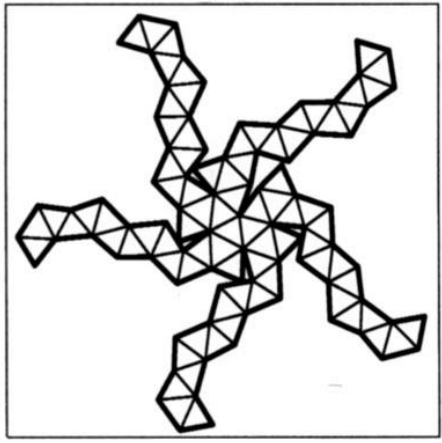

(f)

Figura 2 - Variação de planificação de malhas. Extraído de Taubin e Rossignac (1998).
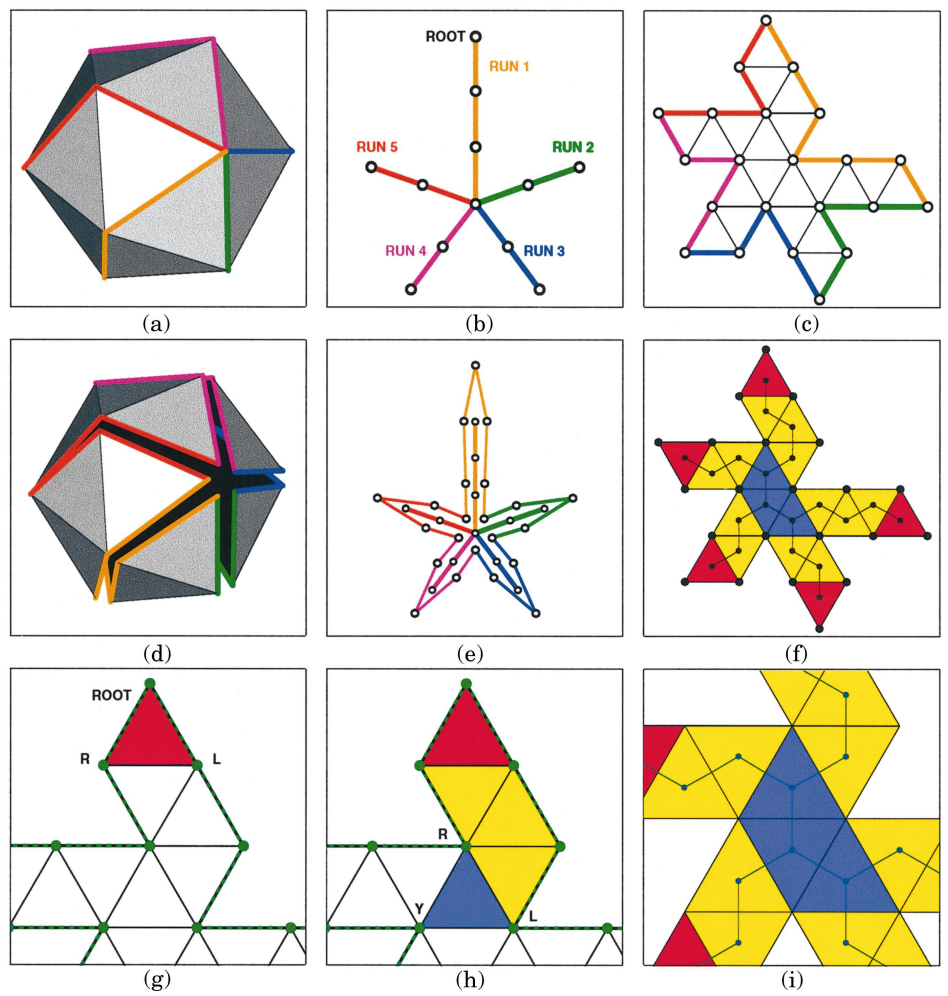

Figura 3 - Árvore topológica da malha e grafo correspondente. Extraído de Taubin e Rossignac (1998). 
Para realizar o caminho inverso, ou seja, a partir da compressão regressar à malha original são utilizados algoritmos que analisam a estrutura topológica da malha comprimida e realizam a reconstrução da malha planificada. A Figura 4 apresenta de maneira gráfica a reconstrução da malha a partir da árvore topológica e da reconstrução dos polígonos que a formam (TAUBIN; ROSSIGNAC, 1998). O algoritmo parte da raiz da árvore topológica e a percorre, realizando a reconstrução. O sentido de processamento é da esquerda para a direita. Os triângulos vermelhos são marcados quando encontram um polígono na extremidade da planificação. Os polígonos em azul representam o centro da planificação. Os polígonos em amarelo são os que conectam os extremos ao centro. A sequência de Figuras de (a) à (i) exemplificam como o algoritmo se comporta identificando e marcando os polígonos.

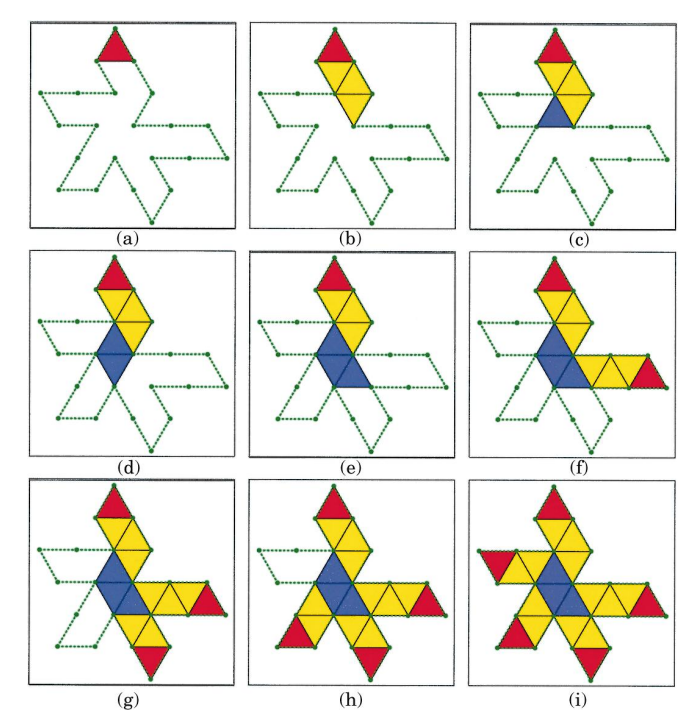

Figura 4 - Reconstrução da malha a partir da planificação. Extraído de Taubin e Rossignac (1998).

Outra forma de tratar a compressão de conectividade da malha é aplicar um algoritmo de simplificação da malha que iterativamente remove os conjuntos de vértices $u_{i}$ em uma versão simplificada da malha (COHEN-OR et al., 1999). No entanto, o algoritmo precisa garantir que o conjunto $u_{i}$ é independente, ou seja, não há arestas conectadas entre nenhum par de vértices em $u_{i}$. O conjunto selecionado deve então ser removido e substituído por um novo conjunto de polígonos. Uma vez que todos os buracos deixados pelo algoritmo foram preenchidos pelos novos polígonos chamados patches, esses patches são interpolados para prever o conjunto de pontos. Os pontos previstos são quantizados e podem ser representadas por quantidades menores de bits com entropia menor que os vértices originais (COHEN-OR et al. 1999). Essa técnica utiliza o recurso de colorir os polígonos utilizados para a formação do patch, de modo que na reconstrução a cor desse 


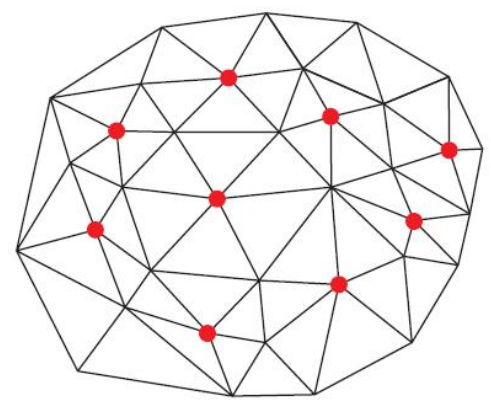

(a) Malha original com os vértices escolhidos.

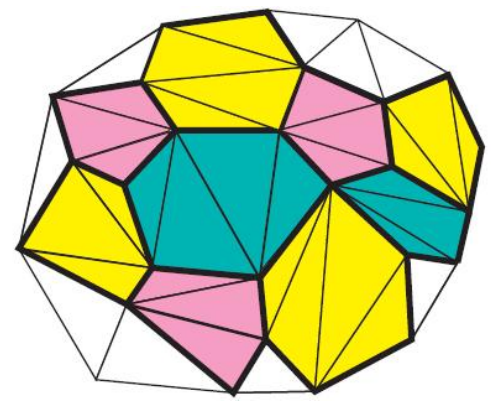

(b) Malha com os triângulos destacados a partir da anterior.

Figura 5 - Representação do algoritmo de criação de patches a partir dos vértices. Extraído de Cohen-Or et al. (1999).

polígono é utilizada como parâmetro. A Figura 5 representa a maneira como o algoritmo se comporta para identificar os patches. Em (a), são exibidos os vértices que não possuem adjacência. Em (b), são representados os patches com os polígonos substituídos. Observa-se que as cores são diferentes em função da adjacência entre cada patch criado. Os polígonos não processados permanecem sem cor.

\subsubsection{Compressão de Geometria}

A compressão de malhas via geometria refere-se a comprimir os pontos (vértices) da malha, preservando sua conectividade. Várias técnicas são utilizadas para esse tipo de compressão. O algoritmo de flipping cruza os triângulos da malha e prediz a posição do próximo vértice, utilizando a regra do paralelogramo, com boa aplicação em compressão de conectividade (CHEN et al., 2005). Esse algoritmo foi adaptado para tratar a geometria utilizando o conceito de grafo para representar os vértices da malha e as arestas para representar as operações de flipping. A Figura 6 apresenta o mecanismo desse algoritmo, onde o próximo vértice pode ser previsto a partir da operação de flipping determinada pela aresta do grafo. Cada seta representa o movimento do algoritmo entre dois vértices adjacentes. Os números asociados às setas e aos vértices previstos correspondentes indicam a ordem na qual foram previstos. Esse tipo de abordagem trata do problema localmente, ou seja, os vértices são previstos a partir de sua adjacência.

Outra abordagem para a compressão da geometria é a utilização de métodos espectrais, que trata da representação dos vetores de geometria da malha em vetores base, que são os autovetores da matriz Laplaciana da malha, derivada da conectividade KARNI; GOTSMAN, 2001). Utilizando funções bases fixas para codificação espectral da malha, é possível comprimir sua geometria, com alto grau de probabilidade e baixo erro. O 


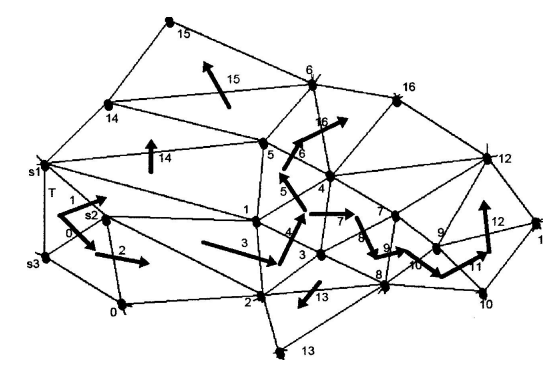

Figura 6 - Exemplo de reconstrução de geometria da malha via algoritmo de flipping. Extraído de Chen et al. (2005).

método proposto por (KARNI; GOTSMAN, 2001) utiliza uma malha padrão para tornar regular a malha a ser comprimida e na sequência, o algoritmo planifica a malha e realiza a compressão. Essa técnica apresenta a desvantagem de ser muito cara para calcular os autovetores quando aplicada em malhas muito grandes. Uma solução para o problema é realizar o particionamento da malha e aplicar a técnica em cada uma das partes separadamente (KARNI; GOTSMAN, 2000). Em contrapartida, a união dos segmentos da malha se torna um problema de certa complexidade que necessita ser abordado no momento da reconstrução da malha pós-compressão.

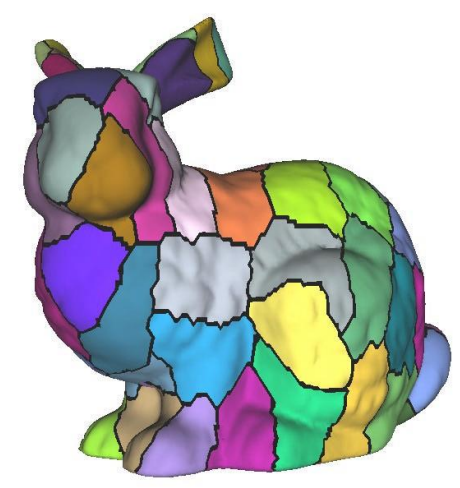

Figura 7 - Particionamento da malha para aplicação de métodos espectrais. Extraído de Karni e Gotsman (2000).

A quantização dos vértices também é uma estratégia que pode ser utilizada para a compressão da geometria ( $\mathrm{CHOW}, 1997)$. A técnica primeiramente realiza uma divisão do objeto a ser quantizado em regiões similares, baseada no tamanho dos polígonos e na curvatura, separando as partes mais detalhadas das menos detalhadas. Tal fato permite escolher um fator de quantização adequado em função desse detalhamento, gerando uma quantização mais precisa. A Figura 8 mostra os efeitos da quantização quando escolhidos fatores muito ou pouco densos. Em (a) é mostrada a grid de quantização sendo "encaixada" no polígono. Em (b), aparece um exemplo quando a grid de quantização não é 


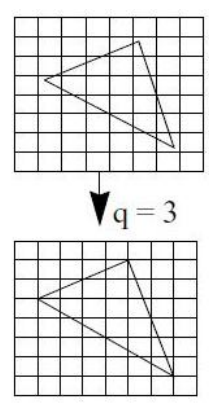

(a)

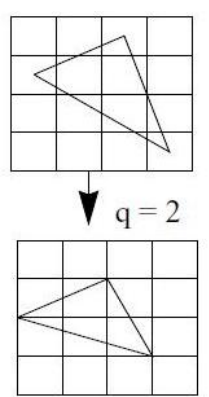

(b)

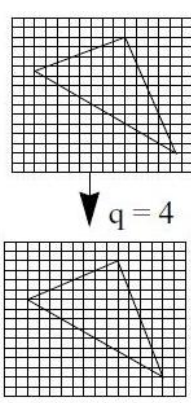

(c)

Figura 8 - Grids de quantização. Extraído de Chen et al. (2005).

precisa o suficiente. Em (c), é mostrada uma grid de quantização mais densa do que o necessário. Tanto em (b) quanto em (c) o resultado não é ótimo.

Outra abordagem para compressão de geometria é utilizar uma compressão progressiva baseada em árvores binárias (HONGNIAN et al., 2009). A compressão progressiva consiste em um processamento por partes, de modo que não é necessário comprimir a malha toda para obter o resultado. A compressão é realizada em subdivisões da malha até que toda ela seja comprimida. No caso de utilização de árvores binárias, cada vértice é atribuído a uma folha da árvore e um identificador numérico é atribuído a esse nó. Logo, esse identificador representa a posição do vértice no espaço e a árvore binária construída pode ser utilizada para recriar a malha. O algoritmo de processamento dessa árvore é capaz de percorrer os nós em toda sua altura e reconstruir a malha, combinando a informação dos vértices com a informação da conectividade preservada da malha (HONGNIAN et al., 2009). A Figura 9 exibe uma malha com 6475 vértices que passou pelo processo de compressão progressiva por árvore binária. Em (a), temos a malha original e em (b) a malha reconstruída. É interessante notar que a malha reconstruída é muito próxima da malha original, mas existem diferenças na conectividade, visíveis principalmente no topo da figura.

\subsubsection{Triangle Mesh}

O algoritmo de compressão de malhas triangulares baseia-se no contexto de compressão de geometria. Os dados dos vértices são quantizados uniformemente e comprimidos com baixa perda de informação (TOUMA; GOTSMAN, 1998). O algoritmo parte do princípio de que os vértices de uma malha poligonal (que trata-se de uma variedade orientável) podem ser ordenados. Essa propriedade não se aplica a grafos em geral. Como 


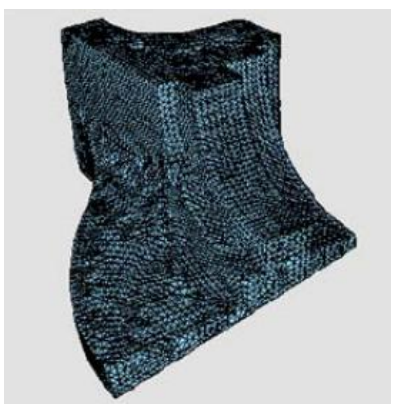

(a)

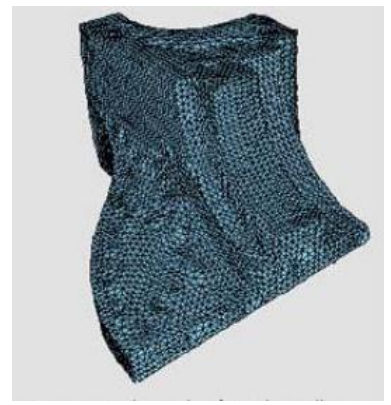

(b)

Figura 9 - Resultado de compressão progressiva com árvore binária. Extraído de Hongnian et al. (2009).

consequência, temos a propriedade de separação das malhas genus-0 [1 que resultam em duas malhas disjuntas (a que está contida no ciclo de vértices e as que não estão).

Logo, essa propriedade permite que a conectividade seja codificada em uma lista de vértices graduados em uma forma específica (TOUMA; GOTSMAN, 1998).

O algoritmo de compressão parte de um triângulo arbitrário na malha, identificando uma lista ativa com três arestas. Um dos vértices desse triângulo é determinado como o foco inicial. O algoritmo então parte para uma "conquista" de arestas em uma ordem antihorária em torno do foco. A cada aresta encontrada, é criado um comando de "adicionar". Quando todos os vértices foram percorridos (o vértice está "cheio"), o foco é movido para o próximo vértice no sentido anti-horário em torno da lista ativa. A "conquista" continua para o novo foco. Se a lista ativa, durante a expansão, intercepta a si mesma, ela é dividida em duas listas ativas, cada uma então é percorrida recursivamente. O processamento termina quando todos os vértices estiverem "cheios" (TOUMA; GOTSMAN, 1998).

O processo inverso é o mesmo, mas em sentido contrário. Para cada comando "adicionar" encontrado, significa um novo triângulo e vértice a ser reconstruído, conectando o novo vértice ao "foco"e seu predecessor na lista ativa.

A Figura 10 exemplifica a execução do algoritmo proposto por TOUMA; GOTSMAN, 1998). Na figura, é possível observar a execução do algoritmo. O algoritmo percorre as arestas, identificando as arestas percorridas. As arestas já percorridas são denotadas por linhas tracejadas. As referências alfabéticas seguintes referem-se à Figura 10. (a) Malha de Entrada. (b) Vértice auxiliar conectado a todos os vértices das bordas. (c) Triângulo inicial escolhido, indicado o vértice "foco"e gerada as palavras de codificação

\footnotetext{
${ }^{1}$ Genus identifica a quantidade de pontos não interligados em uma malha. De forma prática, é a quantidade de "buracos" que existem na estrutura da malha. Por exemplo, uma esfera possui genus-0. Um donut possui genus-1, pois há um buraco no seu centro (GRAY, 1998)
} 
"adicionar 6", "adicionar 7", "adicionar 4". (d) Expande a lista ativa. (e) "Adicionar 8". (f) "Adicionar 5". (g) Vértice do "foco"torna-se "cheio"(todas as arestas percorridas). (h) Vértice "foco" removido e movido para o próximo vértice da lista ativa. (i) "Adiciona 4". (j) "Adiciona 5". Nesse instante, a próxima aresta livre no "foco"leva a um vértice que já consta na lista ativa. (k) Lista ativa é dividida em duas. Gera a palavra código "Split 5" e menor que um na pilha. (l) Vértice "foco" removido e "foco" movido para o próximo estágio. (m) "Adicionar 4". (n) "Adicionar 4". Vértice "foco" está cheio e então é removido. (o) O vértice auxiliar é adicionado "Adicionar Vértice Auxiliar 6". (p) Primeira lista ativa completa. A segunda lista ativa é removida da pilha para processamento. (q) "Adicionar 4". (r) Vértice "foco"removido e o vértice "foco"é reposicionado. (s) Vértice "foco" removido e o vértice "foco" é reposicionado. (t) Segunda lista completa. O código resultante é "adicionar 6, adicionar 7, adicionar 4, adicionar 4, adicionar 8, adicionar 5, adicionar 5, adicionar 4, adicionar 5, split 5, adicionar 4, adicionar 4, adicionar vértice auxiliar 6 , adicionar 4 .

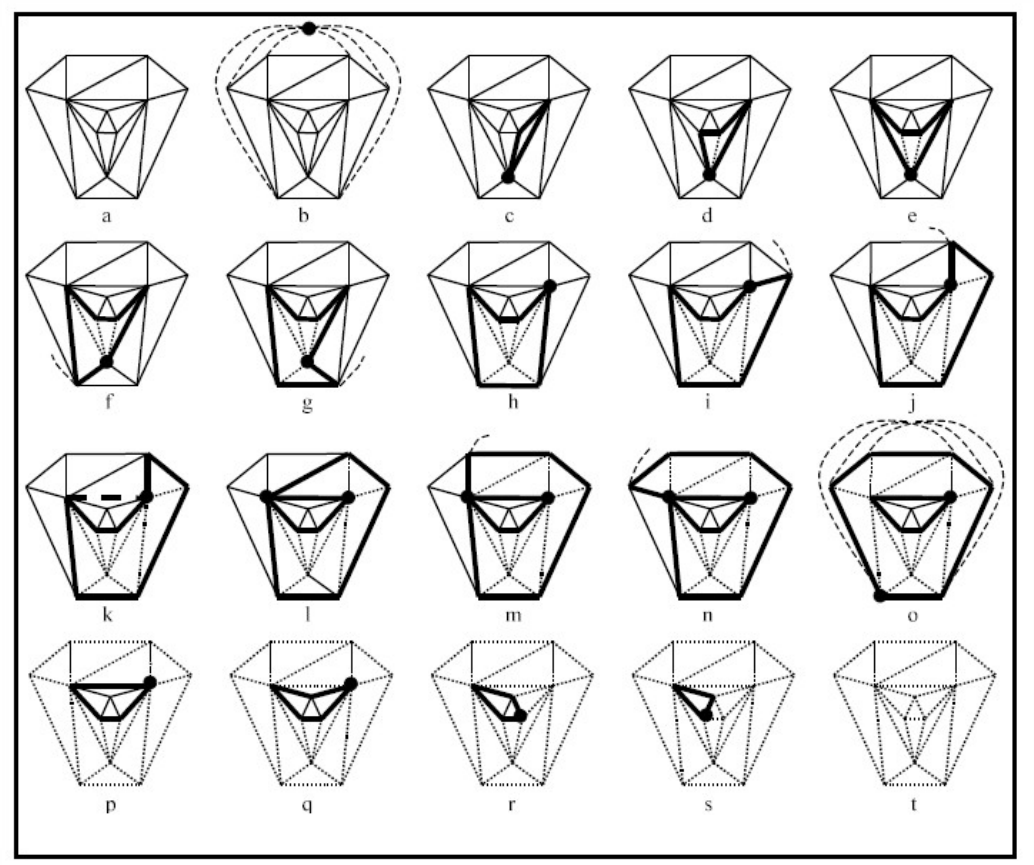

Figura 10 - Esquematização visual do algoritmo de compressão baseado em malhas triangulares. Extraído de Touma e Gotsman (1998). As listas ativas na execução do algoritmo são indicadas pelas linhas em negrito. 


\subsubsection{Wavemesh}

A técnica de wavemesh, baseada num teoria de multirresolução para malhas tridimensionais irregulares, é fundamentada na reconstrução de malhas triangulares mantendo tanto a conectividade quanto a geometria completamente fiéis ao original. O estudo feito por Vallete e Proust (VALETTE; PROST, 2004b) apresenta esse eficiente meio de compressão. O algoritmo desenvolvido e publicado por eles (VALETTE; PROST, 2004a), propõe uma estratégia de compressividade baseada na decomposição de Wavelet (veja Subseção 3.4.2). A Figura 11 ilustra o processo de decomposição. Nessa técnica, uma malha base é subdividida em quatro partes e deformada para que caiba na superfície da malha a ser aproximada.

Após a sobreposição da malha irregular no "gabarito" da malha base, tanto a geometria quanto a conectividade são tratadas de modo que haja uma compressão de seus dados. Conforme apresentado em (VALETTE; PROST, 2004a), otimizações baseadas na conectividade e geometria podem ser utilizadas para aperfeiçoar os resultados da compressão.

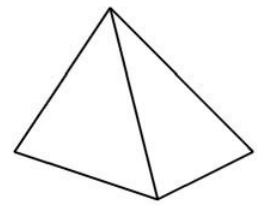

(a)

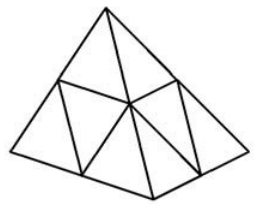

(b)

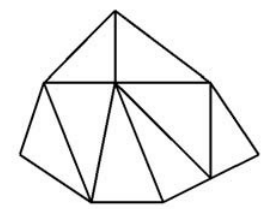

(c)

Figura 11 - Esquema de decomposição de Wavelet. Extraído de (VALETTE; PROST, 2004a). (a)O tetraedro base para a decomposição. (b) O tetraedro base tem cada face subdividida. (c) A superfície resultante é utilizada para sobrepor a malha a ser otimizada.

Este algoritmo propõe que a reconstrução da malha original (mais densa) pode ser realizada a partir da conectividade da malha de menor resolução, ou das subpartes dessa malha. Logo, não é necessário compactar os dados para reconstrução das faces, de maneira que a taxa de compressão alcançada é da ordem de 1 a 3 bits por vértice (VALETTE; PROST, 2004b).

No comparativo realizado no experimento de Valette e Prost (2004b), são apresentados os resultados comparativos da técnica proposta com diferentes configurações. Os números apresentados indicam uma vantagem na técnica, em comparação com as abordagens tradicionais de Rossignac (1998) e Cohen-Or et al. (1999). 


\subsection{Considerações Complementares}

Algumas abordagens de compressão de malhas utilizam uma combinação de técnicas para comprimir tanto a geometria quanto a conectividade. Em Peng et al. (2005), são apresentadas diversas técnicas que tratam tanto da compressão de geometria quanto da compressão de conectividade. Em Bouzidi et al. (2013), uma técnica de compressão progressiva aliada a inclusão de marcas d'água para proteção de originalidade da malha é proposta, com resultados interessantes. Recomendam-se essas leitura para um aprofundamento do assunto. O foco deste trabalho se relaciona com compressão da geometria da malha, conforme será abordado no capítulo seguinte. 


\section{Compressive Sensing}

\subsection{Introdução}

Dispositivos de aquisição de dados vêm se popularizando, o que gera uma necessidade de armazenamento dos dados sensoreados cada vez maior. A compressão de dados para sua armazenagem torna-se importante para redução de espaço utilizado para persistência dos dados. A teoria clássica de sinais é baseada no Teorema de Shannon-Nyquist, que postula a necessidade de amostrar uma quantidade mínima de informação do sinal para que seja possível sua reconstrução, via interpolação (DAVENPORT et al., 2011). Utilizando uma limitação da banda do sinal, esse teorema prevê a utilização de $n$ leituras no seu espectro, tornando possível utilizar funções de reconstrução para recriar o sinal original (PEYRÉ, 2010).

O Teorema de Shannon-Nyquist parte do pressuposto de que como não há conhecimento prévio do sinal, o pior caso deve ser considerado para realizar a amostragem. Esse número de amostras deve ser no mínimo o dobro da frequência máxima do sinal, chamada de Taxa de Nyquist (CANDÈs; WAKIN, 2007). Essa taxa é utilizada em protocolos de aquisição de sinais presentes em dispositivos de áudio e vídeo, equipamentos de processamento de imagens médicas, etc. Logo, por esse teorema, há um limite estabelecido que deve ser seguido para que a reconstrução do sinal seja equivalente ao original.

Na teoria de CS, o sensoreamento (produto interno do sinal por funções teste) é feito de forma compressiva. As técnicas tradicionais amostram o máximo possível do sinal e ao realizar a compressão são descartados os dados redundantes, resultando em um sinal comprimido. Com CS, a própria amostragem já é realizada de forma compressiva, de modo que não há necessidade de descartar dados após sua aquisição e a reconstrução do sinal é possível com um número consideravelmente menor de amostras. Assim, a teoria de CS consegue ser mais otimista que o teorema de Shannon-Nyquist, já que prevê uma quantidade menor de amostras para a reconstrução do sinal. 


\subsection{Teoria}

Compressive Sensing tem como base teórica a utilização simultânea de sensoreamento e compressão utilizando uma redução dimensional linear (DUARTE; ELDAR, 2011). Experimentos mostram que é possível amostrar sinais abaixo da Taxa de Nyquist, com pouca perda de dados. A teoria afirma que um sinal digital $x \in \mathbb{R}^{n}$ pode ser recuperado a partir de uma pequena amostra aleatória de seus coeficientes de Fourier desde que $x$ seja suficientemente esparso (CANDÈS; PLAN, 2010). Suponhamos que o sinal $x$ possua até $k$ amplitudes diferentes de zero, em posições desconhecidas (chama-se esse sinal de $k$-esparso) e tomemos o valor de sua Transformada de Fourier em $m$ frequências escolhidas aleatoriamente. O sinal $x$ pode então ser recuperado resolvendo um problema de otimização que simplesmente encontra, dentro do domínio do sinal, aquele com a menor norma $L_{1}$. O número de amostras necessário é da ordem de $k \log n$ para reconstrução do sinal sem perda de informação (CANDÈS; PLAN, 2010).

A amostragem é realizada através de um vetor de medições $y$, tal que $y=\Phi x$, sendo $\Phi$ uma matriz de medições $m \times n$ (DUARTE; ELDAR, 2011). A construção da matriz $\Phi$ é estruturada de forma a reduzir as medições $M$ tanto quanto possível, permitindo a reconstrução de um vasto conjunto de sinais $x$ a partir de seu vetor $y$. Não obstante, o fato de que $m<<n$ ( $m$ muito menor que $n$ ) implica que a matriz $\Phi$ é não nula. Por conseguinte, implica que para qualquer sinal $x_{0} \in \mathbb{R}^{n}$, um infinito número de sinais $x$ conterá as mesmas medidas $y_{0}=\Phi x_{0}=\Phi x$ para a matriz $\Phi$ escolhida (DUARTE; ELDAR, 2011). A Figura 12 representa de forma visual o processo de multiplicação entre as matrizes e o vetor esparso.

Desta forma, a construção da matriz de medições $\Phi$ deve permitir que sinais distintos $x, x^{\prime}$ sejam identificados de forma única através dos vetores de medição $y=\Phi x, y^{\prime}=\Phi x^{\prime}$, mesmo que $m<<n$ (DUARTE; ELDAR, 2011). É importante observar que para que haja unicidade de solução do problema, ao tomar qualquer conjunto de $m$ colunas da matriz $\Phi$, esse conjunto deve ser composto por um conjunto de vetores linearmente independentes.

A teoria de CS está baseada em três conceitos: esparsidade, isotropia e incoerência (CANDÈS; PLAN, 2010). 


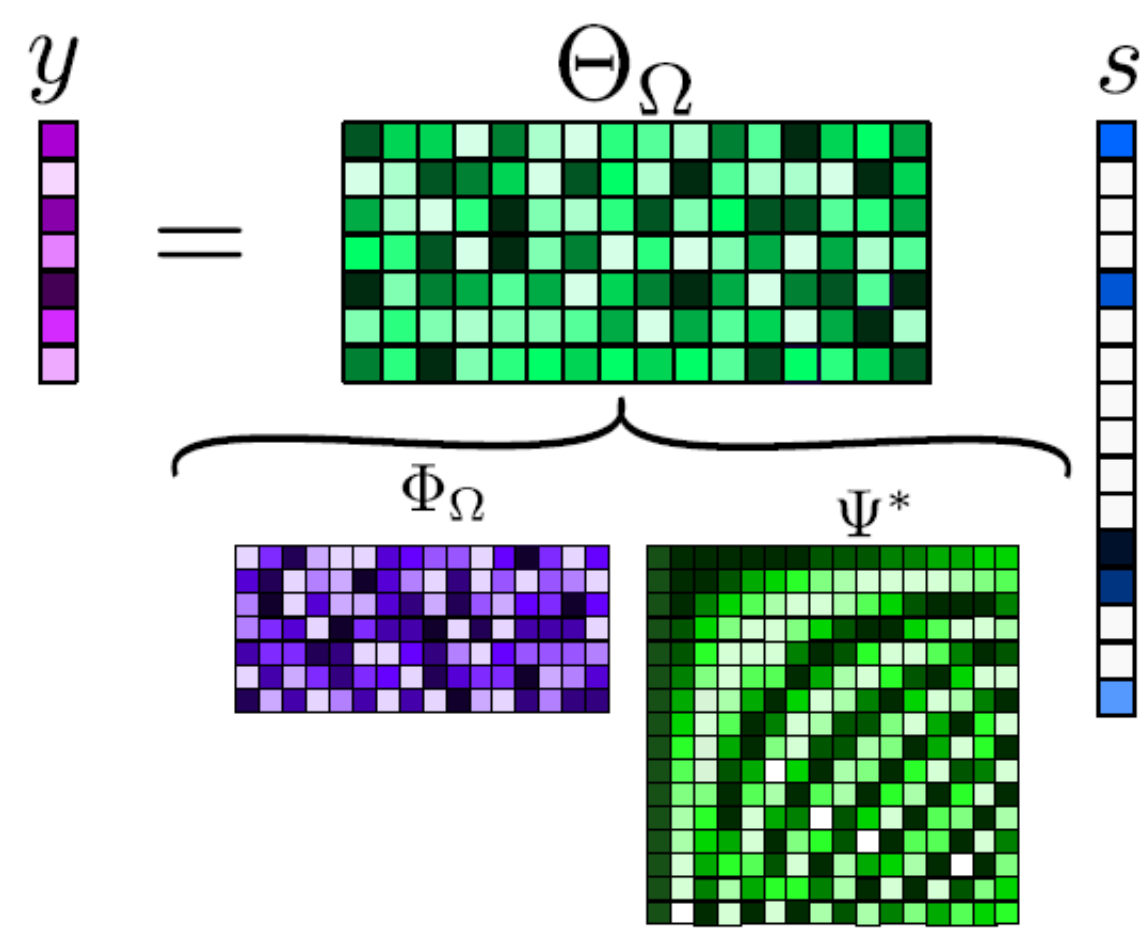

Figura 12 - Representação gráfica do problema algébrico (SCHULZ et al., 2009a).

\subsection{Esparsidade, Isotropia e Incoerência}

O conceito de esparsidade de um sinal está relacionado à quantidade de componentes não nulos presentes em sua constituição (PEREIRA, 2010). Toma-se como exemplo um sinal $x$ com $k$ componentes significativas em $n$ possíveis. Por este exemplo, diz-se que tal sinal possui esparsidade $k$. Matematicamente, temos:

$$
k=\{i: x(i) \neq 0\}=\|x\|_{0}
$$

A esparsidade do sinal pode ser obtida através de uma transformação de bases (transformada cosseno, por exemplo). Formalizando o conceito, temos o seguinte cenário:

- o sinal $s$ é representado em um vetor $x \operatorname{com} n$ componentes e esparsidade $k$;

- $\Psi$ uma transformação com inversa $\bar{\Psi}$

Com este cenário, estrutura-se:

- $x \in \mathbb{R}^{n}$ 
- $\Psi \in \mathbb{R}^{n \times n}$

- $s:=\Psi x$

Utilizando-se de leituras aleatórias no espaço de medição, são extraídos vetores linearmente independentes. Seja $F$ o espaço total de amostras, temos:

$$
\bar{y}_{i}=\left\langle a_{i}, x\right\rangle+\sigma z_{i}, i=1, \cdots, m
$$

onde $x \in \mathbb{R}^{n},\left\{z_{i}\right\}$ é uma sequência de ruídos. Nesta condição, tornam-se obrigatórias as propriedades de isotropia e incoerência.

Em relação à incoerência, tomemos um par $(\Phi, \Psi)$ de bases ortonormais em $\mathbb{R}^{n}$. A primeira base $\Phi$ é usada para realizar o sensoreamento e a segunda representa o resultado amostrado. A coerência entre o sistema de sensoreamento $\Phi$ e a representação do sistema $\Psi$ é dada por:

$$
\mu(\Phi, \Psi)=\sqrt{n} \max _{1 \leq k, j \leq n}\left|\left\langle\varphi_{k}, \psi_{j}\right\rangle\right|
$$

A coerência mede a maior correlação entre dois elementos de $\Phi$ e $\Psi$. Se $\Phi$ e $\Psi$ contêm elementos correlacionados, a coerência é grande. Caso contrário, é pequena (CANDÈS; WAKIN, 2007). Logo, para coerência grandes ou pequenas, $\mu(\Phi, \Psi) \in[1, \sqrt{n}]$. O limite de valor 1 é consequência de que o produto interno $\left|\left\langle\varphi_{k}, \psi_{j}\right\rangle\right|$ entre dois vetores é menor ou igual a 1. O limite inferior é em consequência da relação de Parseval em que cada $j$, $\sum_{k=1}^{n}\left|\left\langle\varphi_{k}, \psi_{j}\right\rangle\right|^{2}=\left\|\psi_{j}\right\|_{l_{2}}^{2}=1$ (CANDÈS; WAKIN, 2007).

Em outras palavras, se o espaço de aquisição do sensoreamento é denso, o espaço de medição é esparso e vice-versa.

\subsection{Matrizes de Medição}

O vetor $x$ é representado no domínio esparso em $s$. A amostragem do sinal através de $m$ amostras é realizada com uma matriz de medição criada como $\Phi$. Cada linha $\phi_{m}$ de $\Phi$ é uma função de amostragem (PEREIRA, 2010). O produto de $\Phi$ pelo vetor $x$ resulta em um vetor de amostras $y$. A operação é representada como:

- $y \in \mathbb{R}^{m}$ 
- $\Phi \in \mathbb{R}^{m \times n}$

- $y:=\Phi x=\Phi \bar{\Psi} s$

Podemos reescrever $\Phi \bar{\Psi}$ como $\Theta$, de forma que $\Theta \in \mathbb{R}^{m \times n}$ e $y:=\Phi x=\Phi \bar{\Psi} s=\Theta s$.

A relação de grandeza entre a esparsidade $k$, o número de amostras $m$ e os componentes significativos do sinal $n$ é dada por:

$$
k<m<<n
$$

Para criar boas matrizes de medição, é preciso utilizar uma matriz cheia $\Theta_{\Omega}$ de forma que qualquer subconjunto de colunas de tamanho $S$ seja aproximadamente ortonormal (SCHULZ, 2008). Como exemplo, temos as matrizes Gaussianas que são geradas com valores aleatórios entre zero e um que permitem a medição necessária para aplicação de CS.

Outra matriz de medição que apresenta aplicações em CS são matrizes Noiselets. A matriz Noiselet é incoerente em relação à Matriz Wavelet de Haar (CANDÈS; ROMBERG, 2007). Se $\Psi$ é um sistema ortnormal de Wavelets de Haar-Walsh 11 e $\Phi$ é o sistema Noiselet ortogonal, então $U=\Phi \Psi$ possui entradas de magnitude constante tal que:

$$
\left|U_{k, j}\right|=1, \forall k, j \Rightarrow \mu(U)=1
$$

Dessa forma, se uma imagem com $n$-pixels é $k$-esparsa no domínio da Wavelet de Haar, ela pode ser reconstruída (com alta probabilidade) a partir de $\sim S \log n$ com os coeficientes aleatórios.

\subsubsection{Matriz Gaussiana}

A matriz gaussiana pode ser utilizada para o sensoreamento das amostras na aplicação da técnica de CS. A matriz utilizada deve ter uma dimensão igual aos valores máximos de amostras do objeto a ser sensoreado.

Dessa forma, a matriz é definida a partir de uma definição de números aleatórios no intervalo do número total de elementos da amostra a ser sensoreada e o número de medidas que será utilizado na medição.

\footnotetext{
${ }^{1}$ A transformada de Haar-Walsh assume somente valores de 1 ou -1 e é utilizada em diferentes aplicações de teoria de sinais (FALKOWSKI; RAHARDJA, 1996).
} 
Outra forma de criar a matriz gaussiana é utilizar a decomposição de valores únicos (em inglês, single value decomposition - SVD). Essa estratégia encontra uma barreira computacional quando trabalha com valores muito altos, pois é necessário realizar o cálculo das determinantes da matriz em criação para definir os valores aleatórios e quando temos um valor muito alto, torna-se inviável do ponto de vista computacional (complexidade de $n^{2}$ ) com a capacidade computacional atual. Experimentos executados com malhas de 25.000 vértices em um computador com $6 \mathrm{~Gb}$ de memória RAM e processador Intel i7 apresentaram tempo de processamento entre 30 a 50 minutos. As malhas com mais vértices apresentam grande consumo de memória ao calcular a SVD, o que também é uma barreira técnica atual.

Algumas definições formais de matrizes gaussianas podem ser encontradas no trabalho de Horn e Johnson (HORN; JOHNSON, 1990).

\subsubsection{Matriz Wavelet}

Dentro da área de processamento de sinais, a função Wavelet apresenta uma importância significativa, devido às suas propriedades de transformação. Basicamente, tratase de uma função senoidal de variação entre um intervalo definido (normalmente, 0 e 1) (SALOMON, 2007). A matriz Wavelet, portanto, é composta por valores nesse intervalo.

As características que tornam a matriz Wavelet interessante para a aplicação em CS referem-se à facilidade de inverter, multiplicar e integrar a matriz, com algoritmos mais performáticos comparados aos que utilizam SVD.

Várias aplicações em malhas e representação de funções são utilizadas com Wavelet. O trabalho de Schröder e Sweldens (1995) apresenta aplicações na definição de esferas. Valette e Prost (2004b) Vallete e Prost 2004a utilizam Wavelets para tratar a compressão progressiva.

A matriz Wavelet representada abaixo mostra uma matriz com valores variando entre -1 e 1.

$$
M=\left[\begin{array}{cccc}
1 & 1 & 1 & 0 \\
1 & 1 & -1 & 0 \\
1 & -1 & 0 & 1 \\
1 & -1 & 0 & 1
\end{array}\right]
$$




\subsubsection{Matriz Noiselet}

A matriz Noiselet trata-se de uma variação da matriz Wavelet, explicitada na Seção 3.4.2. A característica principal da matriz Noiselet é que ela é gerada por uma função que retorna o pior caso da matriz ortogonal de Wavelet (COIFMAN et al., 2001). Essa matriz é construída de tal forma que ela tem a máxima incoerência com a matriz $W a$ velet de Haar (CANDÈS; ROMBERG, 2007). Como visto na Seção 3.3 , essa propriedade é bastante importante para a aplicação de CS. Além disso, como as matrizes Wavelets são computacionalmente interessantes, do ponto de vista de performance para análise de multi-resolução, as matrizes Noiselets acompanham essa característica, com a vantagem de não possuírem ruídos na sua constituição. Conforme apresentado na Seção 3.4.2, a matriz Wavelet varia em um intervalo limitado. Não obstante, em um intervalo contínuo, valores intermediários podem ser encontrados na formação da matriz. A função Noiselet permite remover esses ruídos, mantendo as propriedades da matriz Wavelet e melhorando a definição de valores dentro da matriz (COIFMAN et al., 2001).

O trabalho de Schulz (2008), apresenta matrizes Noiselets que são utilizadas para recuperação de imagens através de CS com resultados muito interessantes. Outro resultado interessante apresentado por Candès e Romberg (2007), mostra a reconstrução de uma imagem a partir de medidas em uma matriz Noiselet.

\section{$3.5 \quad$ Norma $L_{1}$}

O conceito de Norma de um vetor consiste em um mapeamento de

$$
f \rightarrow\|f\|, f \in \zeta, \| f \mid \in \mathbb{R}^{1}
$$

de um espaço vetorial complexo $\zeta$ em um conjunto de números reais (PRUGOVECKI, 1981), que satisfaz as seguintes condições:

(1) $\|f\|>0$ para $f \neq 0$,

(2) $\|0\|=0$,

(3) $\|a f\|=\|a\|\|f\|$ para todo $a \in \mathbb{C}^{1}$,

(4) $\|f+g\| \leq\|f\|+\|g\|$ (desigualdade triangular)

Para um espaço vetorial real, no item 3 é necessário que $a \in \mathbb{R}^{1}$ (PRUGOVECKI, 1981). A última condição é conhecida como desigualdade triangular porque representa, em 
um espaço vetorial real bi ou tridimensional, uma relação satisfeita pelos lados de um triângulo constituído por três vetores $f, g$ e $f+g$ (PRUGOVECKI, 1981).

Dentre as normas definidas pelas regras acima, temos a norma $L_{2}$ e a norma $L_{1}$ (BROOKS et al. 2013). A norma $L_{2}$ de um vetor $x$ é definida por :

$$
\|x\|_{2}=\sqrt{\sum_{i=1}^{m} x_{1}^{2}}
$$

A norma $L_{1}$ de um vetor $x$ é dada por:

$$
\|x\|_{1}=\sum_{i=1}^{m}\left|x_{1}\right|
$$

Quando utilizamos a norma $L_{1}$ para medir a variação entre vetores, resultam diferentes projeções. Quando utilizada a norma $L_{2}$, o resultado são circulares. No caso da norma $L_{1}$, o resultado são diamantes (BROOKS et al., 2013). Essa propriedade permite a utilização da minimização da norma $L_{1}$ para utilização em CS.

Dessa maneia, a norma $L_{1}$ é uma medida de variação entre vetores, calculada a partir da soma das diferenças absolutas de seus pontos (REINHARDT, 2005). Seja $d_{1}$ a norma entre dois vetores $p$ e $q$. O cálculo da norma é realizado de acordo com:

$$
d_{1}(p, q)=\|p-q\|_{1}=\sum_{i=1}^{n}\left|p_{i}-q_{i}\right|
$$

onde $p=\left(p_{1}, p_{2}, \ldots, p_{n}\right)$ e $q=\left(q_{1}, q_{2}, \ldots, q_{n}\right)$

A norma $L_{1}$ apresenta propriedades interessantes para resolução de sistemas não definidos de equações lineares (HA; PATANAVIJIT, 2010). Em várias aplicações, a aplicação da norma $L_{1}$ é robusta, de forma que outliers não conseguem distorcer essa robustez (HA; PATANAVIJIT, 2010). Essa característica a diferencia da norma $L_{2}$ e permite uma eficiência maior contra os outliers e pode ser usado com dados ruidosos, através de um problema de otimização com os coeficientes da norma $L_{1}$.

\subsection{Total Variation}

Uma variação do cálculo da norma $L_{1}$ refere-se à equação de Total Variation, que consiste na(s) derivada(s) da função de cálculo da norma $L_{1}$. 
O modelo TV- $L_{1}$ é utilizado com bons resultados em decomposição de imagens (ZHANG et al. 2012). Um modelo de decomposição e cálculo de imagem baseado no trabalho de Rudin et al. (1992) é apresentado por Zhang et al. (2012), conforme abaixo:

Seja $f$ uma imagem para decomposição, em duas camadas de sinais $u$, composta por componentes suavizados da imagem, e $v$, que contém a componente oscilatória ou texturizada da imagem $f$. A decomposição

$$
f=u+v
$$

pode ser obtida através da seguinte integração

$$
\min _{u} \int|\nabla u|+\lambda \int|u+f| d x
$$

sendo $f, u$ e $v$ funções de intensidade da escala de cinza com valores em $\mathbb{R}^{2}, \nabla u$ é o valor gradiente de $u$ e $\lambda$ o fator constante parametrizável. Dessa forma, $\int|\nabla u|$ é chamada de Total Variation de $u$ e $|u-f|$ o termo fidelidade $L_{1}$ (ZHANG et al., 2012).

\subsection{Minimização da Norma $L_{1}$}

Para utilização em Compressive Sensing, é utilizada a minimização da Norma $L_{1}$, de modo que a solução mais esparsa para os vetores base encontra-se nessa minimização (PEREIRA, 2010). A resolução de

$$
\min _{\tilde{s}}\|\tilde{s}\|_{1} \text {, sujeito a } \Theta \tilde{s}=y
$$

ou de

$$
\min _{\tilde{x}}\|\Psi \tilde{x}\|_{1}, \text { sujeito a } \Phi \tilde{x}=y
$$

proporciona a solução ideal para o problema da minimização. A Figura 13 mostra a relação entre esparsidade e a norma $L_{1}$.

Considerando um sinal qualquer $s$ que possui a menor norma $L_{0}$ e respeita a equação linear em $\mathbb{R}^{2}$, a minimização da norma $L_{2}$ gera como solução ótima $s=b$, que é distante das soluções esparsas $\alpha$ e $\beta$. Em contrapartida, a minimização da norma $L_{1}$ reflete $s=\alpha$, 


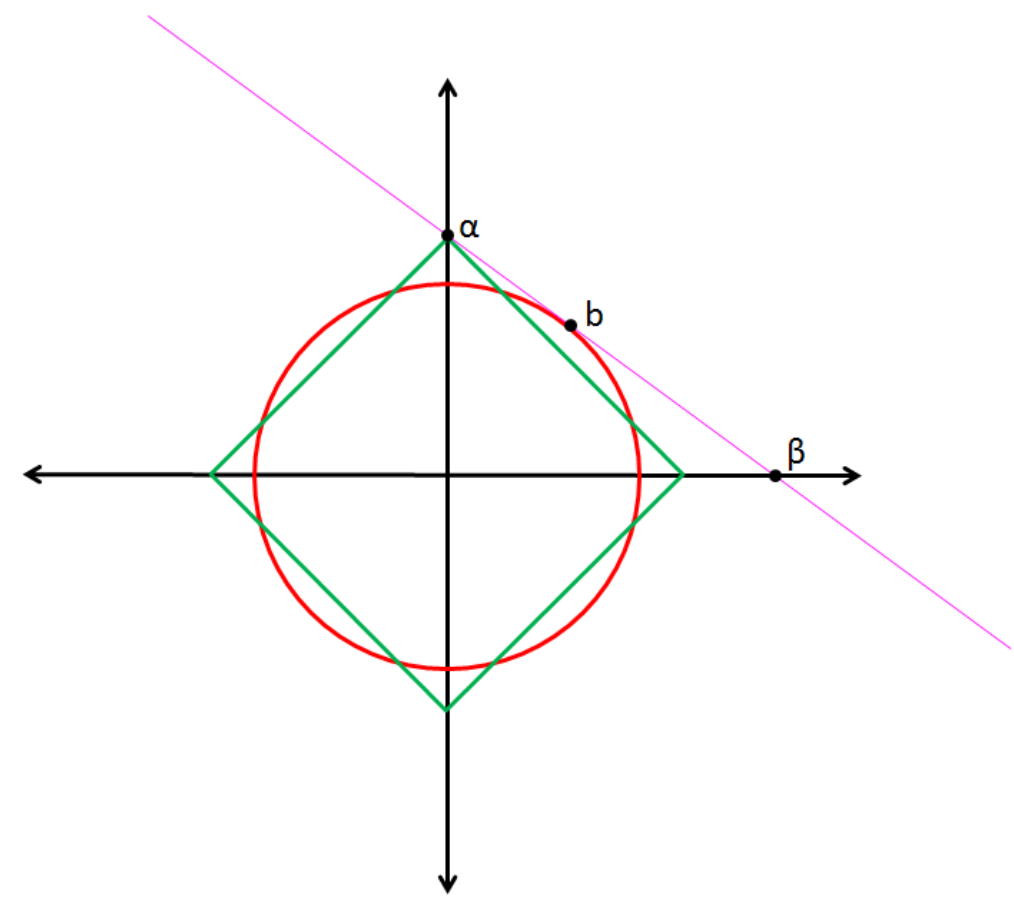

Figura 13 - Esparsidade e Norma $L_{1}$.

sendo a solução procurada (SCHULZ, 2008).

No trabalho de Ha e Patanavijit (2010), um algoritmo de minimização da Norma $L_{1}$ é apresentado justamente para aplicações em CS. O algoritmo proposto no artigo citado apresenta uma maneira relativamente eficaz de recuperar dados de imagens com ruídos a partir de uma observação incompleta (HA; PATANAVIJIT, 2010). Esse é o princípio da teoria de CS apresentada na Seção 3.2 .

O cálculo da minimização pode ser realizado de diferentes maneiras. A seguir, são elencadas algumas maneiras de realizar a minimização da norma $L_{1}$.

Em Candès e Romberg (2005), são apresentadas sete formas de minimização da norma $L_{1}$ :

- Minimização de $L_{1}$ com normas de igualdade;

Também conhecida como busca pela base, procura encontrar a menor norma $L_{1}$ na somatória $\left\|x_{1}\right\|:=\sum_{i}\left|x_{i}\right|$

- Minimização de $L_{1}$ por aproximação de erro;

Em uma matriz $M \times N$, a equação $\min _{x}\|y-A x\|_{1}$ com $y \in \mathbb{R}^{M}$ encontra o vetor 
$x \in \mathbb{R}^{N}$ de maneira que o erro de $y-A x$ tenha a menor norma $L_{1}$.

- Minimização de $L_{1}$ com regras quadráticas;

Esta variação encontra o vetor com a menor norma $L_{1}$ que satisfaz a relação min $\|x\|_{1}$ sujeito a $\|A x-b\|_{2} \leq \epsilon \operatorname{com} \epsilon$ sendo um parâmetro definido.

- Minimização de $L_{1}$ com correlação residual limitada (conhecida também como Seleção de Dantzig);

Semelhando à minimização com regras quadráticas, esta variação utiliza a relação min $\|x\|_{1}$ sujeito a $\left\|A^{*}(A x-b)\right\|_{\infty} \leq \gamma$, sendo $\gamma$ um parâmetro definido. Essa variação relaxa a minimização po regra de igualdade.

- Minimização de Total Variation com regras de igualdade;

Esta consiste em uma variação que trabalha com a Total Variation. Conforme visto na Seção 3.6, a derivada da norma $L_{1}$ pode também ser utilizada para calcular a variação da norma. Nesse caso, a equação torna-se um problema de minimização de $\min T V(x)$ sujeito a $A x=b$.

- Minimização de Total Variation com regras quadráticas;

Da mesma forma que a variação anterior, a equação utilizada para minimizar a norma $L_{1}$ com regras quadráticas é alterada para min $T V(x)$ sujeito a $\|A x-b\|_{2} \leq \epsilon$.

- Minimização de Total Variation com Dantzig.

Neste caso, também é adaptada a equação da seleção de Dantzig para min $T V(x)$ sujeito a $\left\|A^{*}(A x-b)\right\|_{\infty} \leq \gamma$.

Cada uma dessas formas apresenta uma variação da minimização necessária para aplicação de CS. O detalhamento do cálculo pode ser encontrado no texto de Candès e Romberg (2005).

Utilizando-se dos cálculos de minimização apresentados por Candès e Romberg (2005), Yang et al. (2010) apresentam quatro algoritmos rápidos de minimização da norma $L_{1}$. Os algoritmos apresentados são:

- Métodos de Projeção de Gradiente;

Utilizando o multiplicador de Lagrange, o problema de minimização apresentado no início desta seção é reescrito de forma que utilizando a minimização por regras 
quadráticas, é possível encontrar uma solução ao problema. Essa abordagem, conforme apresentado nos resultados de Yang et al. (2010), apresenta uma performance considerável no processamento.

- Método por Homotopia;

Esta abordagem explora o fato de que a função de minimização sofre uma homotopia de $L_{2}$ em relação a $L_{1}$.

- Método Iterativo com Limites de Encolhimento;

Este método considera o problema de minimização como uma composição de funções, que podem ser resolvidas de forma iterativa.

- Método de Aproximação por Gradiente;

Utilizando uma a função convexa com o gradiente contínuo de Lipschitz, através de múltiplas iterações aproximar a forma quadrática da função objetiva, de modo a encontrar os pontos ótimos da minimização.

- Método de Multiplicador de Lagrange Aumentado;

Este tipo de abordagem tem a vantagem de simultaneamente estimar a solução ótima e os multiplicadores de Lagrange de forma iterativa.

Cada um dos métodos acima é detalhado no trabalho de Yang et al. (2010), além de conter um comparativo de performance entre os diferentes algoritmos.

No contexto de Compressive Sensing, outro trabalho interessante, elaborado por Needell e Ward (2013), apresenta garantias para aproximações ótimas utilizando minimização com Total Variation. O trabalho apresenta uma garantia de reconstrução ótima para minimização multidimensional de Total Variation a partir de medidas comprimidas (NEEDELL; WARD, 2013). É uma abordagem interessante, que complementa os métodos de minimização apresentados nesta seção.

\subsection{Exemplo Ilustrativo}

Nesta seção, um exemplo é apresentado para ilustrar como a técnica de CS funciona.

Inicialmente, definimos um vetor de 32 posições com zeros, que chamaremos de $s$, e atribuímos um de seus elementos um valor (0.8). Esse vetor representa o sinal $k$ esparso, 
apresentado na Seção 3.2. Na parametrização deste exemplo, utilizamos 8 medidas, denotadas por $m$. Desta maneira, dentro do conjunto de 32 elementos do sinal, 8 elementos serão escolhidos, de forma aleatória, para a reconstrução do vetor $s$. De acordo com a teoria, o sinal $s$ é $k$ esparso, onde $k=1$.

Na sequência, é definida a matriz de medição $\Phi$, que será usada para a reconstrução do sinal. Essa matriz é definida de acordo com o tamanho original do vetor $s$ (32 posições). Neste exemplo em particular, a matriz é calculada através de uma distribuição normal de números aleatórios em função do número de elementos do vetor $s$ e o número de medidas $m$.

É realizado então o processo de reconstrução. O objetivo é a partir da matriz de medição $\Phi$, escolher aleatoriamente as $m$ medidas e voltar ao sinal $s$.

Na Figura 14, temos a representação do sinal deste exemplo ilustrativo. Podemos observar no eixo $X$ a posição vetorial (neste caso, 32 posições.) e no eixo $Y$ d o valor atribuído à Posição $6(0,8)$.

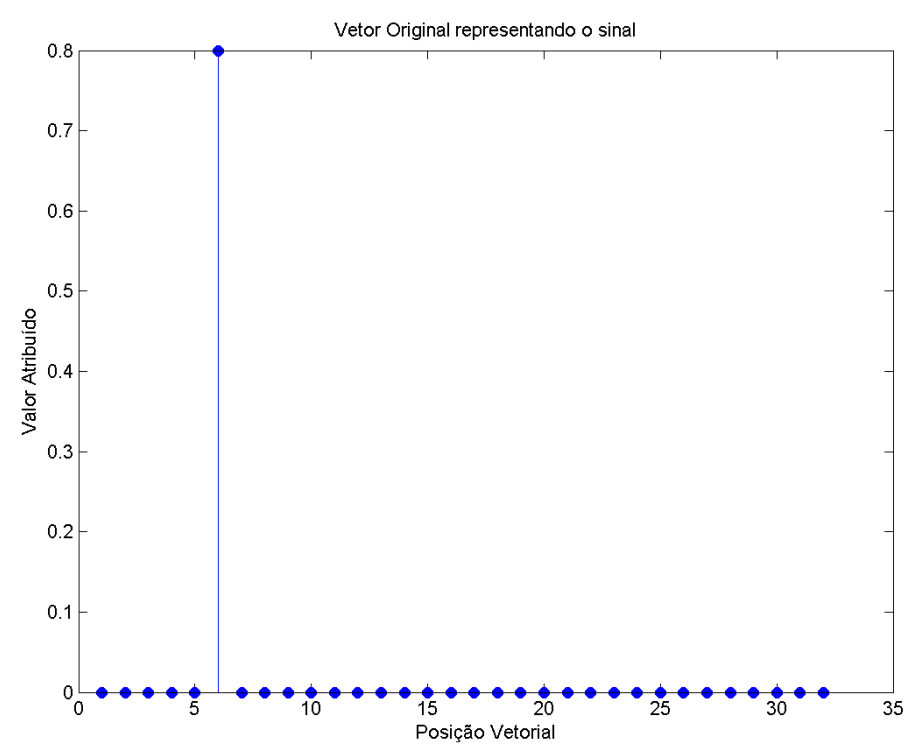

Figura 14 - Exemplo Ilustrativo - Sinal Original.

Na Figura 15, podemos ver o sinal resultante na reconstrução. Utilizando as 8 medidas aleatórias, no universo de 32 possíveis (tamanho do vetor $s$ ), temos uma reconstrução perfeita. Na posição 6 do vetor, temos encontrado o valor 0.8 . 


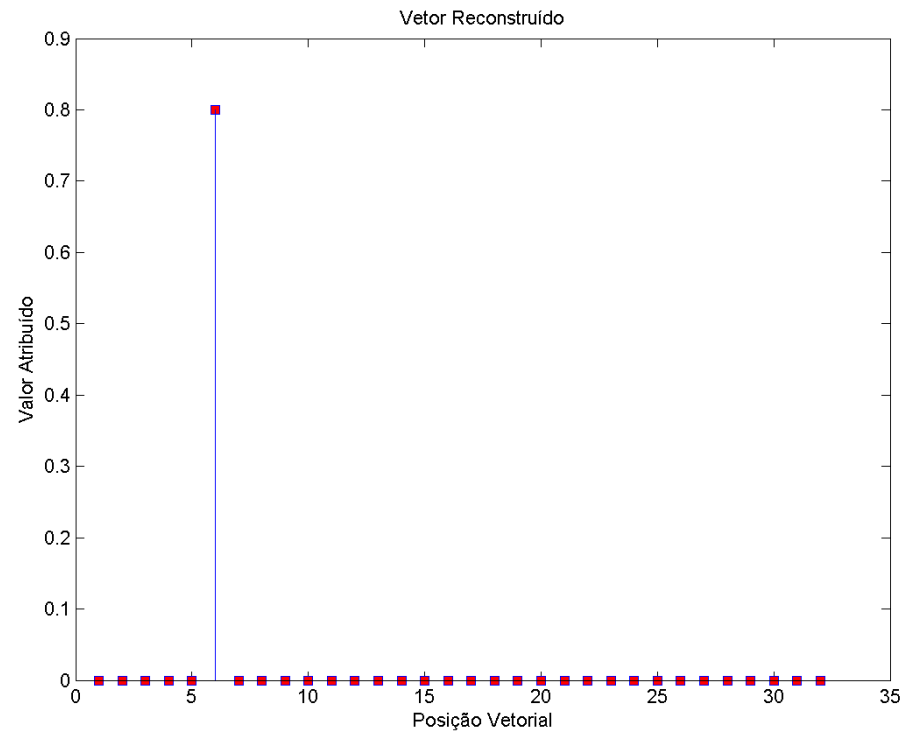

Figura 15 - Exemplo Ilustrativo - Sinal Reconstruído $(m=8)$.

Se executarmos uma variação do experimento, utilizando 6 medidas, ainda assim teremos uma reconstrução fiel do sinal $s$, como vemos na Figura 16.

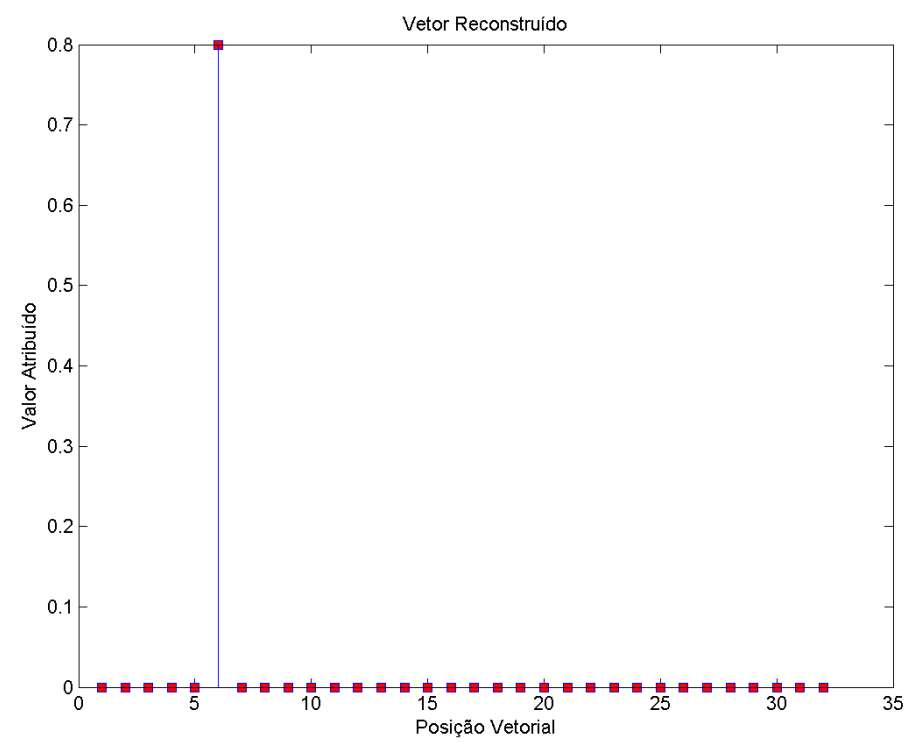

Figura 16 - Exemplo Ilustrativo - Sinal Reconstruído $(m=6)$.

Uma terceira variação do experimento, utilizando $m=4$, temos um resultado com determinação de quatro valores para o vetor reconstruído. Isso indica que existe um número mínimo de medidas que precisam ser tomadas para a que a reconstrução seja perfeita. No 
entanto, diferente das técnicas tradicionais, podemos utilizar quaisquer medidas, desde que um mínimo de medidas seja tomado. As técnicas tradicionais exigem que a tomada de medidas seja distribuída pelo sinal.

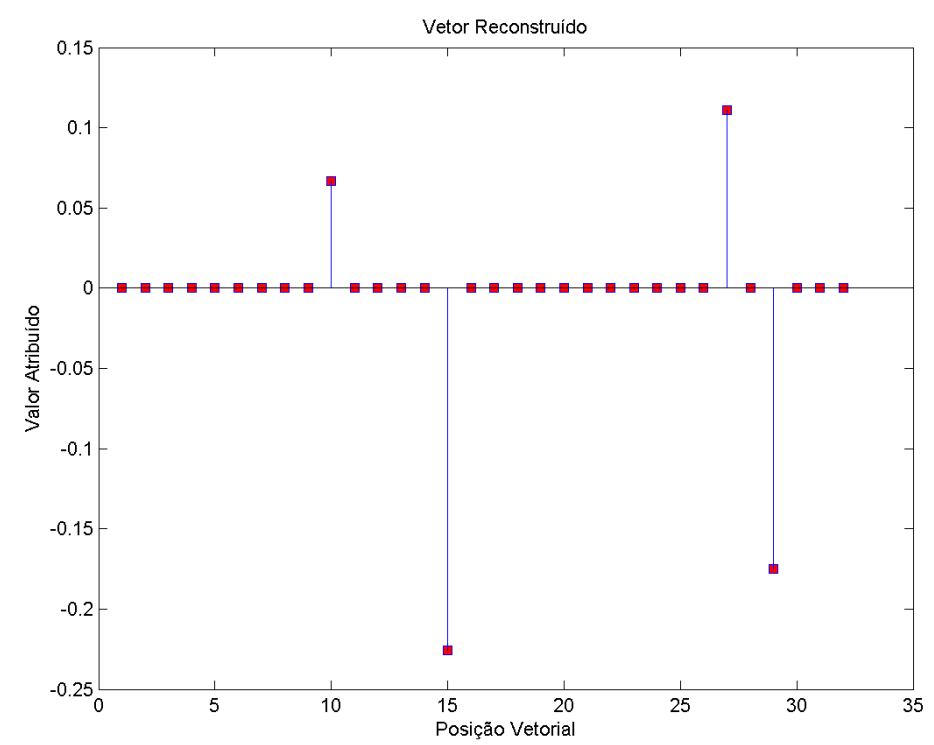

Figura 17 - Exemplo Ilustrativo - Sinal Reconstruído $(m=4)$.

Os experimentos foram executados 10 vezes cada um. Para a parametrização de $m=8$ e $m=6$, todas as reconstruções foram perfeitas. Quando utilizamos $m=4$, algumas vezes temos a reconstrução perfeita. Ou seja, mesmo com poucas medidas, o sinal é reconstruído, mas em função da aleatoriedade da medida, quando temos $m$ insuficiente.

\subsection{Aplicações}

A teoria de CS possui aplicações em diversas áreas, permitindo a utilização do sensoreamento compressivo para tratar qualquer informação que possa ser representada como sinal.

Resultados interessantes na compressão e recuperação de imagens são apresentados em diversos estudos (CANDÈS; WAKIN, 2007). Utilizando-se de diferentes matrizes de medição, é possível reconstruir com boa probabilidade a imagem original a partir do sensoreamento compressivo (HAO et al., 2010).

Diversos estudos corroboram a reconstrução do sensoreamento compressivo. Na Figura 18 é exibida uma reconstrução de imagem a partir de CS utilizando Wavelet como 
matriz de medição. A técnica utilizada nesse exemplo utiliza segmentação da imagem original em recortes de pixels para otimizar o processamento (HAO et al., 2010).
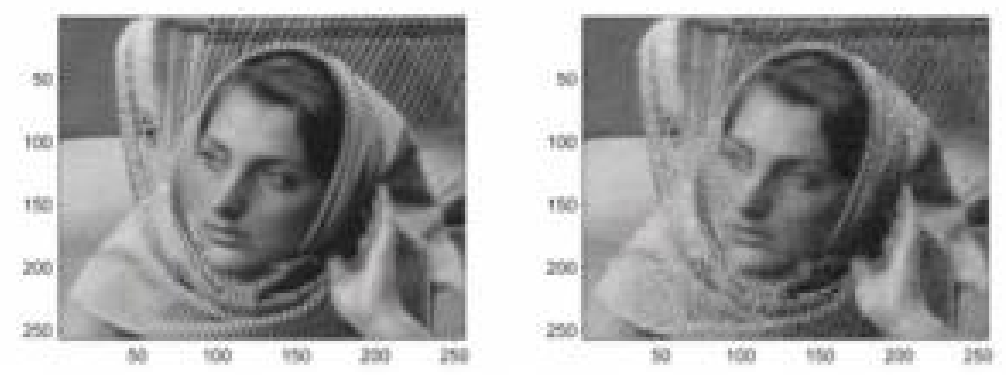

Figura 18 - Compressão de Imagem e reconstrução a partir de coeficientes de matriz Wavelet. Extraído de Hao et al. (2010).

A Figura 19 exibe a reconstrução de imagem a partir de uma árvore construída com coeficientes de Wavelet (a). A imagem representada por (b) mostra a reconstrução da imagem utilizando de pontos amostrados aleatoriamente com a técnica de CoSaMP (DUARTE; ELDAR, 2011). A imagem em (c) é reconstruída com o mesmo número de amostras, mas utilizando a árvore de coeficientes exibida em (a).
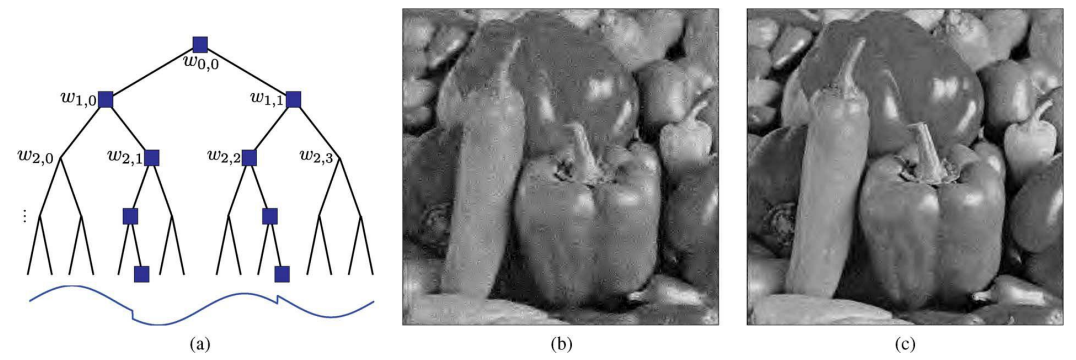

Figura 19 - Exemplo de reconstrução de imagem com CS com árvore estruturada e técnica CoSaMP. Extraído de Duarte e Eldar (2011)

A técnica possui aplicação considerável em compressão de dados, devido à matriz aleatória utilizada para amostragem, particularmente vantajosa em redes de sensores (CANDĖS; WAKIN, 2007). A transmissão de dados se beneficia dos elementos básicos de CS (esparsidade, aleatoriedade), que pode ser utilizada para corrigir erros durante a transmissão de maneira performática. Também é importante ressaltar que a aquisição de dados via CS é muito mais fácil de realizar, uma vez que a amostragem total para compressão posterior possui um custo inexistente em CS, onde a própria amostragem é realizada de forma compressiva (CANDÈS; WAKIN, 2007).

A teoria possui um poder de aquisição de dados tão robusto que pode ser exemplificado na Figura 20. Nesse modelo de câmera, o raio de luz incidente é refletida em um 
dispositivo de matrizes de micro-espelhos digitais cujo orientação é modulada de forma pseudoaleatória, fornecido pelo gerador de números randômicos. Cada espelho diferente produz uma tensão no fotodiodo que corresponde a uma medição. O processo é repetido com diferentes padrões $M$ vezes para obter um vetor de medição completo $y$ (DUARTE; ELDAR, 2011). Após obter o vetor, é aplicada a minimização da norma $L_{1}$ por algumas das técnicas descritas na Seção 3.7. Com a minimização, é possível obter a imagem completa que foi sensoreada pelo pixel.

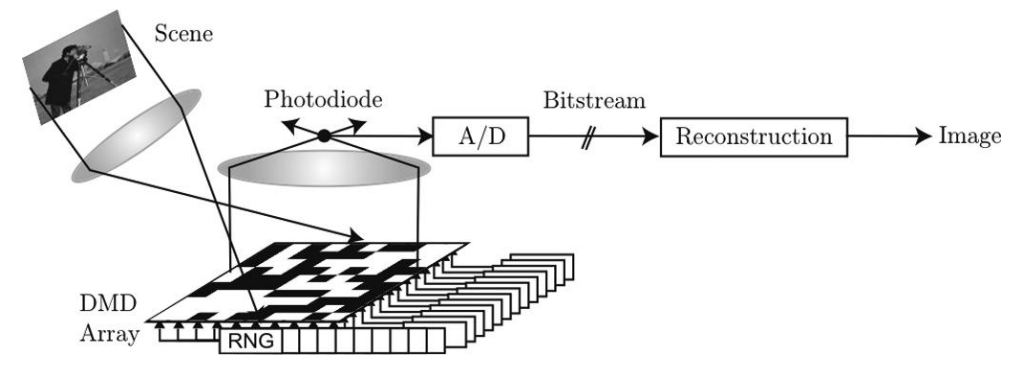

Figura 20 - Diagrama de câmera de um pixel. Extraído de Duarte e Eldar (2011).

Outras aplicações da teoria de CS também é encontrada na literatura. A Tabela 1 apresenta algumas das aplicações encontradas em artigos recentes.

Tabela 1 - Exemplos de Aplicações de CS em Diferentes Áreas.

\begin{tabular}{lll}
\hline \hline Área & Resumo & Referência \\
\hline Áudio & Recuperação de sinais delimitados de áudio. & Defraene et al. $(2013)$. \\
Vídeo & Codificação de quadros de vídeo. & Liu et al. (2013). \\
Radar & Construção de sinais de radar. & Ender (2013). \\
MRI & Utilização da esparsidade da baixa frequência de banda. & Chauffert et al. (2013). \\
\hline
\end{tabular}

Os exemplos apresentados indicam que existe uma variedade de aplicações da técnica de CS em várias áreas. Devido à sua capacidade de aquisição de dados de forma compressiva, a forma como se processam os sinais tem sido repensada (ENDER, 2013). O fato de a teoria de CS ser relativamente recente, motiva os pesquisadores a experimentar essa abordagem em diferentes aspectos. 


\section{Compressive Sensing aplicado em Malhas}

\subsection{Introdução}

Conforme apresentado no Capítulo 3, a teoria de Compressive Sensing (CS) trata do sensoreamento compressivo de sinais. Essa técnica apresenta diversas aplicações, em particular no sensoreamento compressivo em imagens como mostrado no trabalho de Schulz et al. (2009c).

Neste trabalho foi realizada aplicação da técnica de CS em malhas geométricas. A inspiração para aplicação da técnica em malhas advém da similaridade da representação de objetos com a representação de malhas, o que sugere uma aplicabilidade da técnica nesse contexto. O trabalho de Du e Geng (2011) propõe a aplicação de CS em malhas geométricas. Esse estudo trata-se apenas de um trabalho descritivo, sem testes ou comparações, apresentando de forma teórica a aplicabilidade da técnica. No texto de Yoon e Kuijper (2011), é proposto um modelo de recuperação de conteúdo para modelos geométricos baseado em CS, para buscar e retornar de forma automática um conjunto de malhas a partir de uma base de modelos tridimensionais. Essa abordagem explora a possibilidade de sensorear um conjunto de malhas e recuperar uma determinada estrutura.

Esta dissertação explora a ideia de aplicação CS em malhas como técnica de representação compressiva. Como apresentado no Capítulo 2 as técnicas de compressão de malhas possuem diversas aplicações e variações. Logo, a possibilidade de uma maneira adicional de realizar essa compressão é interessante do ponto de vista acadêmico.

De forma geral, o experimento realizado divide os dados da malha em dois conjuntos: vértices (informação geométrica) e conectividade (informação topológica). A técnica de CS é aplicada no conjunto de vértices, transformando essa informação em três vetores $k$ esparsos (compressão) e realizando o sensoreamento através de uma matriz de medição, apresentada na Seção 3.4 A partir desse sensoreamento, os vetores originais são recons- 
truídos e a malha é recriada com essa nova informação geométrica. Comparam-se então as duas malhas (original e reconstruída) através de diferentes métricas, a fim de apurar a acurácia da reconstrução.

As próximas seções apresentam o experimento em detalhe e os resultados obtidos.

\subsection{Experimentos}

O experimento realizado tem como objetivo aplicar a técnica de CS em malhas e comparar sua respectiva reconstrução com as malhas originais. Para tal, foram utilizadas 10 malhas, apresentadas das Subseções 5.1.1 até a 5.10.1.

O processo utilizado no experimento é descrito conforme segue e detalhado no algoritmo 1:

- a malha é dividida em duas matrizes contendo a geometria e a conectividade;

- é definida a densidade da esparsidade que será utilizada (esparsidade do sinal);

- a geometria da malha é particionada em três vetores, onde cada vetor $\left(V_{x}, V_{y}, V_{z}\right)$ recebe uma das coordenadas $(x, y, z)$;

- a matriz de medição $\Phi$ é definida;

- a partir do threshold são removidos os coeficientes pouco significativos;

- os vetores $V_{x}, V_{y}$ e $V_{z}$ são levados para sua representação esparsa, identificados agora como $V_{s x}, V_{s y}$ e $V_{s z}$. Essa representação é realizada através de multiplicação dos vetores por uma matriz laplaciana através de uma operação SVD;

- é aplicada a minimização de $L_{1}$ nos vetores $V_{s x}, V_{s y}$ e $V_{s z}$;

- uma nova matriz é criada com os vetores reconstruídos;

- a malha é reconstruída a partir dos novos vetores e da conectividade preservada;

- utiliza-se a distância de Hausdorff para realizar a comparação entre a malha original e a malha reconstruída.

No experimento realizado dois laços principais foram utilizadas para gerar a base de dados necessária para realização da análise. A primeira trata da taxa de esparsidade e a 
segunda do número de medições. Esses laços são alterados em uma iteração de 1 a 10, de modo que é gerado um conjunto de dados com 100 combinações.

A taxa de esparsidade provoca uma variação na quantidade de pontos esparsos gerados para realizar a medição aleatória apresentada na técnica de CS. Ou seja, é variada a quantidade de pontos significativos dentre o espaço original, de forma que a transformação de bases apresentada no Capítulo 3 seja possível.

A segunda variável trata do número de medidas realizadas na matriz esparsa em processamento. No caso do experimento, o número de medições varia em função do número de vértices da malha de acordo com a iteração realizada. O algoritmo 1 define de forma genérica como o experimento se comporta. Adicionalmente, foi utilizada a biblioteca Numerical Tour, desenvolvida por Peyré (2011).

Entrada: Uma malha $M$

1 Uma matriz $O_{v}$ é criada com os vértices da malha $M$

Uma matriz $O_{f}$ é criada com as faces (conectividade) da malha

Define em limite a quantidade de iterações a realizar

Multiplica-se $V_{s x}, V_{s y}$ e $V_{s z}$ pela matriz de medição $\Phi$

enquanto iteracaoPrincipal < limite faça

$2 \quad$ Esparsidade $=$ functionCalculoEsparsidade(iteracaoPrincipal $)$

$3 \quad$ enquanto iteracaoSecundaria < limite faça

$4 \quad$ NumeroMedidas $=$ numeroVertices/iteracaoSecundaria Calcula-se a matriz de medição $\Phi$

Os vetores $V_{x}, V_{y}$ e $V_{z}$ são obtidos a partir de $O_{v}$

Aplica a minimização de $L_{1}$ nos vetores e calcula a nova matriz $O_{v}{ }^{\prime}$

Reconstrói $M$ em $M^{\prime}$

Cálculo de BPV

Cálculo de PSNR

Armazena em uma matriz de resultados $R$ a comparação de $M$ com $M^{\prime}$ através da distância da Hausdorff

Armazena em um vetor de resultados $B$ o valor de BPV calculado

Armazena em vetor de resultados $P$ o valor de PSNR calculado

5 retorna $R$

Algorithm 1: Algoritmo da aplicação de CS na Malha. 
Como apresentado no algoritmo, a variação do número de medidas transita entre o número total de vértices da malha até um décimo dos vértices. Essa variação, associada a variação da esparsidade, permite reconstruir a malha e analisar os resultados em função da precisão da reconstrução em relação a malha original. O algoritmo genérico representado no algoritmo 1 sofre pequenas variações no que diz respeito ao cálculo da minimização da norma $L_{1}$. Essas variações são apresentadas na sequência.

Os experimentos iniciais utilizaram uma matriz de medição gaussiana (ver Seção 3.4.1) como a matriz $\Phi$ da teoria. Essa matriz apresentou resultados satisfatórios para malhas com baixa densidade, pois para gerar a matriz gaussiana é preciso calcular os determinantes montados a partir dos vetores de vértices. Quando existem vértices na ordem de milhares, esse cálculo é computacionalmente complexo, dependendo de memória disponível na máquina e processamento. Dessa forma, nos resultados apresentados a seguir, apenas alguns exemplos com matriz gaussiana são demonstrados.

Devido à essa dificuldade, escolhemos trabalhar com matrizes Noiselets, que têm uma performance computacional superior e permitiram executar o experimento com malhas na ordem de milhares de vértices. Todos os resultados apresentados correlacionando as taxas de compressão foram executadas nesse cenário.

Uma terceira variação do experimento utilizando Total Variation também foi produzida, mas os resultados não diferiram em relação à minimização da norma $L_{1}$ com regras de igualdade, de forma que somente um resultado é exibido no Capítulo 5. 


\subsubsection{Métricas de Avaliação}

Para avaliar os resultados do experimento, foram utilizadas três métricas para comparação dos resultados: Distância de Hausdorff, PSNR e Bits por Vértice.

\subsubsection{Distância de Hausdorff}

A primeira métrica utilizada trata-se da Distância de Hausdorff . Dado dois conjuntos de pontos finitos $A=a_{1}, a_{2}, \ldots, a_{p}$ e $B=b_{1}, b_{2}, \ldots, b_{q}$, a DH é definida por:

$$
H(A, B)=\max (h(A, B), h(B, A))
$$

O valor de $h(A, B)$ é definido por $h(A, B)=\max _{a \in A} \min _{b \in B}\|a-b\|$. Conforme a definição acima, essa medida é bidirecional, onde pode existir uma variação da métrica se calculada no sentido conjunto $A$ para o conjunto $B$ ou no sentido $B$ para $A$ WANG et al. 2011) BAUDRIER et al., 2004).

Essa métrica foi calculada com a variação entre as malhas originais e as malhas reconstruídas, sendo aplicado o conceito do cálculo da distância de Hausdorff no conjunto de vértices da malha original $(A)$ contra a malha reconstruída $(B)$. Para cada iteração apresentada no algoritmo 1, o cálculo da distância de Hausdorff é executada e seu valor é armazenado numa matriz que relaciona o número de medições utilizadas na iteração para o processamento de CS e a esparsidade dos vértices durante a iteração. Com essa matriz, são gerados os mapas de cores apresentados no Capítulo 5.

Nos experimentos, foi utilizado o software MATLAB (MATLAB, 2010), através da biblioteca ToolBoxGraph (PEYRÉ, 2009).

Uma aplicação adicional da DH pode ser encontrada no trabalho de Gao et al GAO et al., 2013). Nesse trabalho, é utilizada uma abordagem para reconstrução de objetos tridimensionais a partir de medições da DH.

\subsubsection{PSNR}

A segunda métrica utilizada nos experimentos foi o peak signal to noise ratio - PSNR. Esta métrica de erro também trabalha na comparação entre a malha original e a malha reconstruída (SALOMON, 2007). Como característica para este cálculo, quanto maior seu valor, melhor a reconstrução. O número produzido no cálculo é sem dimensão e deve 
possuir pouca sensibilidade a pequenas variações nas reconstruções.

Para realizar o cálculo, primeiramente é definido o erro quadrático médio, através da equação:

$$
E Q M=\frac{1}{n} \sum_{i=1}^{n}\left(P_{i}-Q_{i}\right)^{2}
$$

Na equação acima, $P$ representa o conjunto de vértices da malha original e $Q$ o conjunto de vértices da malha reconstruída. O PSNR é definido então por:

$$
P S N R=20 \log _{1} 0 \frac{\max _{i}\left|P_{i}\right|}{R E Q M}
$$

A raiz do erro quadrático médio (REQM) é calculada a partir da raiz quadrada de EQM.

Quanto melhor a reconstrução entre as malhas, o REQM é menor, o que implica em um PSNR maior.

Valores típicos de PSNR variam de 20 a 40.(SALOMON, 2007) e 30 a 50 (LEE et al., 2010). Um valor de REQM de zero (reconstruções idênticas) resulta em um valor infinito de PSNR.

Nos experimentos realizados com as malhas, foram gerados gráficos combinando a variação entre o PSNR e o número de bits por vértice.

\subsubsection{Bits Por Vértice (BPV)}

O cálculo de Bits por Vértice (BPV) é uma métrica que avalia a quantidade de bits necessária para armazenar a informação de um determinado vértice da malha. O cálculo de bits por vértice é realizado da seguinte maneira:

- Um nível de quantização $T$ é definido (neste experimento, o nível é 0.5);

- Os coeficientes são calculados, para que fiquem em valores inteiros;

- O histograma dos coeficientes então é calculado;

- A entropia é calculada a partir do histograma calculado $(E)$;

- O número de bits por vértice é $3 * E$; 
De acordo com Peyré (2008) na forma matemática, temos:

$$
\begin{gathered}
T=0.5 \\
\text { VetorQuantizado }=\left\lfloor\left|\frac{\text { Vetor }}{T}\right|\right\rfloor * \text { sgn }(\text { Vetor }) \\
\text { Limites }=\min (\text { Vetor }): \max (\text { Vetor }) \\
\text { Histograma }=\text { hist }(\text { VetorQuantizado, Limites }) \\
\text { Histograma }=\max (\text { Histograma }, 1 e-10) \\
\text { Histograma }=\frac{\text { Histograma }}{\sum_{\text {Histograma }}} \\
\text { E }=-\sum \log (\text { Histograma }) * \text { Histograma } \\
\text { BPV }=3 * E
\end{gathered}
$$

No Algoritmo 1, existem as indicações do momento do cálculo de BPV e PSNR.

\subsubsection{Variações do Experimento}

Na realização dos experimentos, foram realizadas algumas variações, modificando-se a forma de minimização da Norma $L_{1}$ e a matriz de medição utilizada.

A primeira variação envolve a minimização de norma $L_{1}$ com regras de igualdade e utilização de matriz de medição gaussiana. A matriz $\Phi$ é gerada de forma aleatória, baseados na distribuição normal. Esse cálculo toma como parâmetros de entrada o número de vértices da malha e o número de medidas definido na iteração do algoritmo.

A segunda variação utiliza a minimização de norma $L_{1}$ com regras de igualdade e matriz de medição Noiselet. As matrizes Noiselets foram apresentadas na Subseção 3.4.3. Esta variação foi a predominante nos experimentos, em função das razões apresentadas na Seção 4.2 .

A variação final utilizada envolve a utilização de matrizes Noiselets e minimização de Total Variation. Conforme apresentado na Seção 3.6, Total Variation é a derivada da norma $L_{1}$, de forma que o que muda nesta abordagem é a forma da minimização. Os demais princípios de CS mantém-se os mesmos. 
Com base nessas variações, foram produzidos gráficos que ilustram e correlacionam as informações de reconstrução das malhas e as taxas de compressão obtidas.

O primeiro tipo de gráfico produzido é ilustrado na Figura 21, que apresenta um modelo de gráfico correlacionando a distância de Hausdorff, o número de medições realizadas e a esparsidade utilizada. O eixo A indica a esparsidade do sinal utilizada durante as iterações do experimento. O eixo C, indica a quantidade de medições realizadas em cada iteração. A escala em B indica a variação da distância de Hausdorff distribuída no mapa. É importante observar que a esparsidade é uma medida inversamente proporcional, ou seja, quanto maior o número exibido no gráfico no eixo A, menos elementos significativos existem na matriz de medição.

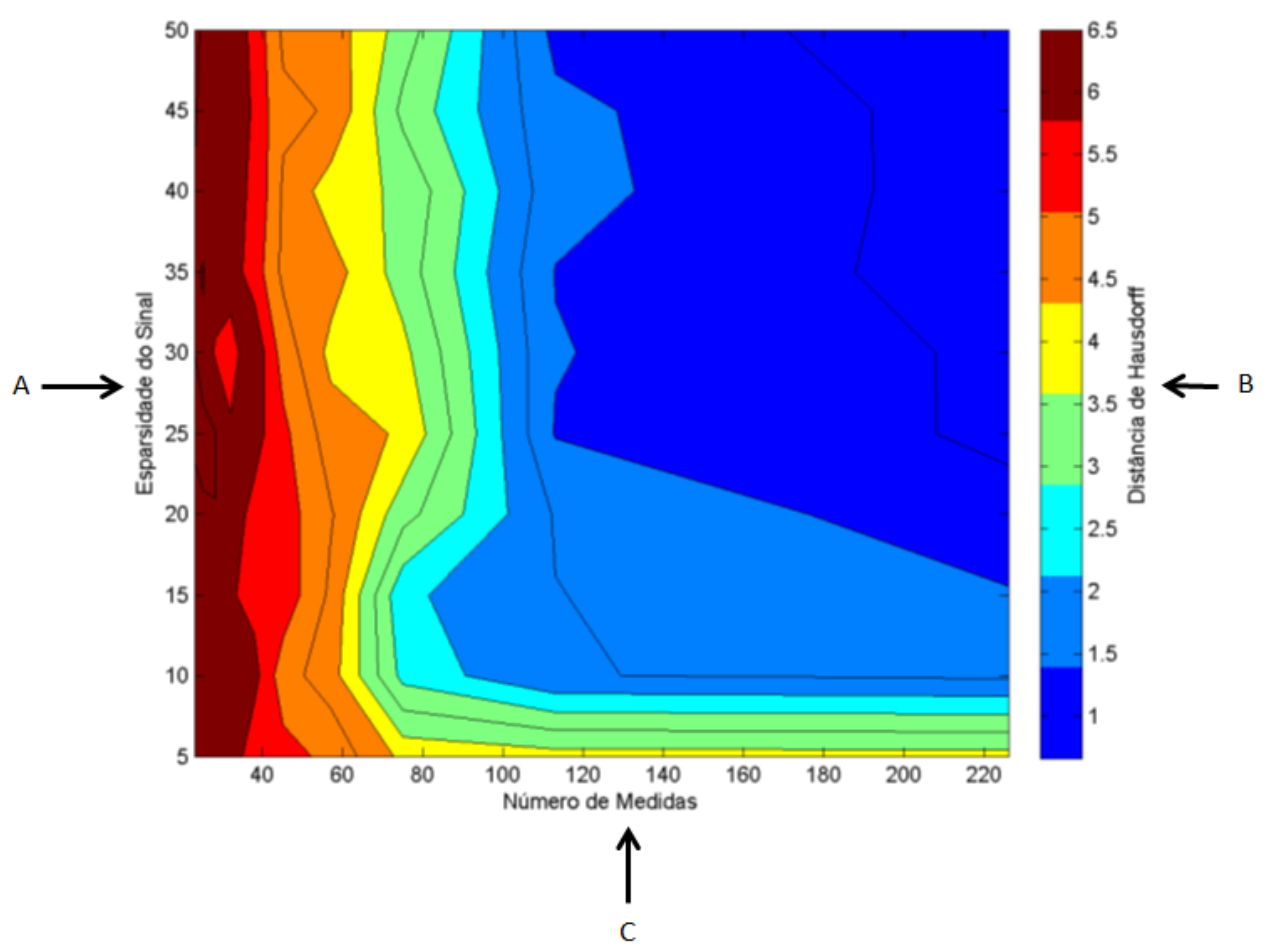

Figura 21 - Modelo de gráfico de mapa de cores.

O segundo tipo de gráfico produzido apresentado na Figura 22, correlaciona a variação da distância de Hausdorff com a taxa BPV calculada para o experimento. O eixo A indica a variação da distância de Hausdorff e o eixo B aprensta a variação da taxa BPV. Dentro da iteração do algoritmo, os gráficos gerados para exibir essa correlação utilizam a última iteração de esparsidade, variando somente as medições, de modo a gerar o gráfico com a variação linear exibida no gráfico. 


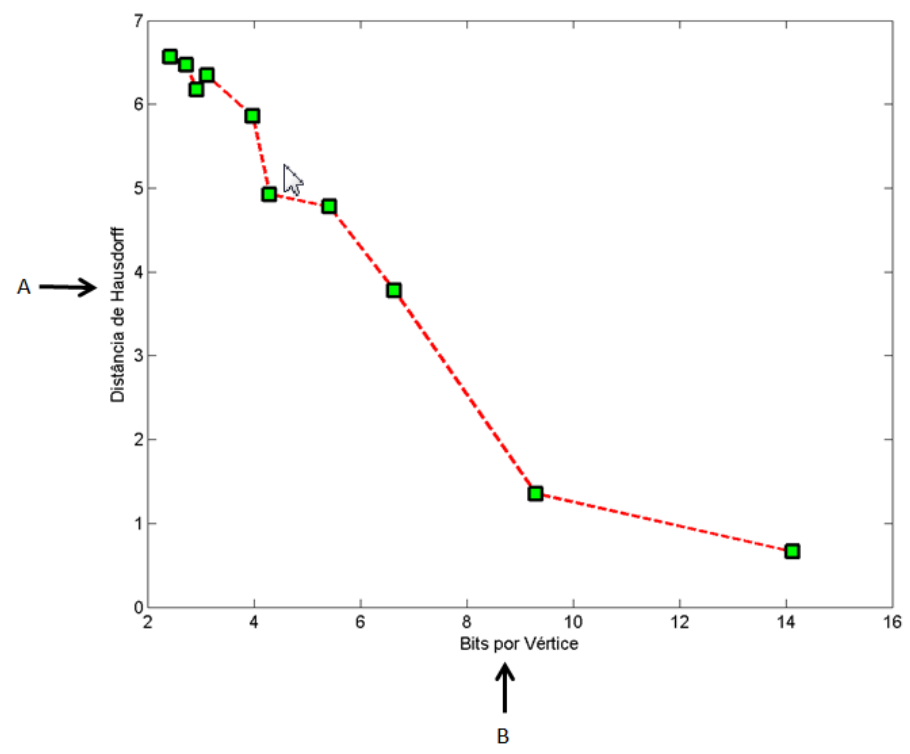

Figura 22 - Modelo de gráfico correlacionando a distância de Hausdorff e BPV.

Por fim, o último tipo de gráfico gerado é exemplificado na Figura 23. O eixo A indica a variação da taxa PSNR e o eixo B indica a variação de Bits por Vértice. Conforme apresentado na Subseção 4.2.3, a PSNR é uma medida sem dimensão, de maneira que os valores apresentados são referências para a variação em relação ao número de bits por vértice. As medições desses gráficos também foram efetuadas na última iteração de esparsidade, variando somente as medidas tomadas.

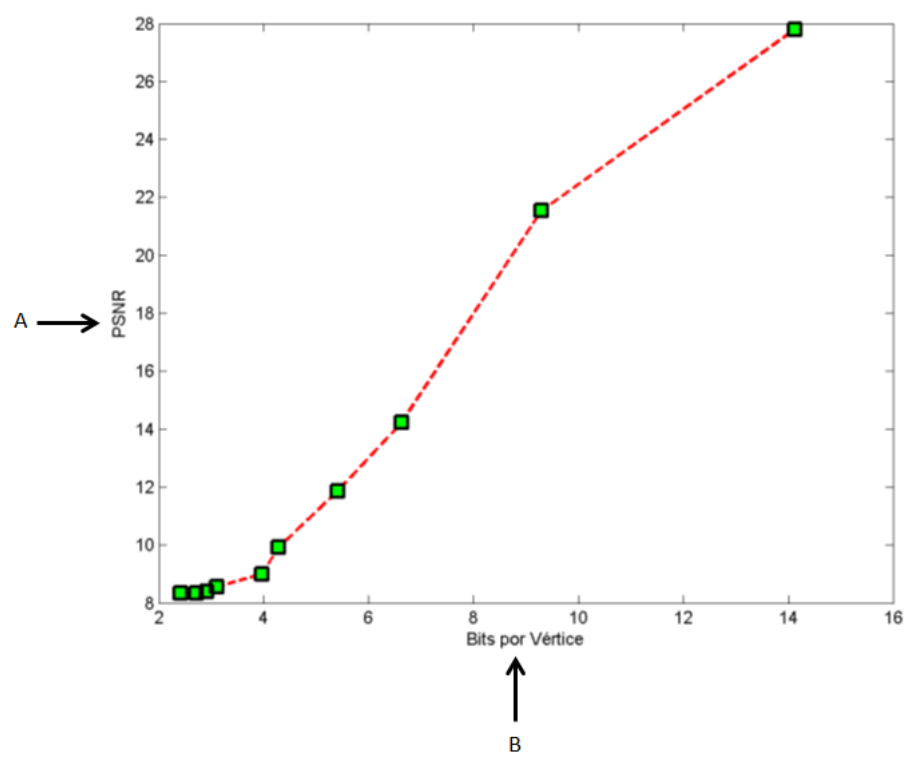

Figura 23 - Modelo de gráfico correlacionando a taxa de PSNR e BPV. 


\section{Resultados}

Neste Capítulo são apresentados os resultados obtidos pelo experimento. Os dados de cada malha utilizada são listados, juntamente com sua representação espacial e os gráficos obtidos no experimento listados subsequentemente. Após cada apresentação de resultado, são exibidas as considerações de análise sobre o experimento e os indicadores obtidos.

A Tabela 2 apresenta a relação das malhas utilizadas nos experimentos, com o número de vértices que as compõem juntamente com o número de faces.

Tabela 2 - Relação de Malhas Utilizadas nos Experimentos.

\begin{tabular}{lcc}
\hline \hline Malha & Nr. Vértices & Nr. Faces \\
\hline Cogumelo & 226 & 448 \\
Manequim & 428 & 839 \\
Cavalo & 712 & 1.420 \\
Vaca & 2.904 & 5.804 \\
Cabeça de Davi & 11.882 & 23.639 \\
Homem & 17.495 & 34.986 \\
Fandisk & 24.894 & 51.784 \\
Elefante & 24.955 & 49.918 \\
Coelho & 34.835 & 69.473 \\
Dragão & 50.000 & 100.000
\end{tabular}




\subsection{Cogumelo}

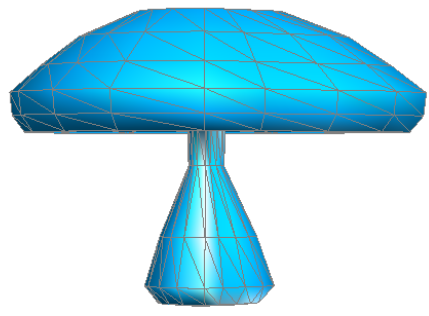

(a) Malha triangular representando um cogumelo, formada por 226 vértices e 448 faces.

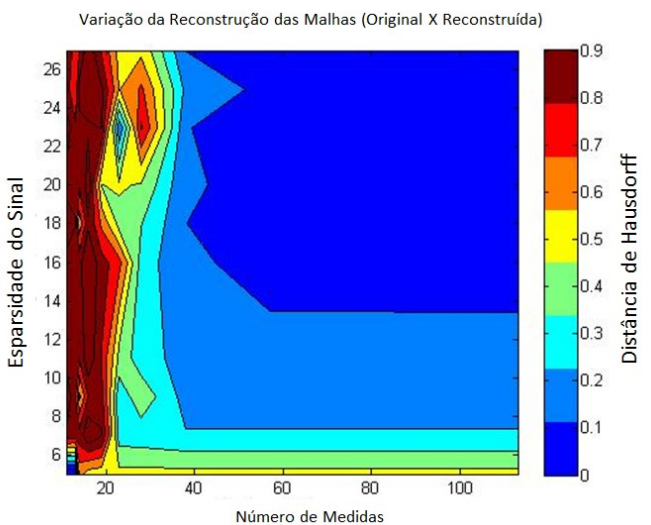

(c) Variação Distância de Hausdorff (Gaussiana) durante as reconstruções da malha do cogumelo, utilizando matriz de medição Gaussiana com no máximo 50 coeficientes significativos.

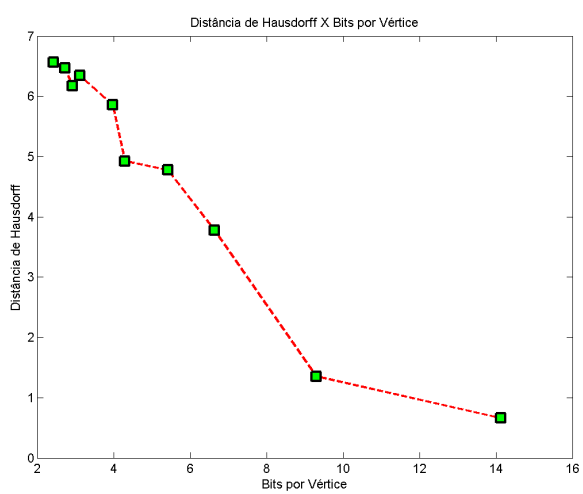

(e) Gráfico correlacionando a quantidade de bits por vértice e a distância de Hausdorff durante as reconstruções utilizando matriz de medição Noiselet com no máximo 50 coeficientes significativos.

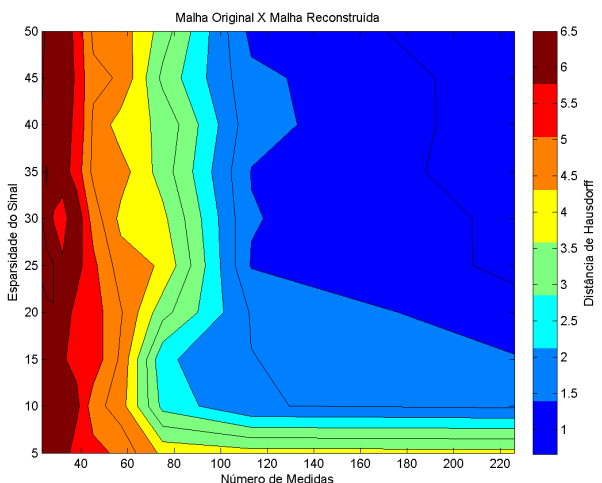

(b) Variação Distância de Hausdorff (Noiselet) durante as reconstruções da malha do cogumelo, utilizando matriz de medição Noiselet com no máximo 50 coeficientes significativos.

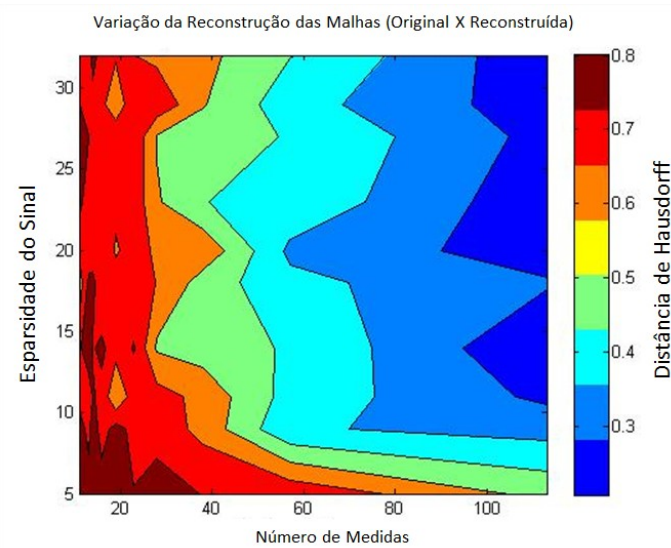

(d) Variação Distância de Hausdorff (Noiselet) durante as reconstruções da malha do cogumelo, utilizando matriz de medição Noiselet com no máximo 50 coeficientes significativos e minimização com Total Variation.

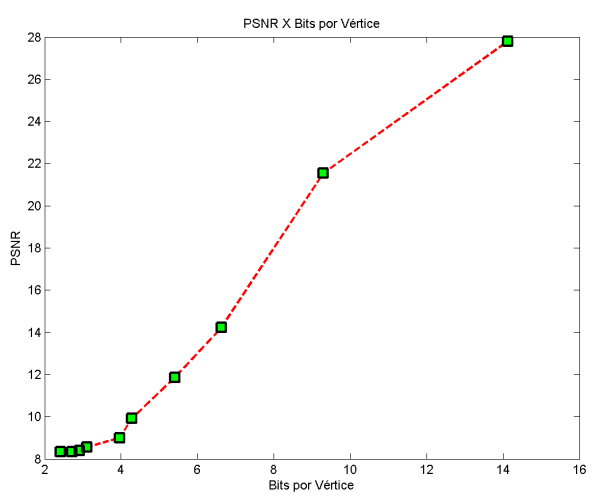

(f) Gráfico correlacionando a quantidade de bits por vértice e a taxa de distorção do sinal (PSNR) utilizando matriz de medição Noiselet com no máximo 50 coeficientes significativos.

Figura 24 - Resultados Experimento - Cogumelo. 


\subsubsection{Análise dos Resultados do Cogumelo}

O experimento realizado com o cogumelo foi exploratório, devido à incerteza da aplicabilidade da técnica de CS tendo malhas como objeto de aplicação. Essa malha foi escolhida em função de sua baixa densidade (poucos vértices) e para avaliar quais matrizes ou técnicas de minimização poderiam ser utilizadas na aplicação da técnica.

Os resultados preliminares foram interessantes do ponto de vista de viabilidade da técnica. Os resultados obtidos mostrados na Figura 24 indicam que a reconstrução da malha possui uma acuracidade razoável (pouca variação nas comparações das Distâncias de Hausdorff), em função dos parâmetros utilizados no experimento. Na Figura 24b, podemos observar que as melhores reconstruções ocorrem quando há um número de medidas mínimo, aliado a uma esparsidade não tão baixa. Observa-se que ao utilizar 200 medidas, por exemplo, a variação da esparsidade, a partir de um limite, não influencia no resultado da reconstrução.

A Figura 24c apresenta os resultados da reconstrução utilizando a matriz de medição gaussiana. Nesse caso, foi utilizada uma quantidade menor de medidas (limitadas a 120) e esparsidade reduzida (limite 26) e o resultado é semelhante ao processo utilizando a matriz Noiselet. A diferença principal nesse caso é o tempo de processamento e capacidade computacional, que ficará claro quando da utilização de malhas mais densas. Além disso, a matriz gaussiana só pôde ser utilizada para malhas não muito densas, devido às razões apresentadas na Seção 4.2 .

A variação do experimento usando minimização de Total Variation é apresentada na Figura 24d. Os parâmetros de medidas e esparsidade foram os mesmos utilizados na medição com matriz gaussiana. Nesse resultado, nota-se que a obtenção de uma reconstrução próxima a malha original ocorre com menor frequência que os demais experimentos. No entanto, não é possível inferir que a utilização de Total Variation seja uma técnica pior que as demais minimizações, pois a amostragem nesse experimento é muito pequena.

O gráfico exibido na Figura 24e apresenta uma relação entre a distância de Hausdorff e a taxa de Bits por Vértice. Quando maior a distância de Hausdorff (logo, pior a reconstrução), utilizam menos bits por vértice. Conforme a distância reduz, a taxa BPV aumenta. Ou seja, para uma reconstrução mais precisa, é necessário uma utilização maior de bits por vértice.

Por fim, o gráfico que correlaciona a taxa PSNR com BPV apresentada na Figura 24f, mostra que para uma taxa de PSNR aceitável entre 20 e 40 ocorrem com a utilização de 
mais bits por vértice. Esse intervalo entre 20 e 40 da taxa de PSNR é considerado bom conforme mostrado no trabalho de Salomon (2007). Portanto, os gráficos da DH e PSNR correlacionados com BPV são coerentes entre si.

\subsection{Manequim}

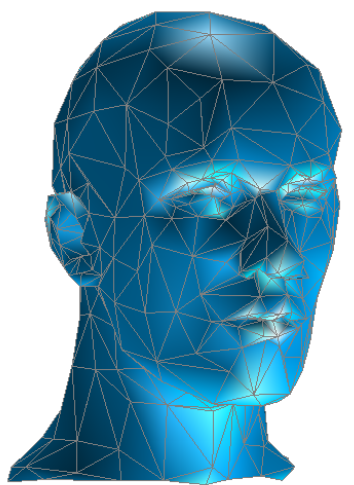

(a) Malha triangular representando uma cabeça de manequim, formada por 428 vértices e 839 faces.

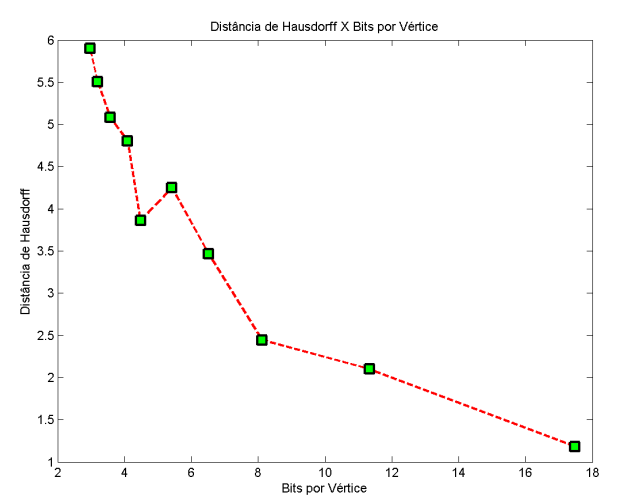

(c) Gráfico correlacionando a quantidade de bits por vértice e a distância de Hausdorff durante as reconstruções utilizando matriz de medição Noiselet com no máximo 100 coeficientes significativos.

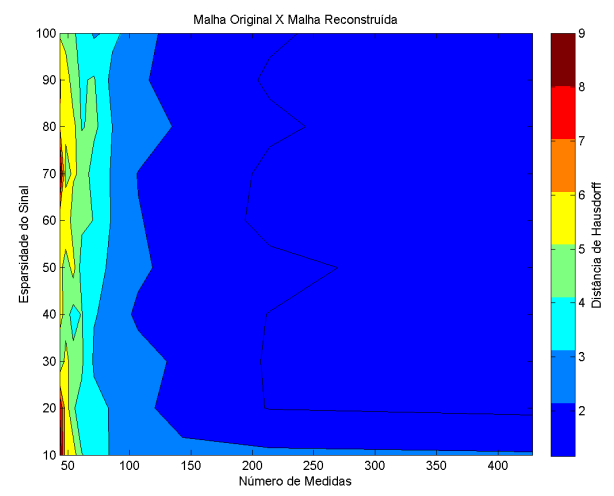

(b) Variação Distância de Hausdorff (Noiselet) durante as reconstruções da malha do manequim, utilizando matriz de medição Noiselet com no máximo 100 coeficientes significativos.

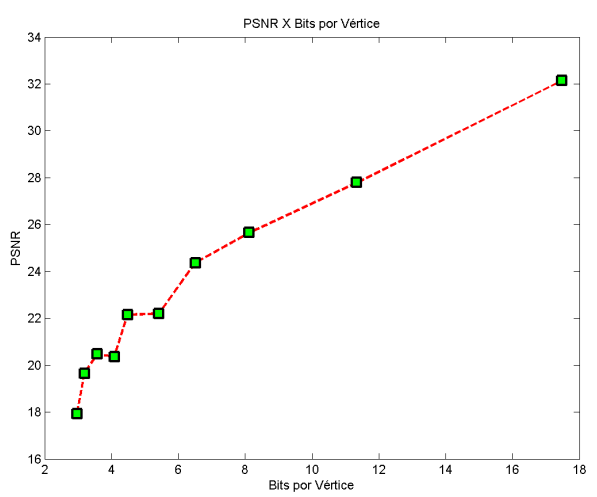

(d) Gráfico correlacionando a quantidade de bits por vértice e a taxa de distorção do sinal (PSNR) utilizando matriz de medição Noiselet com no máximo 100 coeficientes significativos.

Figura 25 - Resultados Experimento - Manequim. 


\subsubsection{Análise dos Resultados do Manequim}

A malha do manequim utilizada mostrada na Figura 25a apresenta também uma malha pouco densa, de forma que a performance do processamento da técnica é razoável em termos de tempo.

No mapa 25b, a configuração apresentada mostra que boa parte das reconstruções teve bom aproveitamento. O limite de medidas para reconstrução razoável é alcançado rapidamente, de forma que mesmo com uma esparsidade alta (20), as reconstruções são bem sucedidas com medidas superiores a 150 .

As tendências dos gráficos 25c e 25d são coerentes entre si, uma vez que conforme aumenta-se a taxa BPV, a distância de Hausdorff diminui e a taxa PSNR aumenta, ficando no intervalo desejado de 20 a 40. 


\subsection{Cavalo}

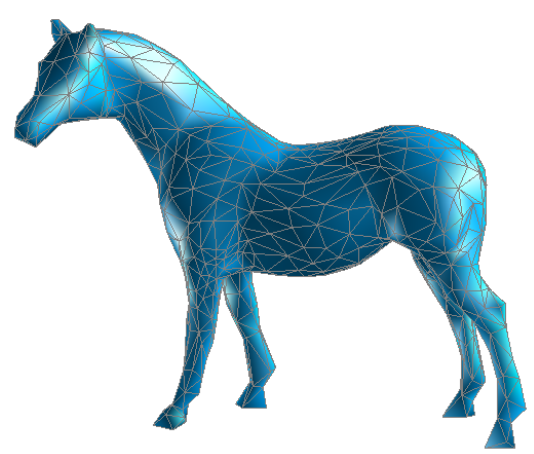

(a) Malha triangular representando um cavalo, formada por 712 vértices e 1.420 faces.

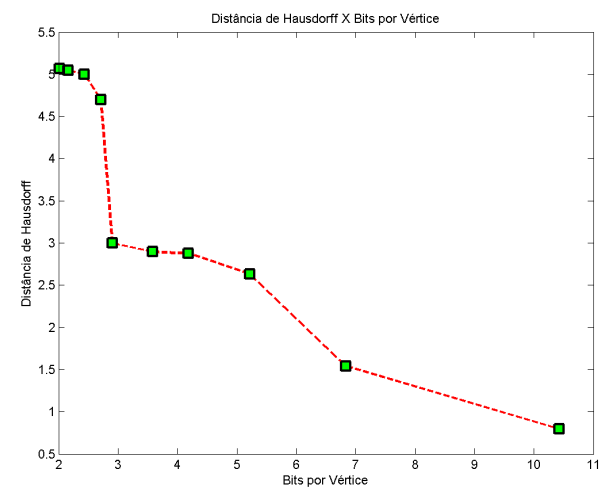

(c) Gráfico correlacionando a quantidade de bits por vértice e a distância de Hausdorff durante as reconstruções utilizando matriz de medição Noiselet com no máximo 200 coeficientes significativos.

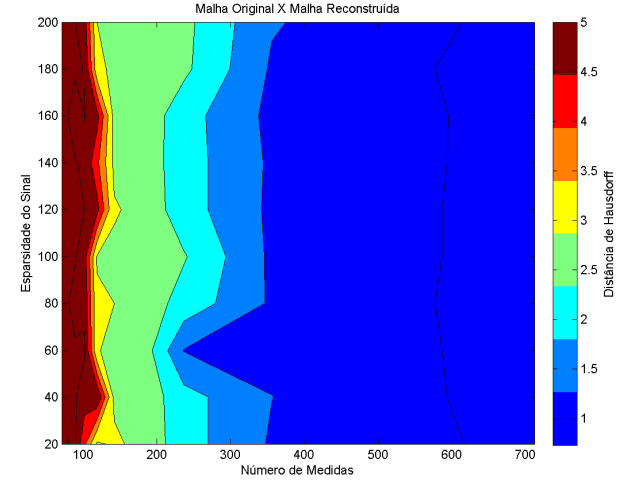

(b) Variação Distância de Hausdorff (Noiselet) durante as reconstruções da malha do cavalo, utilizando matriz de medição Noiselet com no máximo 200 coeficientes significativos.

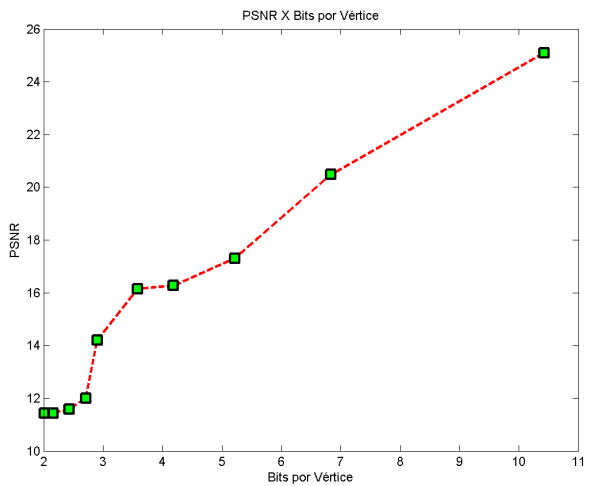

(d) Gráfico correlacionando a quantidade de bits por vértice e a taxa de distorção do sinal (PSNR) utilizando matriz de medição Noiselet com no máximo 200 coeficientes significativos.

Figura 26 - Resultados Experimento - Cavalo.

\subsubsection{Análise dos Resultados do Cavalo}

A malha do cavalo apresentada na Figura 26a também apresenta densidade baixa. Os resultados obtidos com essa variação do experimento apresentam um limiar entre as reconstruções razoáveis e as distorcidas. Dentro do intervalo de esparsidade apresentado na Figura 26b, a partir de um número de medidas em torno de 350, temos a reconstrução 
realizada com boa aproximação. Nesse caso, a partir de metade da informação de vértices da malha, é possível reconstruí-la.

Observa-se também nos gráficos exibidos em 26c e 26d a mesma tendência de aumento na taxa de BPV em função da diminuição da DH e o aumento da PSNR para valores no intervalo objetivo. Isso ocorre porque quanto maior a precisão necessária para a reconstrução da malha, maior será o número de bits por vértice necessários para representá-la. 


\subsection{Vaca}

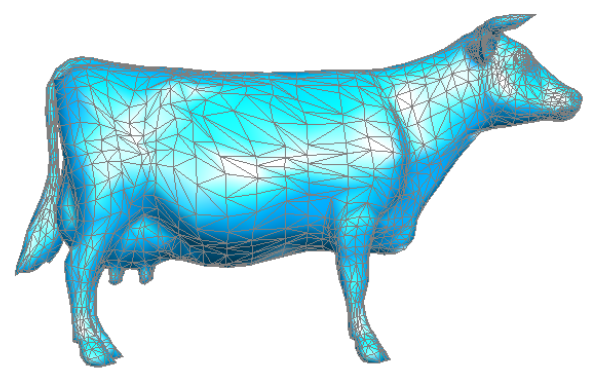

(a) Malha triangular representando uma vaca, formada por 2.904 vértices e 5.804 faces.

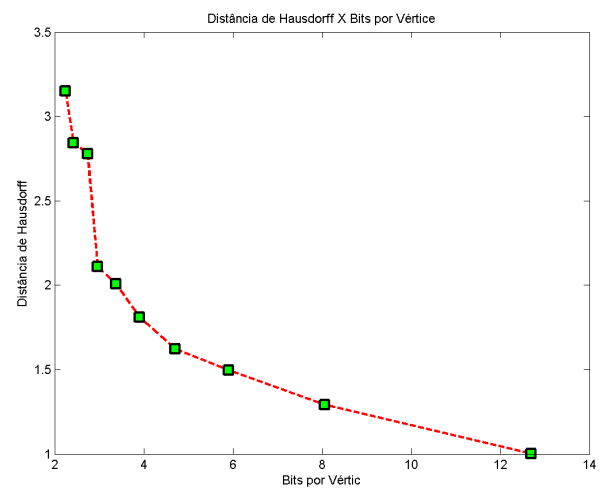

(c) Gráfico correlacionando a quantidade de bits por vértice e a distância de Hausdorff durante as reconstruções utilizando matriz de medição Noiselet com no máximo 100 coeficientes significativos.

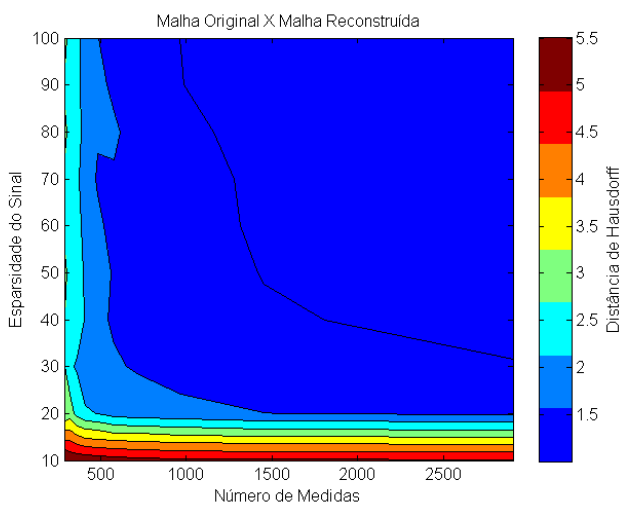

(b) Variação Distância de Hausdorff (Noiselet) durante as reconstruções da malha da vaca, utilizando matriz de medição Noiselet com no máximo 100 coeficientes significativos.

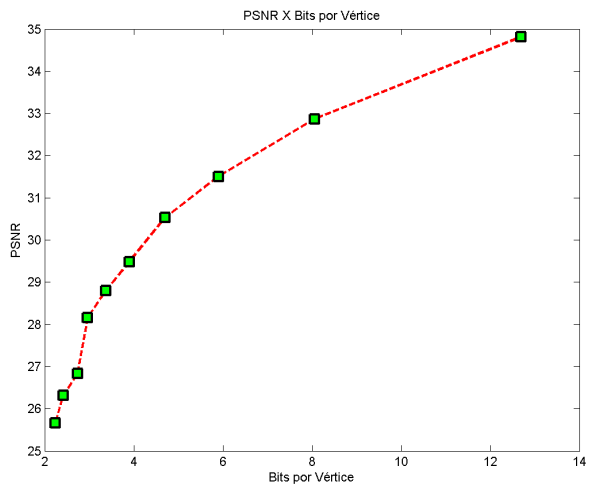

(d) Gráfico correlacionando a quantidade de bits por vértice e a taxa de distorção do sinal (PSNR) utilizando matriz de medição Noiselet com no máximo 100 coeficientes significativos.

Figura 27 - Resultados Experimento - Vaca.

\subsubsection{Análise dos Resultados da Vaca}

A malha 27a teve suas reconstruções apresentadas no mapa 27b. Pode-se visualizar no mapa que as reconstruções têm um nível bom de reconstrução quando a esparsidade chega a um nível de 30 (ou seja, esparsidade alta). Nesse caso, a partir de 1000 medições, é possível fazer uma reconstrução razoável da malha. Esse número indica que com um terço 
de medidas, é possível reconstruir a malha. Logo, seria necessário armazenar somente um terço da informação de vértices para compactar a malha.

Os gráficos 27c e 27d também apresentam a tendência mostrada nas Subseções 5.1.1. 5.2.1 e 5.3.1. Dessa forma, podemos inferir um padrão no qual ao aumentarmos a taxa de BPV (consequentemente, aumentando a definição da malha), teremos necessariamente menores distâncias de Hausdorff e PSNR's dentro do intervalo satisfatório esperado (entre 20 e 40$)$. 


\subsection{Cabeça de Davi}

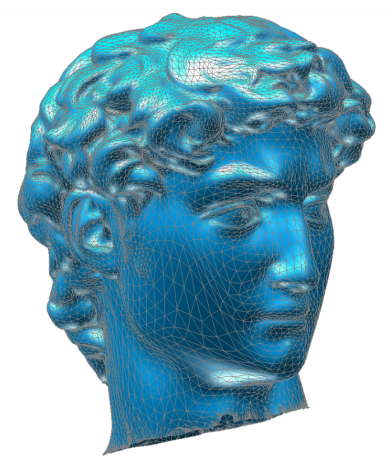

(a) Malha triangular representando a cabeça de Davi, formada por 11.882 vértices e 23.639 faces.

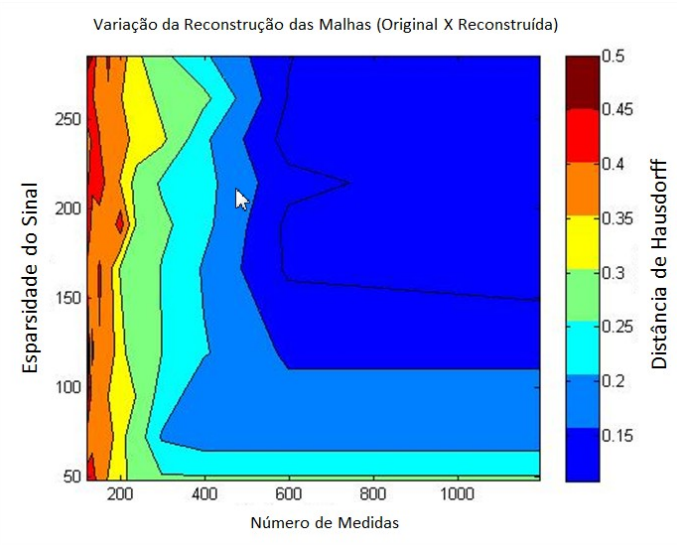

(c) Variação Distância de Hausdorff (Gaussiana) durante as reconstruções da malha da cabeça de Davi, utilizando matriz de medição Noiselet com no máximo 200 coeficientes significativos.

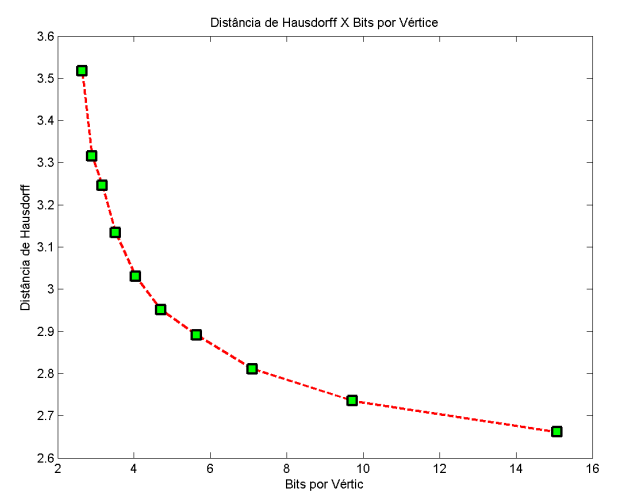

(e) Gráfico correlacionando a quantidade de bits por vértice e a distância de Hausdorff durante as reconstruções utilizando matriz de medição Noiselet com no máximo 200 coeficientes significativos.

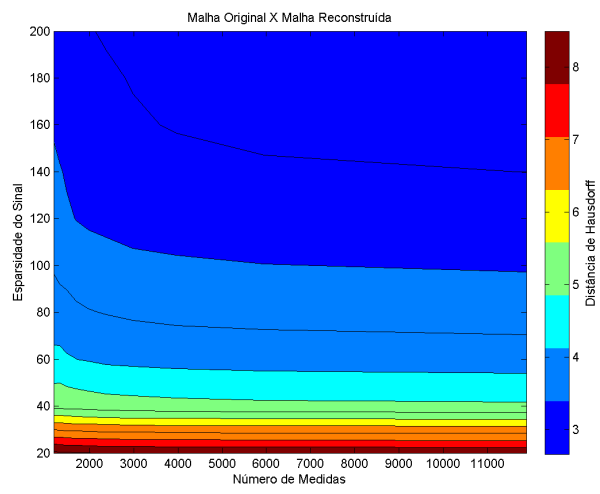

(b) Variação Distância de Hausdorff (Noiselet) durante as reconstruções da malha da cabeça de Davi, utilizando matriz de medição Noiselet com no máximo 200 coeficientes significativos.

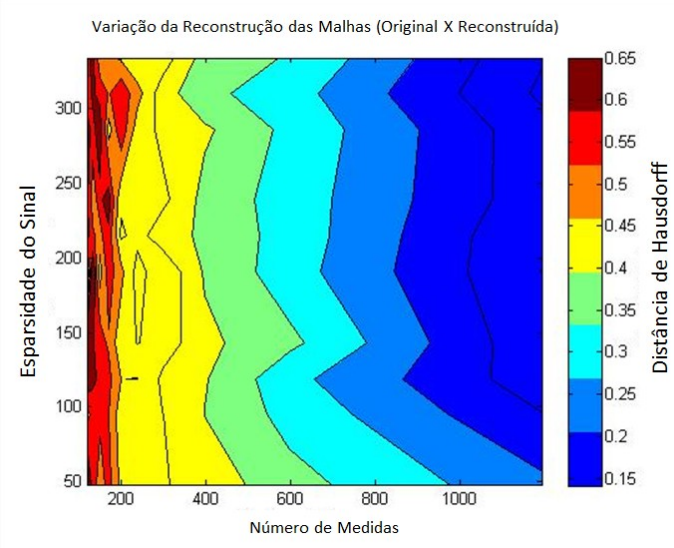

(d) Variação Distância de Hausdorff (Noiselet) durante as reconstruções da malha da cabeça de Davi, utilizando matriz de medição Noiselet e Total Variation com no máximo 200 coeficientes significativos.

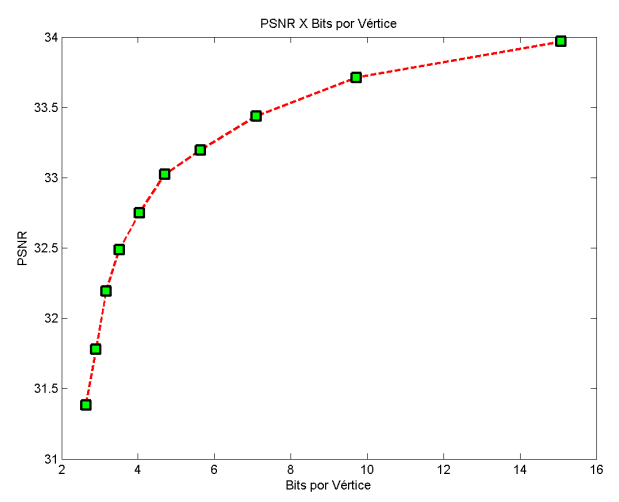

(f) Gráfico correlacionando a quantidade de bits por vértice e a taxa de distorção do sinal (PSNR) utilizando matriz de medição Noiselet com no máximo 200 coeficientes significativos.

Figura 28 - Resultados Experimento - Cabeça de Davi. 


\subsubsection{Análise dos Resultados da Cabeça de Davi}

Os experimentos com a malha 28a foram executados com duas variações extras. Além da execução do experimento com minimização da norma $L_{1}$ e matriz Noiselet, foram realizados dois experimentos com minimização da norma $L_{1}$ e matriz gaussiana e com minimização de Total Variation e matriz Noiselet. Esse dois últimos experimentos, foram limitados a 1000 medições e esparsidade de 250.

Na Figura 28b, os resultados com matriz Noiselet mostram que a partir de certo nível de esparsidade, as reconstruções são realizadas de forma satisfatória, independente do número de medidas. Ou seja, com um conjunto baixo de medidas, é possível reconstruir a malha, desde que haja uma esparsidade mínima. Quando utiliza-se a matriz gaussiana, exemplificado na Figura 28c, também temos reconstruções satisfatórias, mas com limites maiores de esparsidade e medidas. Apesar de o gráfico ter sido gerado com limites de medidas e esparsidade, quando comparado com a Figura 28b, vemos coerência nos resultados. O mesmo acontece com o mapa 28d, onde a minimização é feita com Total Variation. No entanto, a irregularidade é maior. Isso ocorre porque a miminização com Total Variation provoca outros pontos de reconstrução, mais irregulares, quando comparada com a minimização de $L_{1}$.

Os gráficos 28e e 28f mostram também a correlação encontrada nas outras malhas. Ao diminuirmos a distância de Hausdorff, torna-se necessário uma taxa maior de bits por vértice, já que a informação que precisa ser armazenada é mais complexa. O mesmo ocorre com a taxa de PSNR. Ela atinge o intervalo alvo quando aumenta-se a taxa de BPV, já que são necessárias mais informações para representar a malha com um nível de satisfação adequado. 


\subsection{Homem}

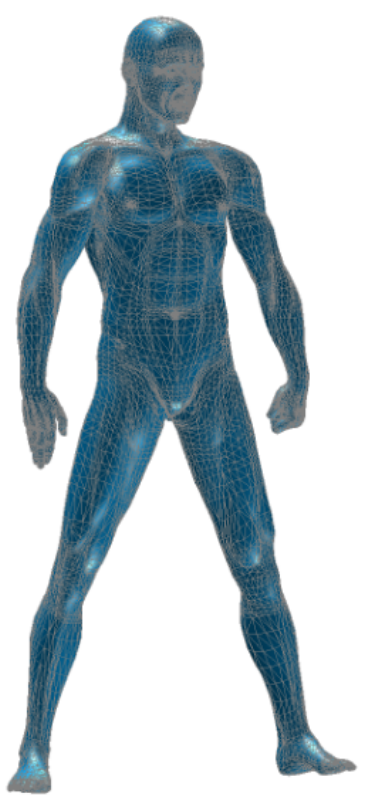

(a) Malha triangular representando um homem, formada por 17.495 vértices $\mathrm{e}$ 34.986 faces.

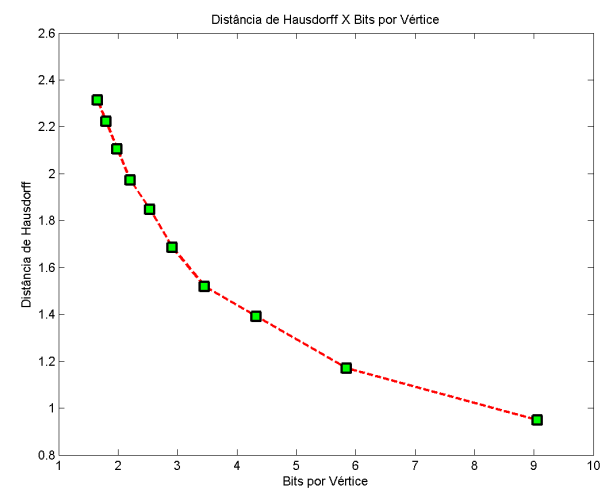

(c) Gráfico correlacionando a quantidade de bits por vértice e a distância de Hausdorff durante as reconstruções utilizando matriz de medição Noiselet com no máximo 300 coeficientes significativos.

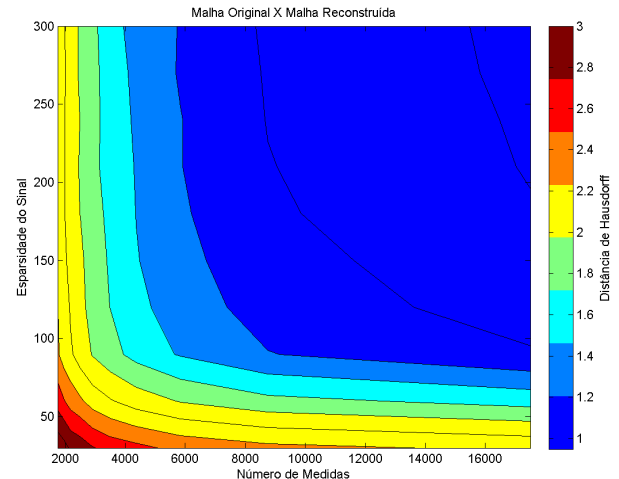

(b) Variação Distância de Hausdorff (Noiselet) durante as reconstruções da malha do homem, utilizando matriz de medição Noiselet com no máximo 300 coeficientes significativos.

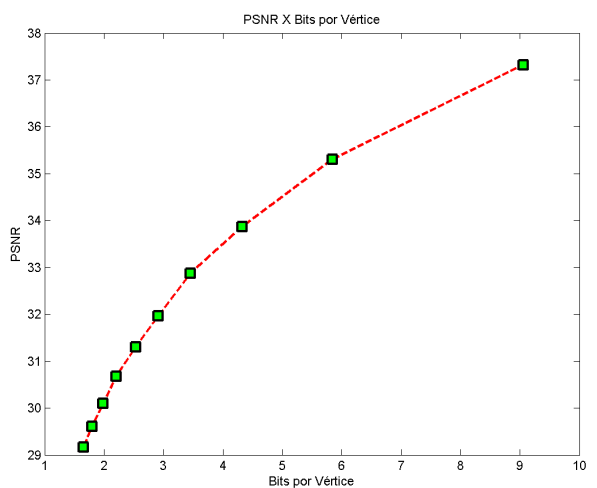

(d) Gráfico correlacionando a quantidade de bits por vértice e a taxa de distorção do sinal (PSNR) utilizando matriz de medição Noiselet com no máximo 300 coeficientes significativos.

Figura 29 - Resultados Experimento - Homem. 


\subsubsection{Análise dos Resultados do Homem}

A malha representada na Figura 29a possui uma densidade maior (aproximadamente 17.000 vértices). O comportamento apresentado no mapa de cores (Figura 29b), segue um padrão de reconstrução que apresenta um limiar de medições ao redor de 8000, a partir do qual a reconstrução passa a ser satisfatória. Não obstante, além desse limiar, também é necessário uma esparsidade relativa em torno de 100 elementos.

Os gráficos apresentados nas Figuras 29c e 29d apresentam uma correlação entre a taxa de bits por vértice com a distância de Hausdorff e a PSNR. É possível dizer que ambos são coerentes pois conforme apresentados nas Subseções 5.1.1, 5.2.1, 5.3.1, 5.4.1, e 5.5.1, a taxa BPV varia de acordo com a precisão necessária para a representação da malha. Logo, quanto melhor a representação da malha, maior a taxa de BPV. Como consequência, temos uma DH menor e a PSNR no intervalo desejado de 20 a 40, o que também encontramos nos resultados desta variação do experimento. 


\subsection{Fandisk}

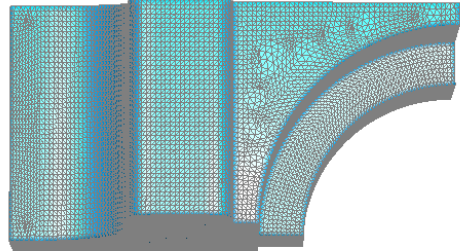

(a) Malha triangular representando um recorte espacial de uma peça técnica, formada por 24.894 vértices e 51.784 faces.

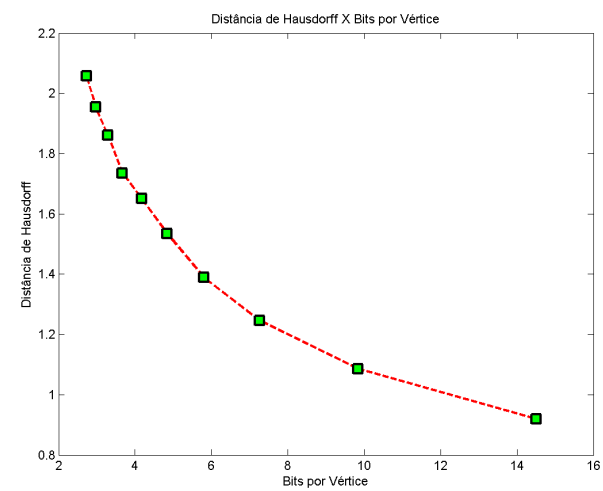

(c) Gráfico correlacionando a quantidade de bits por vértice e a distância de Hausdorff durante as reconstruções utilizando matriz de medição Noiselet com no máximo 300 coeficientes significativos.

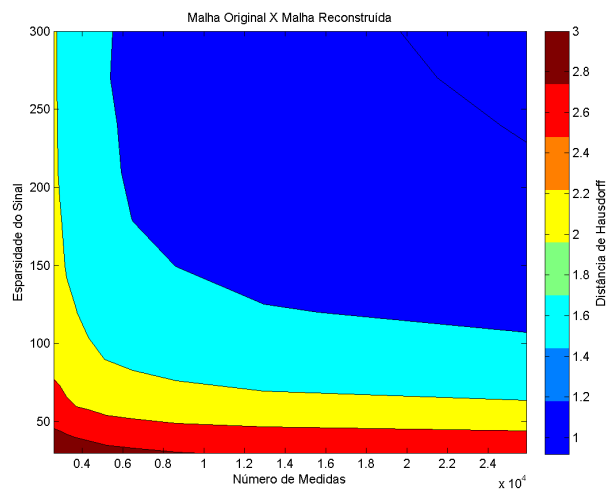

(b) Variação Distância de Hausdorff (Noiselet) durante as reconstruções da malha do fandisk, utilizando matriz de medição Noiselet com no máximo 300 coeficientes significativos.

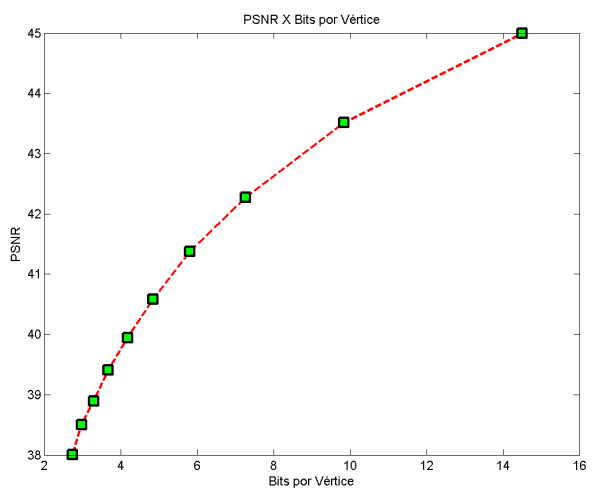

(d) Gráfico correlacionando a quantidade de bits por vértice e a taxa de distorção do sinal (PSNR) utilizando matriz de medição Noiselet com no máximo 300 coeficientes significativos.

Figura 30 - Resultados Experimento - Fandisk.

\subsubsection{Análise dos Resultados do Fandisk}

Seguindo o aumento de densidade das malhas utilizadas no experimento, a malha da Figura 30 a possui mais vértices que os experimentos anteriores. As reconstruções realizadas produziram o mapa de cores da Figura 30b. Pode-se observar que a área de reconstrução satisfatória representa uma parte considerável das reconstruções, com uma tendência de reconstrução satisfatória a partir de 8000 medidas e esparsidade de 150 . 
Também o gráfico que mostra a tendência da DH com BPV (Figura 30c) acompanham a tendência apresentada nos experimentos anteriores. Conforme temos uma melhor definição da malha reconstruída (ou seja, uma distância de Hausdorff menor), temos a taxa BPV maior (devido à necessidade de mais informação a ser armazenada). A PSNR também alcança o intervalo alvo de 20 a 40, na maior parte dos pontos (Figura 30d). Isso ocorre porque a maior parte das reconstruções mostradas no mapa apresentaram uma reconstrução satisfatória. Entre as as malhas utilizadas nos experimentos, esta foi a que apresentou alguns dos melhores resultados. 


\subsection{Elefante}

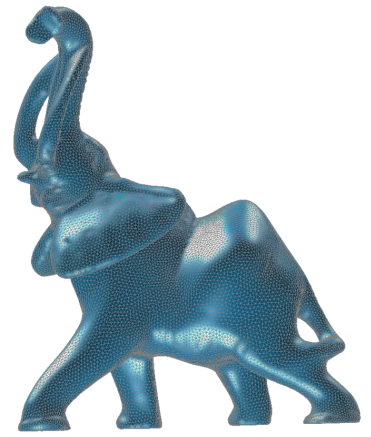

(a) Malha triangular representando um elefante, formada por 24.955 vértices e 49.918 faces.

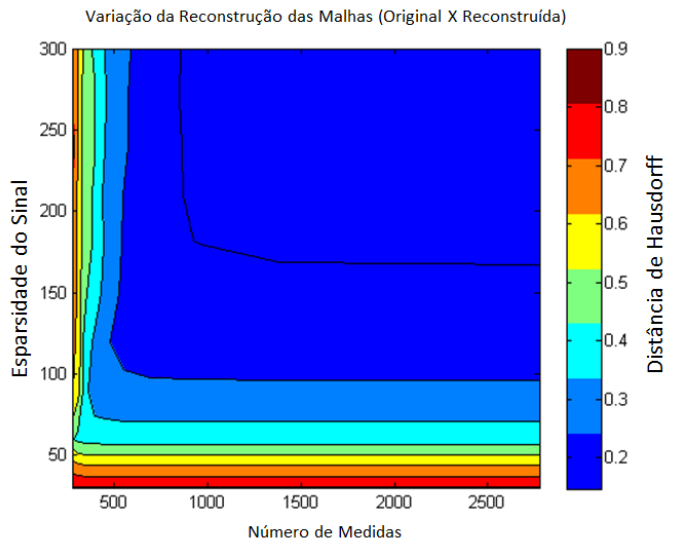

(c) Variação Distância de Hausdorff (Gaussiana) durante as reconstruções da malha do elefante, utilizando matriz de medição gaussiana com no máximo 300 coeficientes significativos.

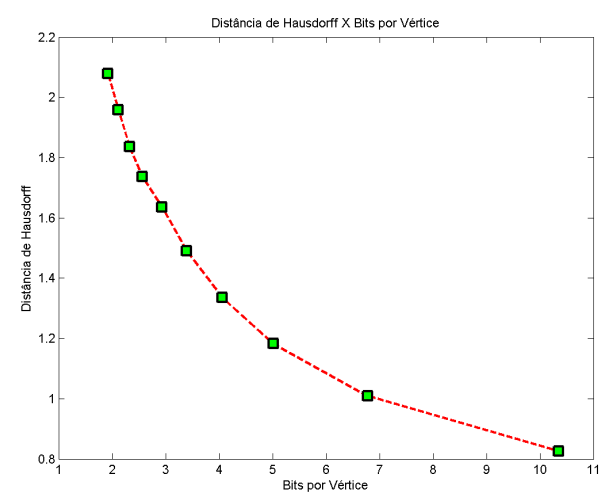

(e) Gráfico correlacionando a quantidade de bits por vértice e a distância de Hausdorff durante as reconstruções utilizando matriz de medição Noiselet com no máximo 200 coeficientes significativos.

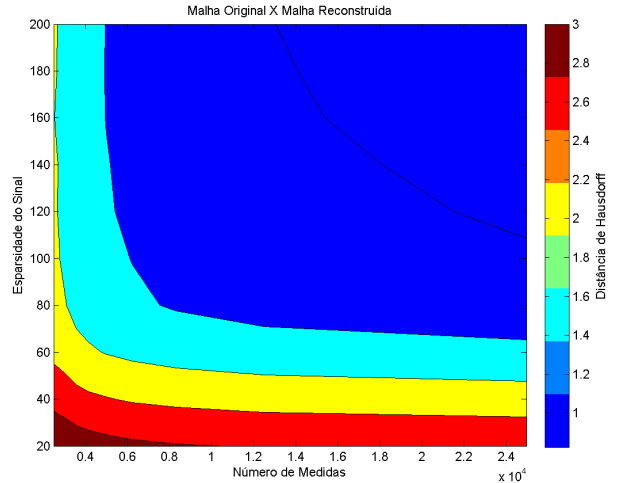

(b) Variação Distância de Hausdorff (Noiselet) durante as reconstruções da malha do elefante, utilizando matriz de medição Noiselet com no máximo 200 coeficientes significativos.

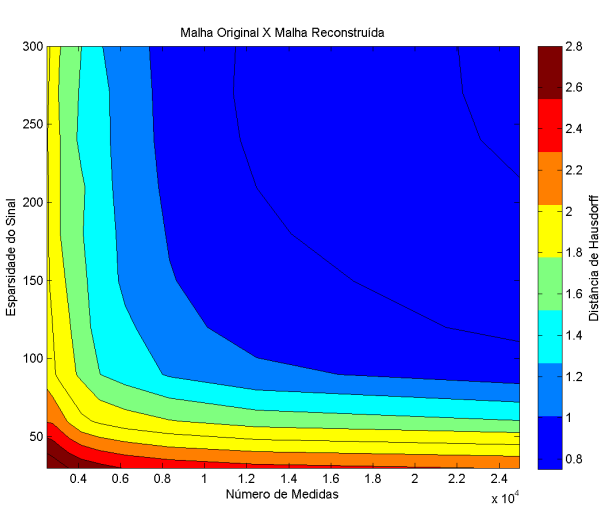

(d) Variação Distância de Hausdorff (Noiselet) durante as reconstruções da malha do elefante, utilizando matriz de medição Noiselet com no máximo 300 coeficientes significativos.

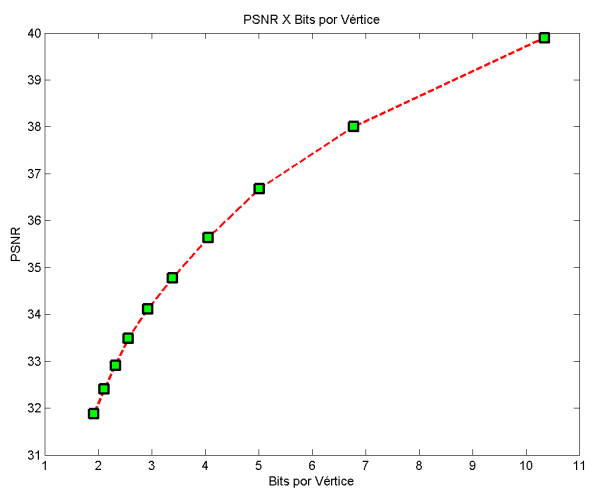

(f) Gráfico correlacionando a quantidade de bits por vértice e a taxa de distorção do sinal (PSNR) utilizando matriz de medição Noiselet com no máximo 200 coeficientes significativos.

Figura 31 - Resultados Experimento - Elefante. 


\subsubsection{Análise dos Resultados do Elefante}

O experimento realizado com a malha do elefante (Figura 31a) foi feito com três variações. A primeira, foi utilizada matriz de medição Noiselet e minimização da norma $L_{1}$. Esse resultado é exibido na Figura 31b. Nesta malha densa, também temos uma área de reconstrução satisfatória a partir de uma esparsidade 80 e 10.000 medidas. Essa reconstrução segue uma tendência apresentada na Seção 5.7.1.

A Figura a 31c apresenta uma variação utilizando uma matriz de medição gaussiana. Nesse experimento, foi fixado um limite máximo de 300 coeficientes significativos, com uma malha reduzida em $90 \%$ dos vértices. Ou seja, foi gerada uma malha menor, baseada na malha principal, com apenas 2.500 vértices. Nesse experimento, também temos uma boa margem de reconstruções da malha, de modo que comparativamente, a matriz de medição gaussiana teve um intervalo de reconstruções melhor do que a matriz Noiselet.

O terceiro mapa apresentado na Figura 31c, é uma repetição do primeiro mapa (31b), com aumento dos coeficientes significativos (máximo de 300). Nesse caso, o mapa de cores apresenta a tendência de reconstrução observada no experimento com no máximo 200 coeficientes, mas apresenta mais resultados com reconstruções ruins. É curioso observar que com mais coeficientes significativos (300), temos mais reconstruções mal sucedidas, do que com menos coeficientes (200). Esse comportamento tem explicação na aleatoriedade da técnica de CS, uma vez que mesmo a repetição do experimento com os mesmos parâmetros, pode resultar num mapa de cores particular.

Os gráficos de de DH por BPV (31e) e PSNR por BPV (31f) apresentam os resultados coerentes com os demais experimentos. É interessante notar que o PSNR fica limitado no intervalo de interesse (20 a 40) em todo o gráfico, o que condiz com o mapa 31b. Da mesma forma, a taxa de BPV aumenta conforme a DH diminui. 


\subsection{Coelho}

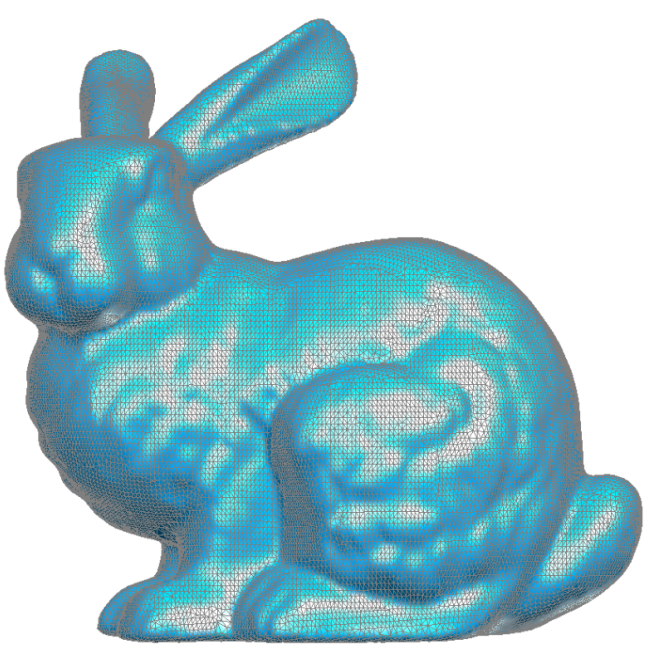

(a) Malha triangular representando um coelho, formada por 34.835 vértices e 69.473 faces.

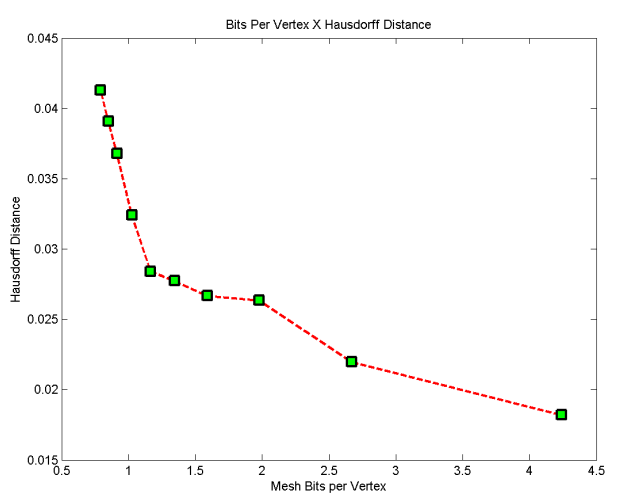

(c) Gráfico correlacionando a quantidade de bits por vértice e a distância de Hausdorff durante as reconstruções utilizando matriz de medição Noiselet com no máximo 200 coeficientes significativos.

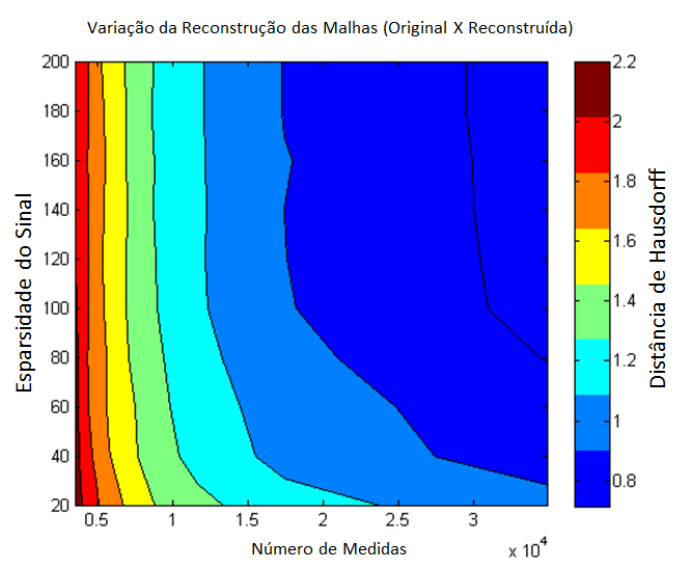

(b) Variação Distância de Hausdorff (Noiselet) durante as reconstruções da malha do coelho, utilizando matriz de medição Noiselet com no máximo 200 coeficientes significativos.

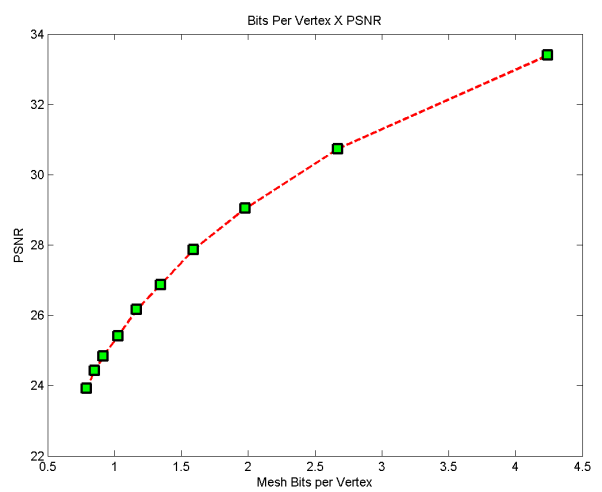

(d) Gráfico correlacionando a quantidade de bits por vértice e a taxa de distorção do sinal (PSNR) utilizando matriz de medição Noiselet com no máximo 200 coeficientes significativos.

Figura 32 - Resultados Experimento - Coelho.

\subsubsection{Análise dos Resultados do Coelho}

A malha de coelho 32a é a segunda malha mais densa utilizada nos experimentos. Com a matriz Noiselet e minimização da norma $L_{1}$ produziu reconstruções cujos resultados das distâncias de Hausdorff estão apresentadas no mapa 32b. Nesta variação há também 
uma tendência de reconstrução satisfatória a partir de um limiar de medidas (20.000) e esparsidade (100). Esse comportamento para ser predominante nas malhas mais densas, conforme visto nas seções anteriores.

A relação entre DH e BPV (Figura 32c) e PSNR e BPV (32d) continuam apresentando a tendência das malhas anteriores, que demonstram coerência com o mapa de cores.

\subsection{Dragão}

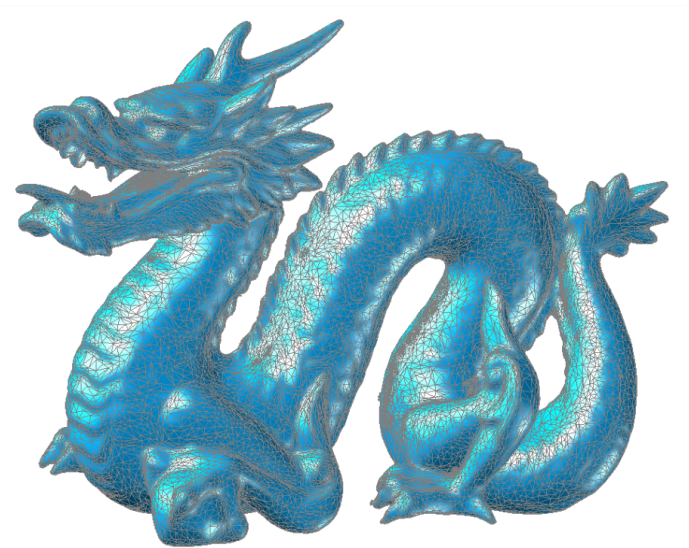

(a) Malha triangular representando um dragão, formada por 50.000 vértices e 100.000 faces.

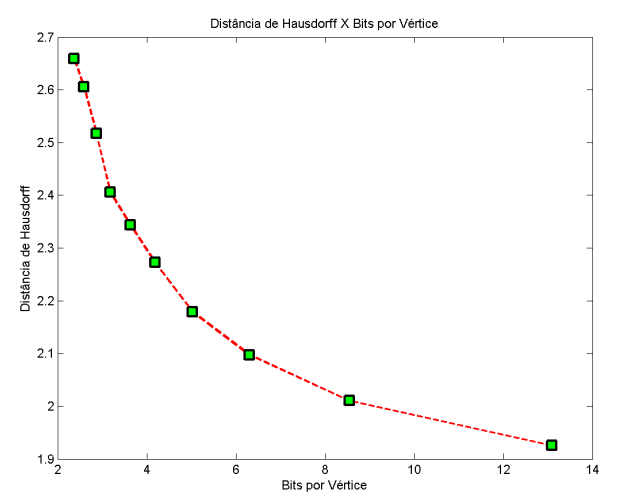

(c) Gráfico correlacionando a quantidade de bits por vértice e a distância de Hausdorff durante as reconstruções utilizando matriz de medição Noiselet com no máximo 500 coeficientes significativos.

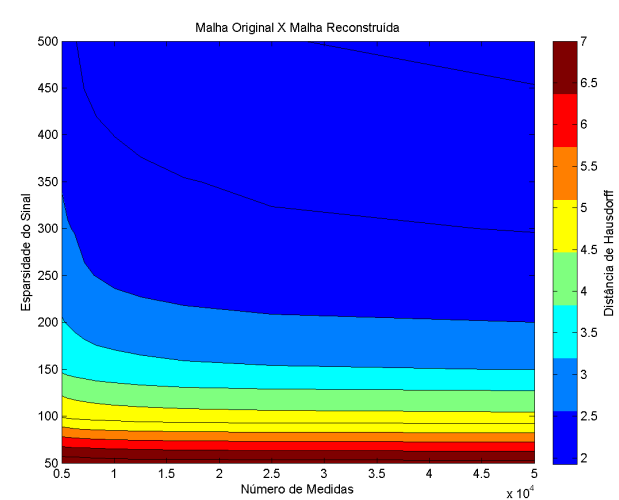

(b) Variação Distância de Hausdorff (Noiselet) durante as reconstruções da malha do dragão, utilizando matriz de medição Noiselet com no máximo 500 coeficientes significativos.

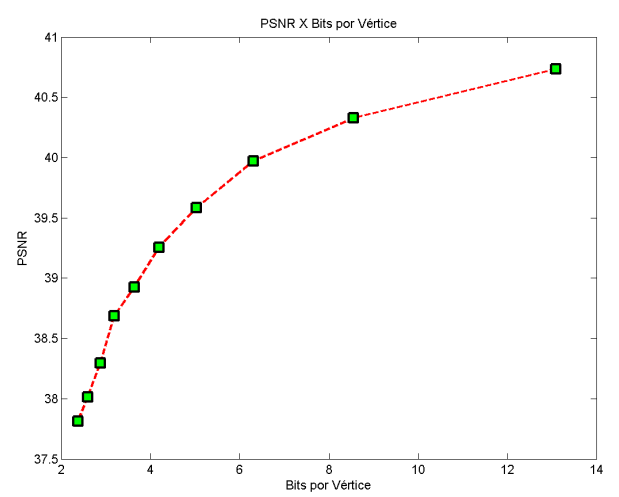

(d) Gráfico correlacionando a quantidade de bits por vértice e a taxa de distorção do sinal (PSNR) utilizando matriz de medição Noiselet com no máximo 500 coeficientes significativos.

Figura 33 - Resultados Experimento - Dragão. 


\subsubsection{Análise dos Resultados do Dragão}

A malha mais densa utilizada foi a malha do dragão representada na Figura 33a. Essa malha teve um comportamento interessante durante as reconstruções. No mapa representado na Figura 33b, todas as medidas conseguiram uma reconstrução satisfatória. A variável influente nesse caso foi a esparsidade utilizada. Com base no mapa, a partir de 10.000 medidas é possível reconstruir a malha, com a esparsidade a partir de 250 .

Também os gráficos exibidos nas Figuras 33c e 33d mostram a mesma tendência das malhas anteriores e são coerentes com o mapa da distância de Hausdorff.

\subsection{Análise Complementar}

A Tabela 3 apresenta um resumo das variações utilizadas em cada uma das malhas. Nessa tabela, estão indicadas as combinações utilizadas no experimento (forma de minimização e matriz de medição) e a indicação de "sim"para aplicação da variação ou "não" caso contrário. Conforme citado no Capítulo 4, a utilização de matrizes gaussianas se apresentou inviável para determinadas malhas. Não obstante, a utilização de matriz de medição Noiselet permitiu a utilização da técnica de CS em todas as malhas dos experimentos.

Tabela 3 - Resumo das Variações dos Experimentos.

\begin{tabular}{lccc}
\hline \hline Malha & $\boldsymbol{L}_{\mathbf{1}}$ e Noiselet & $\boldsymbol{L}_{\mathbf{1}}$ e Gaussiana & Total Variation e Noiselet \\
\hline Cogumelo & Sim & Sim & Sim \\
Manequim & Sim & Não & Não \\
Cavalo & Sim & Não & Não \\
Vaca & Sim & Não & Não \\
Cabeça de Davi & Sim & Sim & Sim \\
Homem & Sim & Não & Não \\
Fandisk & Sim & Não & Não \\
Elefante & Sim & Sim & Não \\
Coelho & Sim & Não & Não \\
Dragão & Sim & Não & Não \\
\hline
\end{tabular}

No trabalho de Mamou et al. (2010), um comparativo ilustra as taxas de BPV obtidas utilizando-se outros algoritmos de compressão. A Tabela 4 apresenta as taxas de BPV apuradas aplicando-se determinado algoritmo. Nessa tabela, estão as malhas que coincidiram com as utilizadas nesta dissertação. Pode-se observar que as taxas de BPV apuradas nas Seções 5.1 a 5.10 estão condizentes com as taxas apontadas na Tabela 4 . 
Tabela 4 - Comparativo de Taxas de BPV em alguns algoritmos.

\begin{tabular}{lccc}
\hline \hline Malha & Wavemesh 1 & Triangle Mesh ${ }^{2}$ & Progressive Compression ${ }^{3}$ \\
Cavalo & 17.5 & 19.7 & 20.9 \\
Manequim & 13.1 & 14.45 & 19.9 \\
Fandisk & 13.4 & 18.26 & 25 \\
\hline
\end{tabular}

Os resultados apresentados neste capítulo apontam uma tendência de reconstrução das malhas a partir de CS que levam em consideração duas variáveis principais: esparsidade dos vetores e número de medições (amostragem). Observa-se também que a densidade da malha influencia na quantidade de medições necessárias para reconstrução. Os gráficos indicam um limiar estimado entre um terço e metade do número total de vértices, para iniciar uma reconstrução satisfatória.

\subsection{Discussão}

Os resultados encontrados na aplicação de CS em malhas apresentam coerência com a teoria básica de CS. As variações encontradas nos experimentos envolvem os elementos presentes na CS:

- aleatoriedade: o que implica em resultados ligeiramente diferentes na execução de um mesmo experimento;

- mínimo de medidas: apesar de reduzir o limite proposto pelo Teorema de ShannonNyquist, ainda assim é necessário um número suficiente de medidas para a reconstrução.

- matrizes de medição: existe influência da matriz de medição utilizada para realizar o experimento.

- minimização da Norma $L_{1}$ : variações na minimização da norma provocam diferentes reconstruções.

Em relação à aleatoriedade, como as medidas para reconstrução são realizadas dessa maneira dentro do conjunto de pontos possíveis, a repetição dos experimentos com os

\footnotetext{
1 TOUMA; GOTSMAN, 1998 apud MAMOU et al. 2010)

2 (VALETTE; PROST, 2004b apud MAMOU et al., 2010)

3 ALLIEZ; DESBRUN 2001 apud MAMOU et al. 2010)
} 
mesmos parâmetros nem sempre retornam exatamente o mesmo resultado, como podemos verificar nos resultados da malha do elefante (5.8). No entanto, a tendência de reconstrução pode ser observada, de modo que mesmo que o resultado não seja idêntico, existe um padrão de semelhança entre os resultados.

Os mapas de figuras apresentados nas Seções 5.5 e 5.10 apresentam reconstruções satisfatórias com qualquer número de medidas a partir de uma determinada esparsidade. Esse comportamento foi observado pois o algoritmo aplicado utiliza o número de vértices da malha em processamento para calcular a quantidade de medidas. Como essa malhas são maiores, o número de medidas sempre foi superior ao mínimo necessário para a reconstrução. Nesses exemplos, a única variável que pode ser considerada foi a esparsidade utilizada.

Diferentes matrizes de medição apresentaram resultados específicos dentro dos experimentos. Usando-se matrizes de medição noiselet ou gaussiana, podem ser obtidas reconstruções com níveis de acuracidade diversos.

A minimização da Norma $L_{1}$ pode ser executada conforme diferentes processos apresentados por Candès e Romberg (2005). Nos experimentos realizados, a utilização de duas variações da minimização apresentaram acuracidade diferente nos experimentos. Essa variação ocorre devido à forma como são calculadas as distâncias mínimas entre os pontos durante o processamento. Ou seja, métodos diferentes de minimização podem influenciar nas reconstruções. 


\section{Conclusão}

O objetivo deste estudo foi aplicar a técnica de CS como método de representação compressiva de malhas. Houve a necessidade de explorar a viabilidade da técnica e, quando determinada essa possibilidade, avaliar a coerência das reconstruções das malhas comprimidas durante os experimentos.

Conforme apresentado no Capítulo 4, o algoritmo desenvolvido foi capaz de decompor a malha em dois conjuntos principais: vértices e faces. A partir do conjunto de vértices, aplicou-se a técnica de CS e foi possível reconstruir a malha a partir de uma configuração esparsa de seus vértices. Conforme as tendências apresentadas nas Seções de 5.1 .1 a 5.10 .1 , existe um limiar para cada malha utilizada no experimento, composta por uma variável de esparsidade e uma variável de medidas utilizadas para a reconstrução. Esse limiar é diferente para cada malha, em função de sua densidade geométrica.

Foi possível avaliar que malhas podem ser representadas compressivamente através de CS, representando de forma esparsa a componente geométrica das malhas e recriando a malha "completa" a partir dessa representação.

Dentre as abordagens utilizadas, foi detectado empiricamente que a utilização de matriz de medição Noiselet proporcionou a melhor estratégia, uma vez que a matriz gaussiana se mostrou inviável computacionalmente. As minimizações de norma $L_{1}$ utilizadas (por regras de igualdade e Total Variation) também se mostraram coerentes com a teoria de CS e viabilidade da técnica em malhas.

Adicionalmente, utilizamos métricas para avaliar o caráter compressivo da técnica. As taxas de BPV geradas estão condizentes com as apresentadas no trabalho de Mamou et al. (2010), onde são comparadas as taxas de BPV entre diferentes técnicas. Conforme apresentado na Seção 5.11, os resultados obtidos estão coerentes com os algoritmos utilizados tradicionalmente para compressão de malhas, o que indica a possibilidade da utilização de CS como técnica de compressão.

Os valores de PSNR obtidos também estão coerentes com a literatura, conforme re- 
ferenciado na Seção 4.2.3 e no livro de Salomon (2007). Este é um indicativo de que as reconstruções obtidas a partir da representação compressiva estão dentro de um intervalo aceitável.

O diferencial da técnica de CS é a aquisição compressiva dos dados. Conforme apresentado no Capítulo 3, a grande vantagem é poder sensorear (adquirir) os valores necessários para a reconstrução de um sinal de forma compressiva, diferente de outras técnicas que fazem a aquisição de grande volume de valores e depois os descarta através de um processo de aproximação.

Aplicada em malhas, a técnica de CS se apresentou conforme a teoria, permitindo adquirir a informação (dados dos vértices) de forma compressiva e reconstruir a malha a partir dos dados sensoreados.

\subsection{Contribuições}

Este trabalho explorou uma abordagem diferente para aquisição de dados para reconstrução de malhas. Alguns artigos encontrados propõem a técnica de CS aplicada em malhas ((DU; GENG, 2011), (YOON; KUIJPER, 2011)). No entanto, suas abordagens não trataram da possibilidade de aplicação da técnica de CS como uma alternativa para compressão.

Esta dissertação foi elaborada baseada nessa possibilidade. Os experimentos realizados procuraram avaliar a aplicação de CS no contexto de aquisição de dados na forma compressiva e verificar se os resultados encontrados possuíam métricas de compressão (BPV e PSNR) dentro dos limites da literatura.

O fato de que a teoria de CS ainda é relativamente recente proporcionou a possibilidade de explorar uma pesquisa com poucas referências (CS aplicado em malhas), de maneira que a pesquisa se mostrou produtiva.

\subsection{Trabalhos Futuros}

Alguns aspectos observados durante a pesquisa necessitam de estudos adicionais.

Um ponto de interesse é avaliar os fatores determinantes para a melhor aplicação de uma determinada matriz de medição (Noiselet ou Wavelets, por exemplo) e a melhor forma de minimização da norma $L_{1}$. Empiricamente, foi detectado que a matriz de medição 
Noiselet possui uma boa aplicação, mas não foi explorada a raiz desse comportamento.

Outro fator observado é que na malha do dragão (Figura 33a), a variação do experimento foi em relação à esparsidade, somente. Isso ocorreu em função do cálculo de medidas mínimo para essa figura e foi proporcional ao tamanho da malha. Variações extras dos experimentos com malhas de densidades diferenciadas e acima de 50.000 vértices são necessárias para explorar esse comportamento.

A representação compressiva de malhas utilizando CS pode ser explorada como um método de compressão, em complemento às técnicas de compressão existentes apresentadas no Capítulo 2. Um aprofundamento deste trabalho, para transformar efetivamente a aplicação de CS em uma alternativa competitiva para compressão de malhas é interessante do ponto de vista científico e prático, dada a necessidade de transmissão e armazenamento de malhas. 


\section{$A P \hat{E} N D I C E A$}

\section{Biblioteca de Códigos}

A execução dos experimentos foi feita com a utilização de bibliotecas e toolboxes do software Matlab (MATLAB, 2010). Neste apêndice, apresentamos o código fonte desenvolvido e orientações para reprodução do experimento, com o indicativo dos sites com as bibliotecas.

\section{A.1 Arquivo de Controle}

Este código foi idealizado para executar o processamento sequencial dos experimentos. São identificados as malhas a serem processadas e a indicação dos caminhos onde constam as demais bibliotecas. Este código deve ser salvo em um arquivo com o nome "ProcessarExperimentos.m".

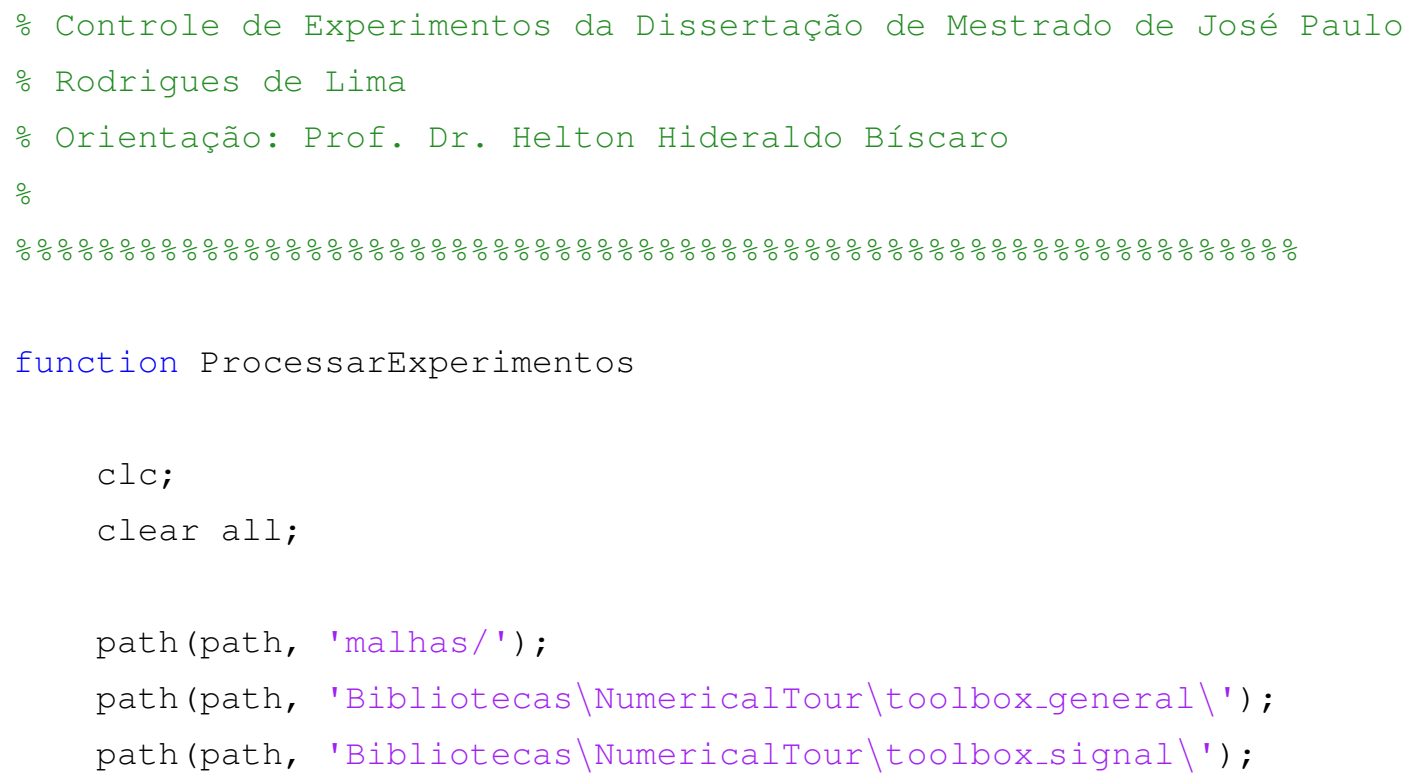




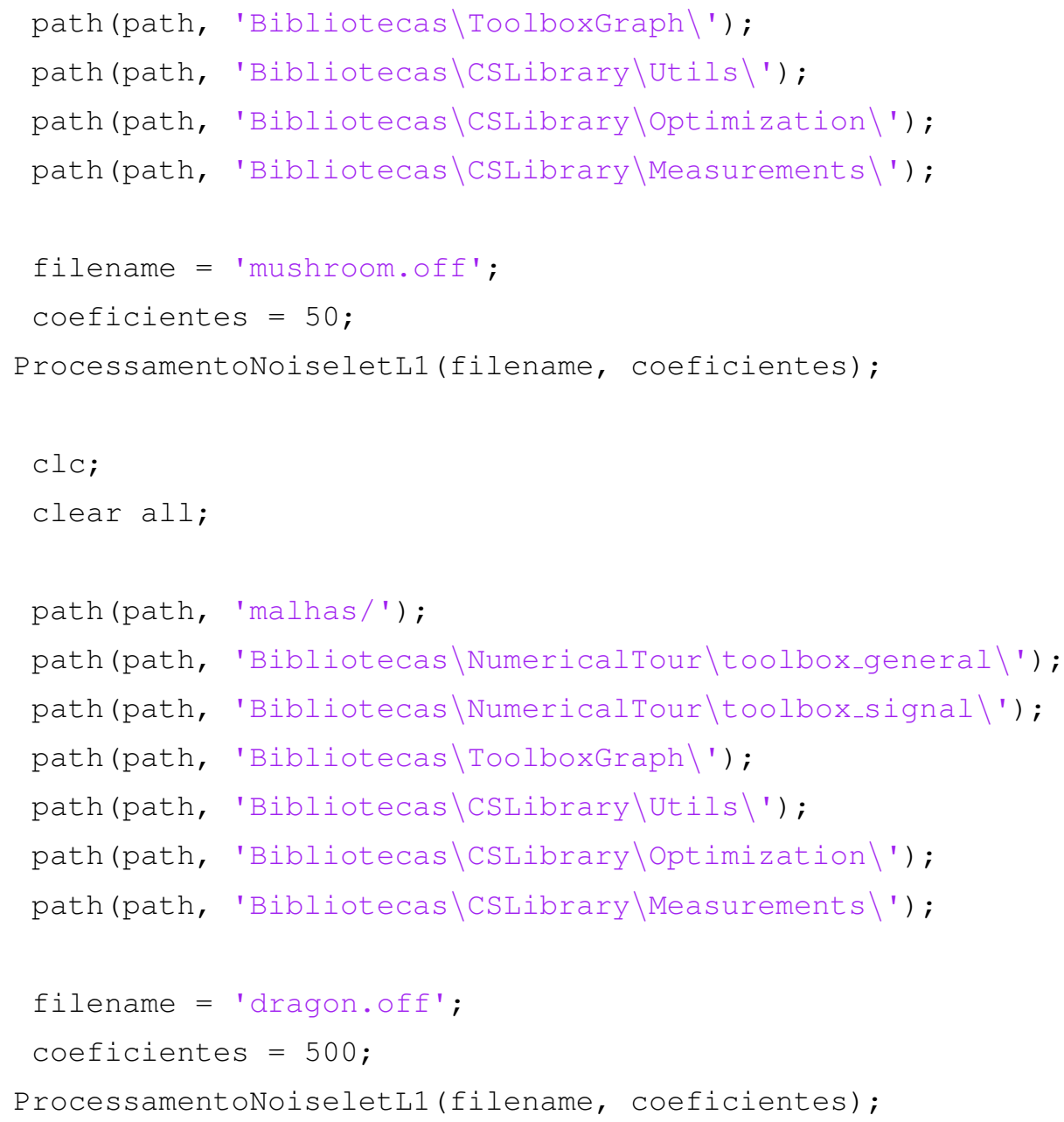




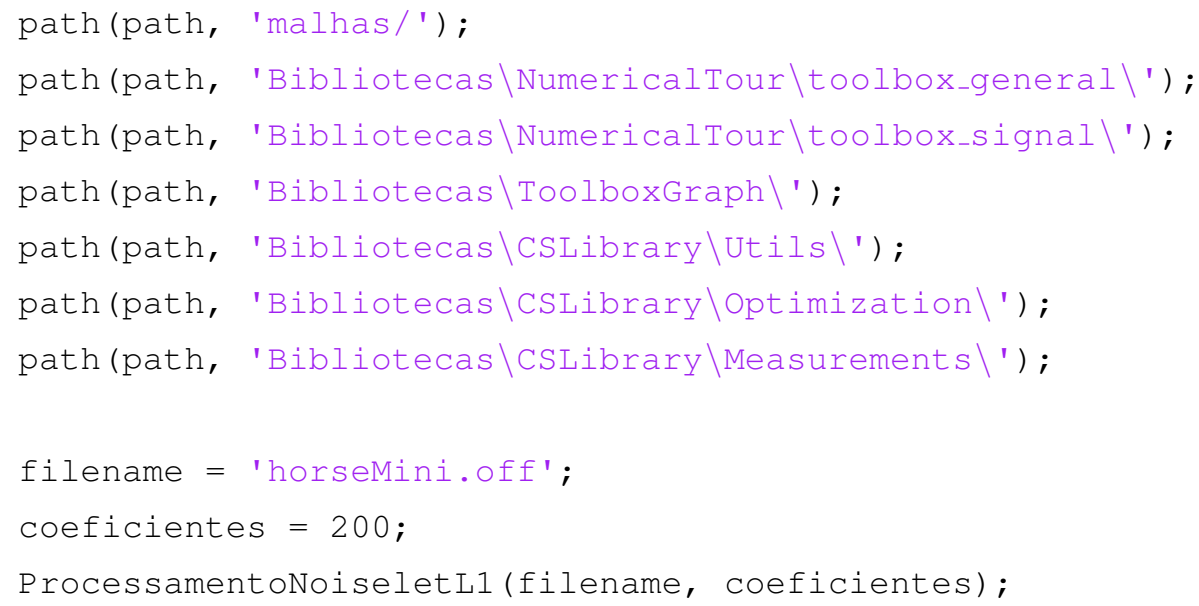


ProcessamentoNoiseletL1 (filename, coeficientes);

응

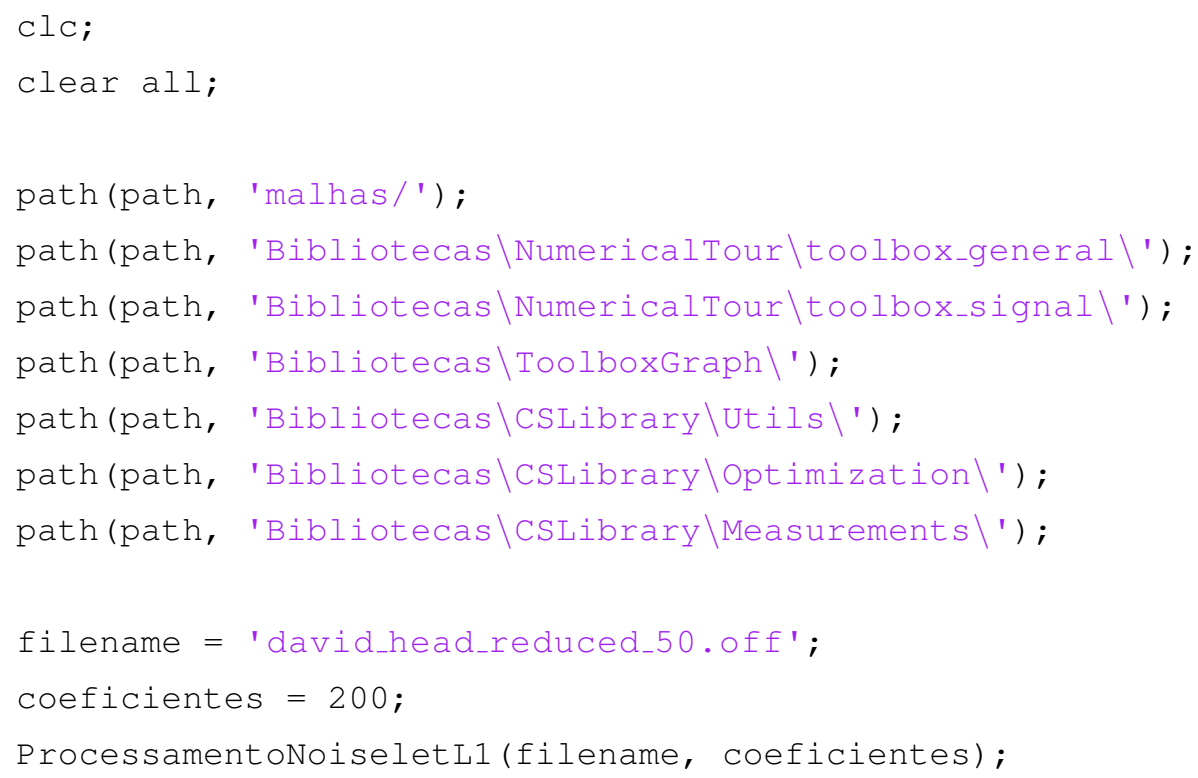




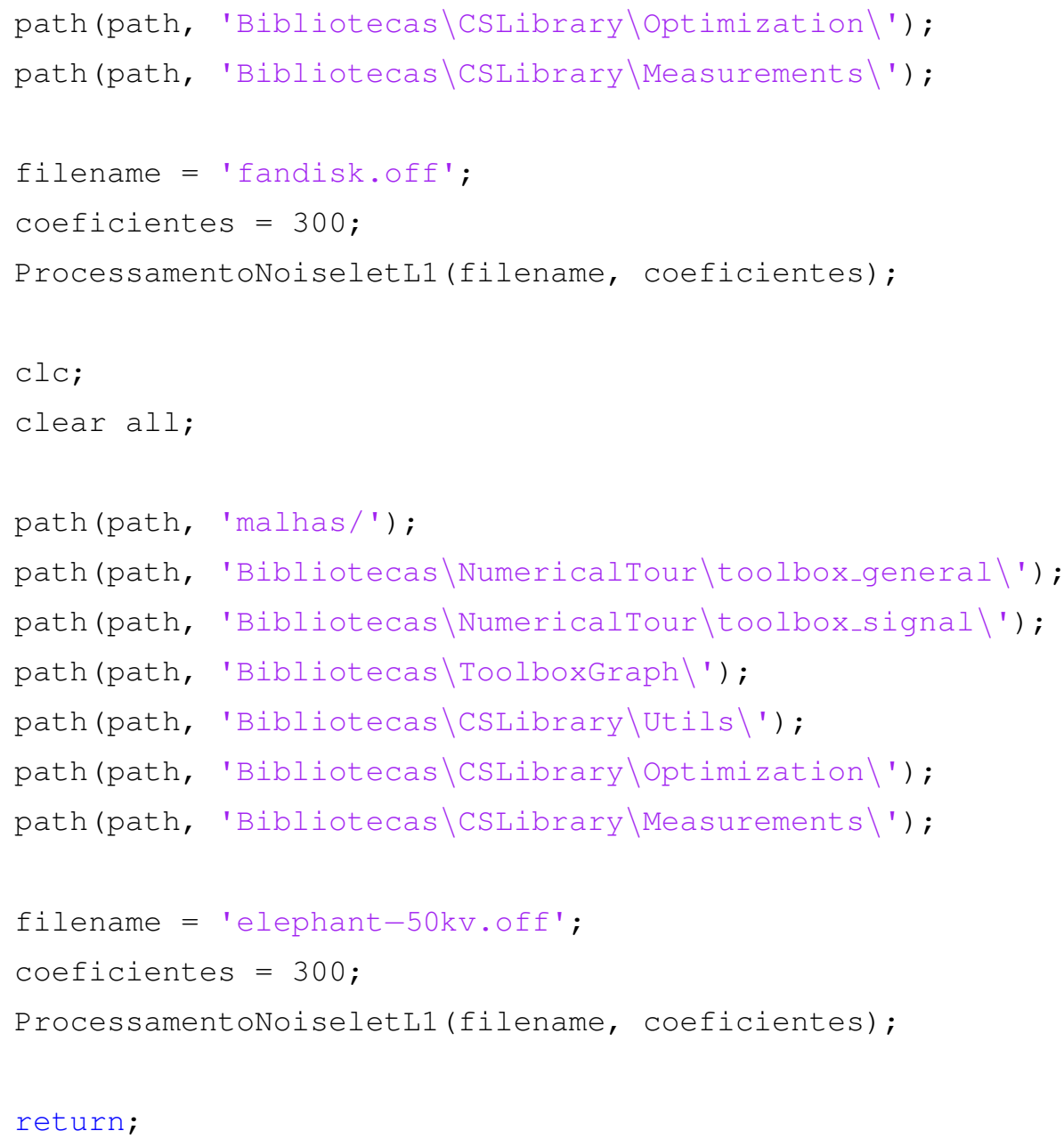

end

\section{A.2 Processamento Noiselet}

Aqui segue a reprodução do arquivo contendo o processamento com a matriz de medição Noiselet. Este código deve ser salvo em um arquivo com o nome "ProcessamentoNoiseletL1.m".

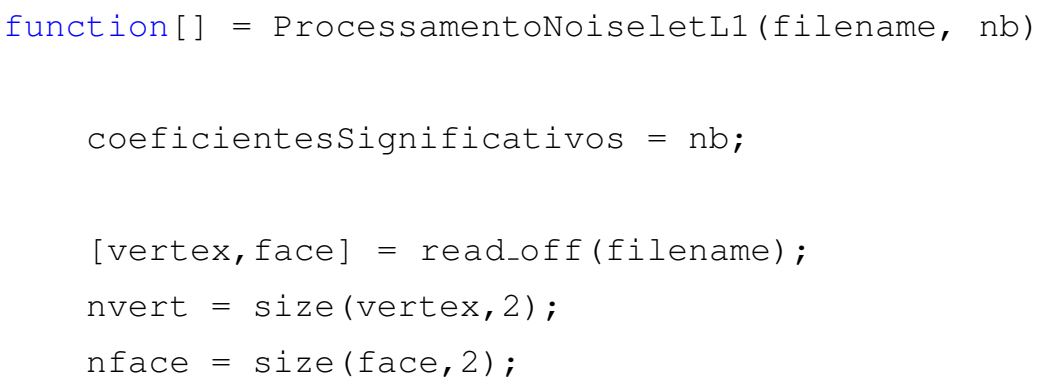


[vertex,faces] = read_mesh(filename);

options.name = filename;

$\mathrm{n}=\operatorname{size}(\operatorname{vertex}, 2)$;

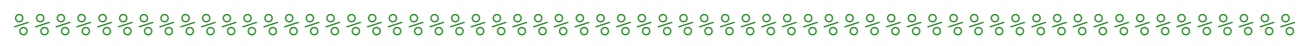

$E=\left[\operatorname{faces}\left(\left[\begin{array}{ll}1 & 2\end{array}\right],:\right) \operatorname{faces}\left(\left[\begin{array}{ll}2 & 3\end{array}\right],:\right) \operatorname{faces}\left(\left[\begin{array}{ll}3 & 1\end{array}\right],:\right)\right]$;

$\mathrm{p}=\operatorname{size}(\mathrm{E}, 2)$;

ocompute the adjacency matrix.

$\mathrm{W}=\operatorname{sparse}(\mathrm{E}(1,:), \mathrm{E}(2,:), \operatorname{ones}(\mathrm{p}, 1)) ;$

$\mathrm{W}=\max \left(\mathrm{W}^{\prime}, \mathrm{W}^{\prime}\right)$;

ocompute the combinatorial Laplacian, stored as a sparse matrix.

$\mathrm{D}=\operatorname{spdiags}\left(\operatorname{sum}(\mathrm{W})^{\prime}, \boldsymbol{0}, \mathrm{n}, \mathrm{n}\right) ;$

$\mathrm{L}=\mathrm{D}-\mathrm{W}$;

disp('Compute the eigenvectors.');

opts.disp $=0$;

$[\mathrm{U}, \mathrm{S}]=\operatorname{eigs}\left(\mathrm{L}, \mathrm{nb}, \mathrm{SM}^{\prime}\right.$ ', opts);

$\mathrm{S}=\operatorname{diag}(\mathrm{S})$;

order the eigenvector by increasing frequencies.

vertexaux $=$ zeros $(3$, nvert $)$;

vertex2 = zeros (3, nvert);

vertex3 = zeros (3, nvert);

vertex3sparse $=\operatorname{zeros}(3, \mathrm{nb})$;

$[S, I]=\operatorname{sort}(S$, 'ascend');

$\mathrm{U}=\operatorname{real}(\mathrm{U}(:, \mathrm{I}))$;

pvertex $=$ vertex $\star U$;

oplot dos 3 Eixos

ocomentado

figure (1);

clf;

plot (pvertex'); axis('tight');

legend ('X', 'Y', 'Z');

\%Quantization

$\mathrm{T}=.05$; $\frac{\circ}{\mathrm{O}} \mathrm{uantization}$ rate

pvertexI $=$ floor (abs (pvertex/T)) .*sign(pvertex);

pvertexQ $=\operatorname{sign}($ pvertexI $) . \star(\operatorname{abs}($ pvertexI $)+.5) . * \mathrm{~T}$; 


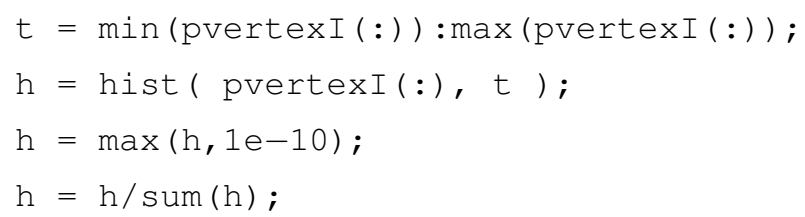

figure (2);

clf;

plot (pvertexQ'); axis('tight');

legend ('X', 'Y', 'Z');

$p=3 ;$

№mber of measures.

iteracoesGeral $=1 ; \quad$ oControle para iterações;

medidas.numero $=0.0 ; \quad$ ID da medição;

medidas.amostras $=0.0 ; \quad$ onúmero de amostras para realizar a CS;

medidas.dist_max $=0.0 ; \quad$ oDistância de hausdorff máxima;

medidas.media $=0.0 ; \quad$ omédia da distância de hausdorff;

iteracoeskeep $=1$;

iteracoescontrole $=109$;

MMedidas=zeros $(10,10)$;

MDistancias $=$ zeros $(10,10)$;

while (iteracoeskeep < 11)

$\mathrm{p}=3 ;$

$\mathrm{pp}=3$;

nbr_max_keep = iteracoeskeep;

$\mathrm{s}=\operatorname{round}(\mathrm{nb} * 0.1) ;$

iteracoes $=1$;

oControle para iterações;

while (iteracoes < 11)

disp(sprintf('Iteracao d de od.', iteracoes, iteracoeskeep));

keep $=1+r o u n d\left(10 * n b r \_m a x \_k e e p / p p^{\wedge} 2\right) ; \%$ nbr de pourcent gard?

measures = round(nvert/(11-iteracoeskeep));

tic; 


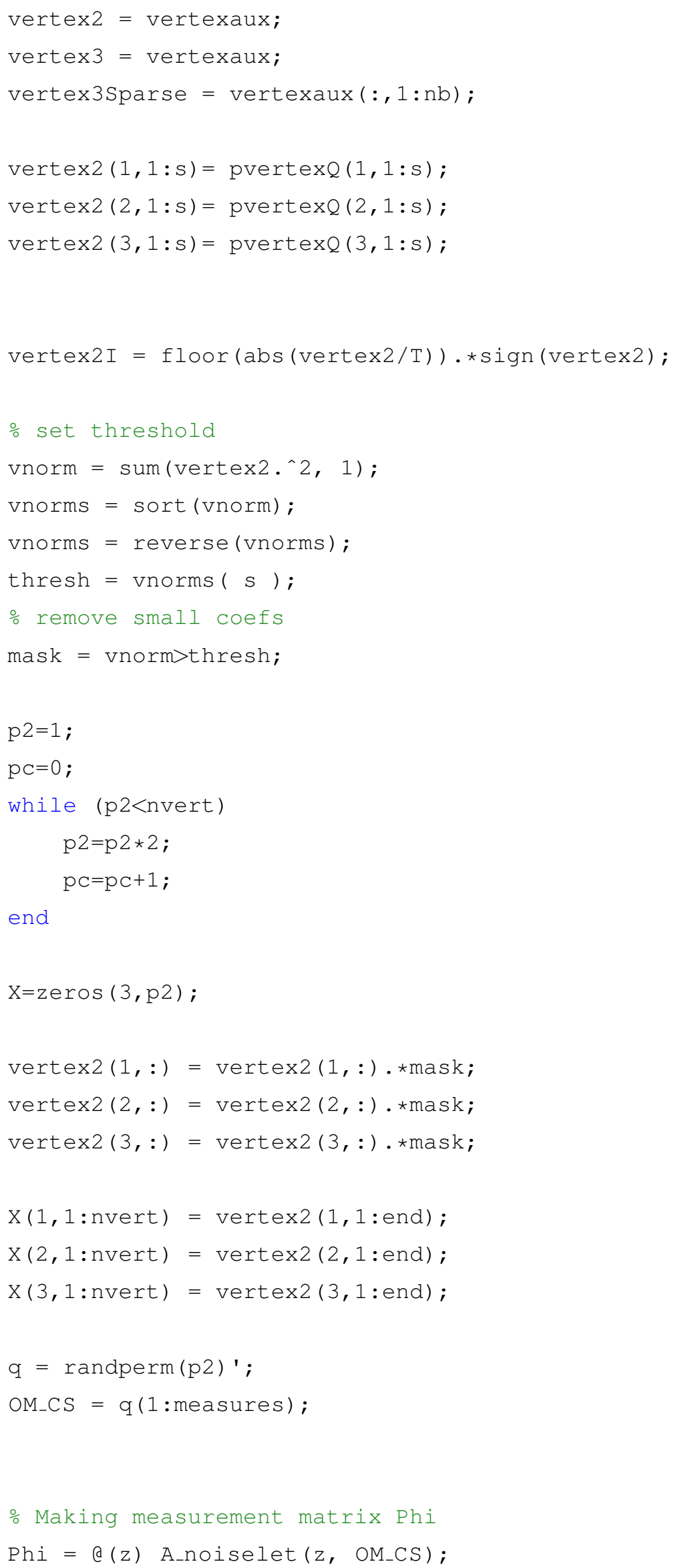


Phit $=a(z)$ At_noiselet $(z$, OM_CS, p2);

omeasurements

$\mathrm{yx}=\operatorname{Phi}\left(\mathrm{X}(1,:)^{\prime}\right)$;

yy=Phi $\left(x(2,:)^{\prime}\right)$;

$y z=\operatorname{Phi}(x(3,:) ')$;

vAux $=$ zeros (3, nvert);

$\operatorname{vAux}(1,1:$ measures $)=\mathrm{yx} ;$

$\operatorname{vAux}(2,1:$ measures $)=y y ;$

$\operatorname{vAux}(3,1:$ measures $)=y z$;

vAuxI $=$ floor $(\operatorname{abs}(\operatorname{vAux} / T)) \cdot \star \operatorname{sign}($ vAux $)$;

$t=\min (\operatorname{vAuxI}(:)): \max (\operatorname{vAuxI}(:))$;

$\mathrm{h}=\operatorname{hist}(\operatorname{vAuxI}(:), \mathrm{t})$;

$\mathrm{h}=\max (\mathrm{h}, 1 \mathrm{e}-10)$;

$\mathrm{h}=\mathrm{h} / \operatorname{sum}(\mathrm{h})$;

$\mathrm{E}=-\operatorname{sum}(\log 2(\mathrm{~h}) \cdot * \mathrm{~h}) ;$

disp(['Nbr.bits per vertex $=$ ' $\operatorname{num} 2 \operatorname{str}(3 * \mathrm{E}, 3)])$;

disp(['Error, PSNR = ' num2str(psnr(vertex, vertex2), 3) ]);

niter $=500$;

\% min 12 for CS

PPt $=$ a (z) Phi (Phit $(z))$;

xini= Phit (cgsolve (PPt, yx, 1e-8, 200));

yini= Phit (cgsolve (PPt, yy, 1e-8, 200));

zini= Phit (cgsolve(PPt, yz, 1e-8, 200));

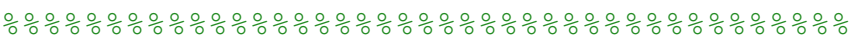

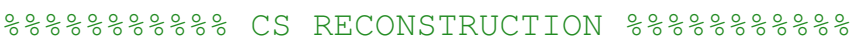

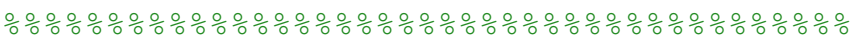

\% CS Reconstruction

\% parameters for optimization code

\%lbtol = 918; 


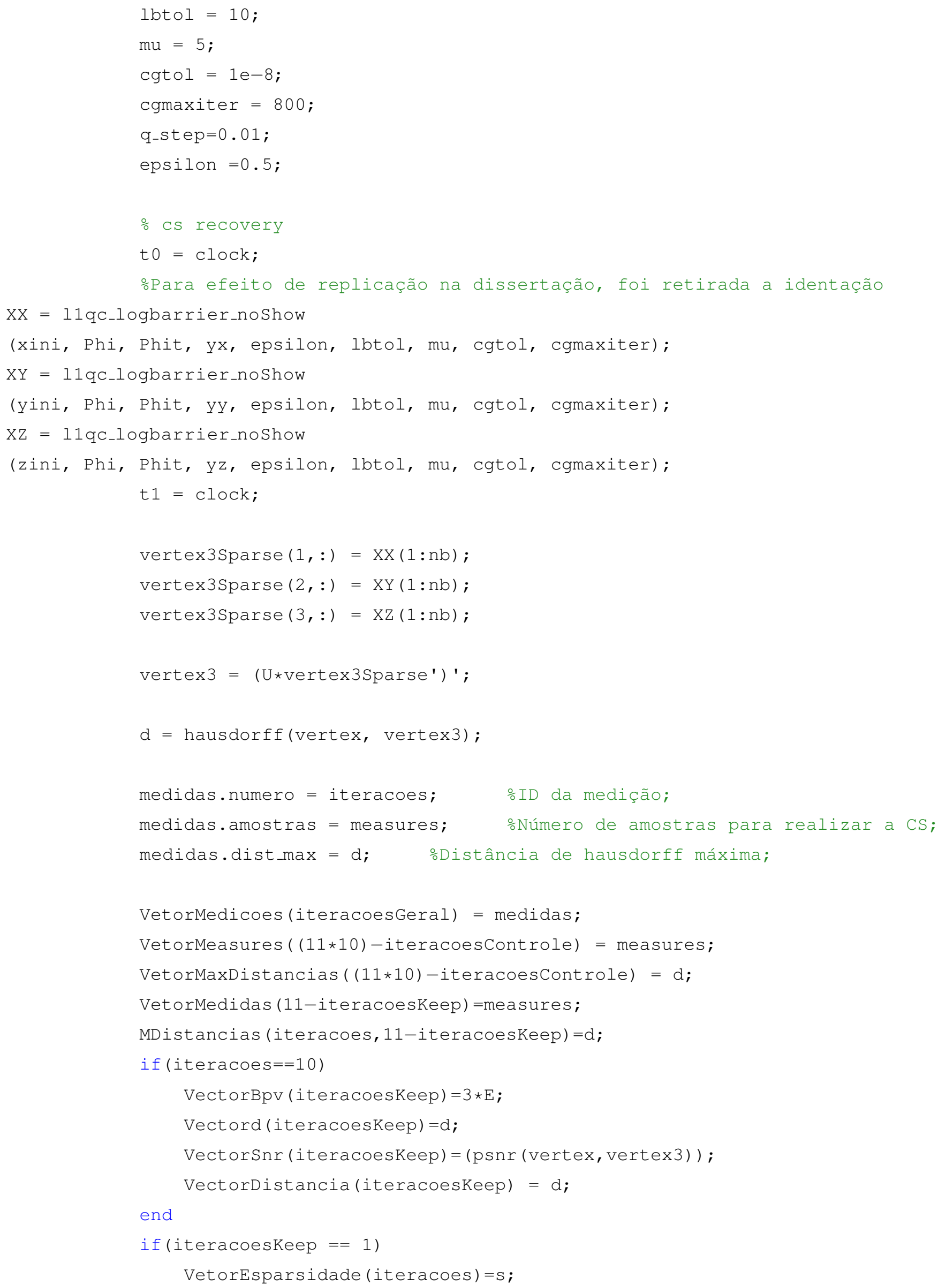




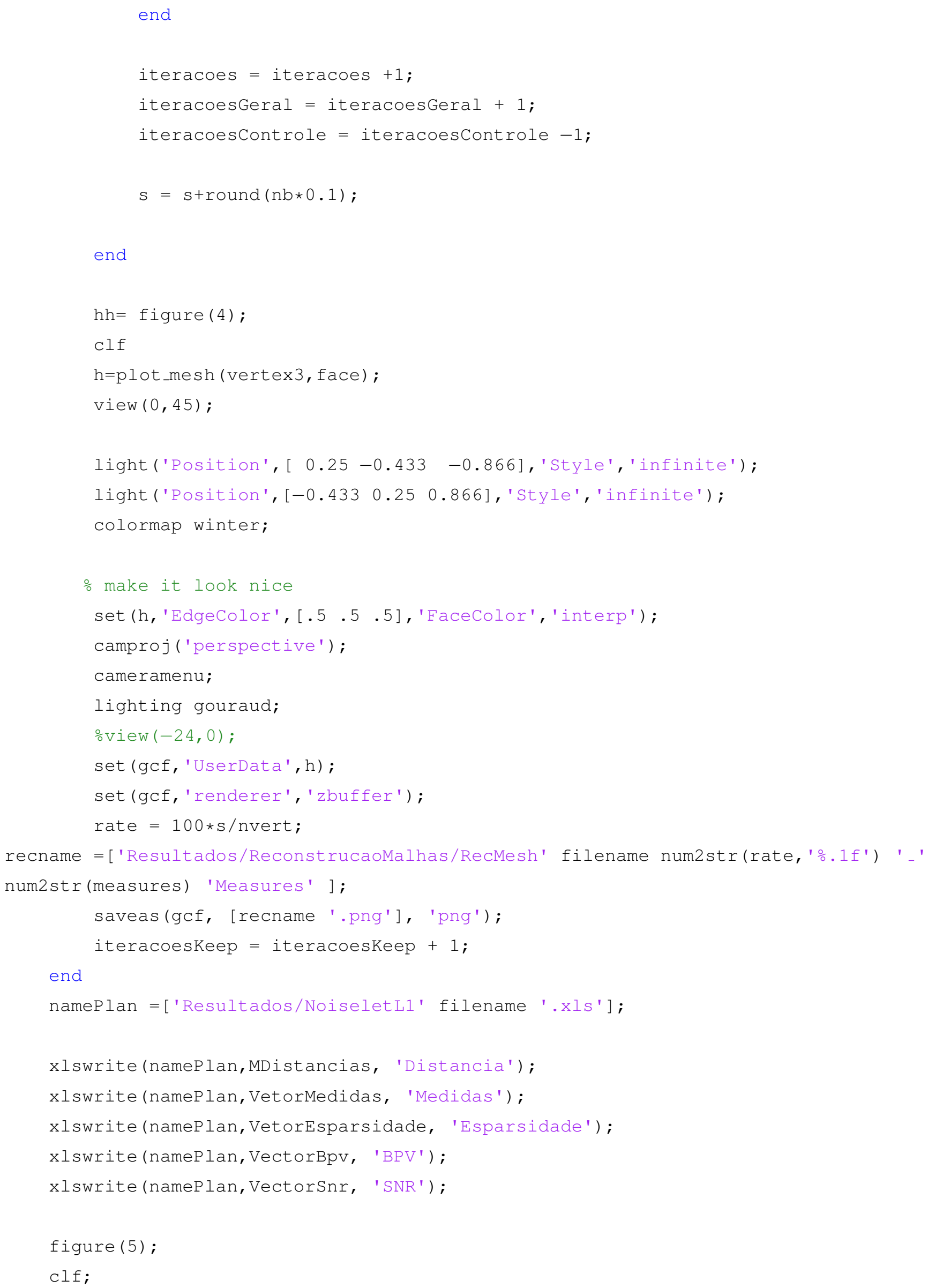




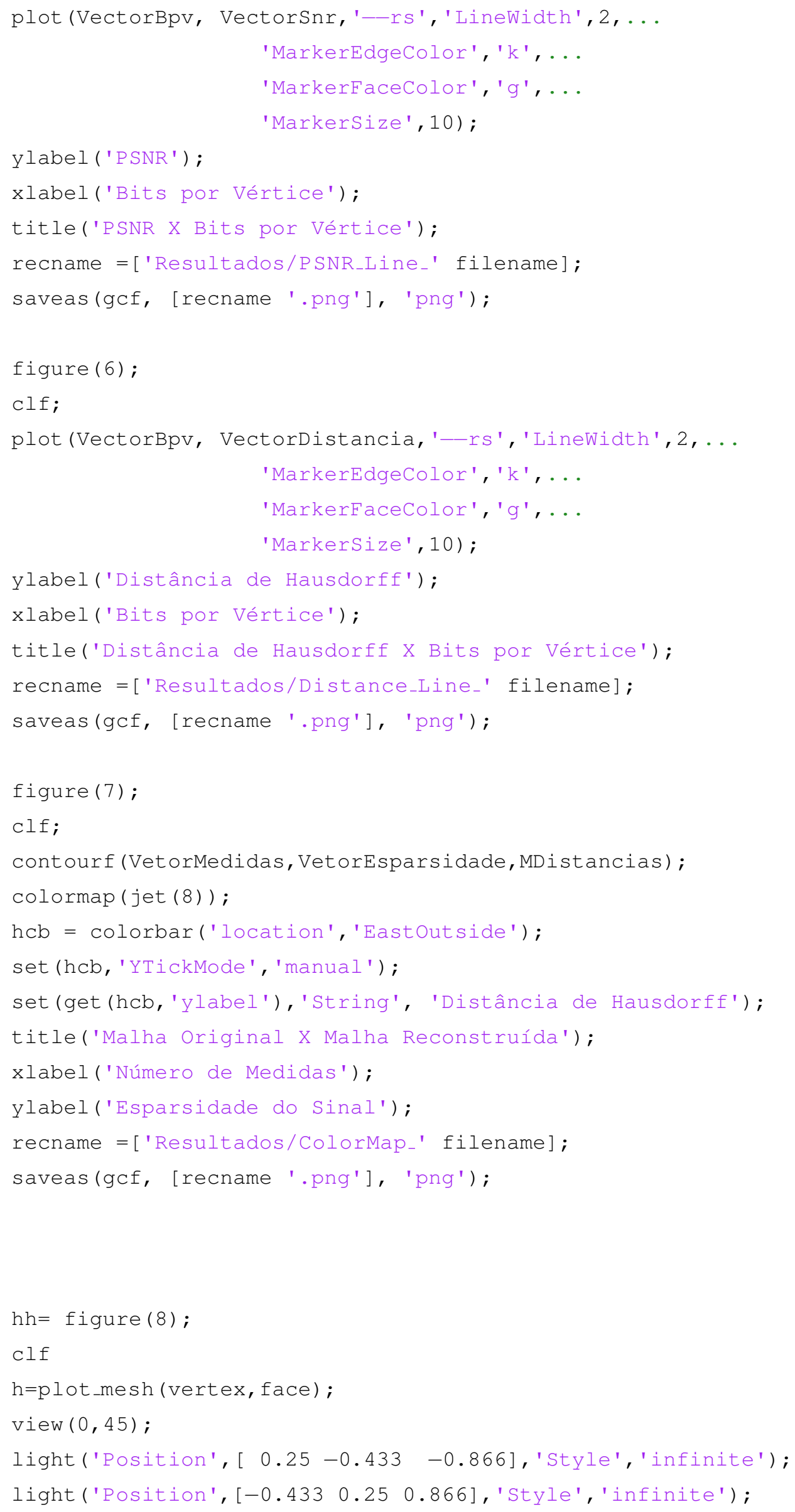




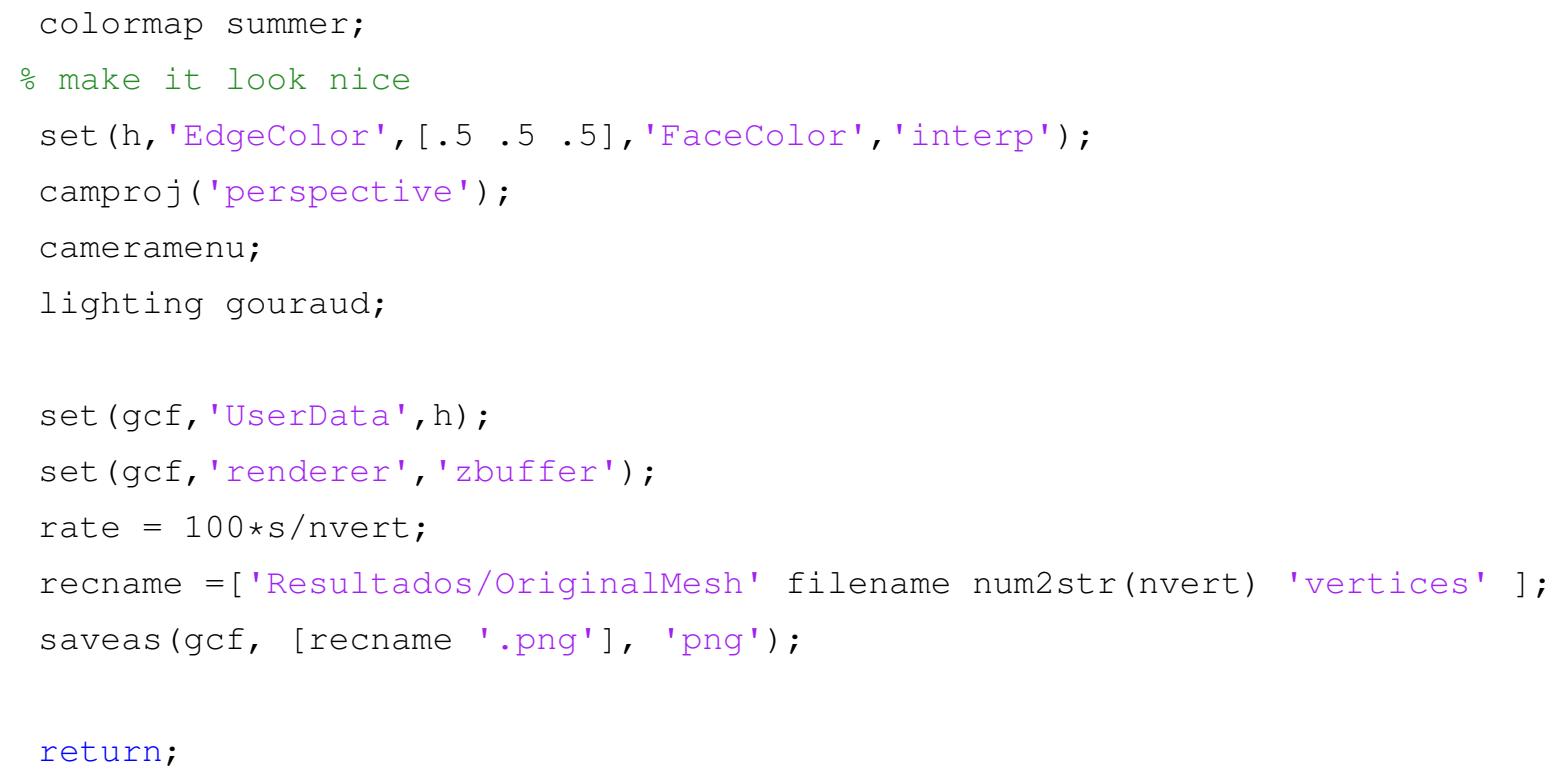

\section{A.3 Parametrização dos Experimentos}

No Seção A.1, o código exibido indica alguns parâmetros para a execução do experimento. Para o setup apropriado, deve-se levar em consideração o seguinte:

- criar uma pasta "Malhas" dentro do diretório de execução do experimento. Nessa pasta, deverão ser colocados os arquivos ".off" que serão processados;

- criar uma pasta "Bibliotecas", onde deverão ser colocadas as bibliotecas indicadas na Tabela 5.

Tabela 5 - Bibliotecas Utilizadas nos Experimentos

\begin{tabular}{ll|}
\hline \hline Biblioteca & Fonte \\
\hline toolbox_general (NumericalTour) & Peyré \\
toolbox_signal (NumericalTour) & $\overline{\text { Peyré }}(\overline{2011})$ \\
ToolboxGraph & $\overline{\text { Peyré }}(\overline{\overline{2009}})$ \\
$\begin{array}{l}\text { CSLibrary (Optimization) } \\
\text { CSLibrary (Measurements) }\end{array}$ & Schulz et al. \\
\hline
\end{tabular}

Nas bibliotecas apresentadas na Tabela 5, existem configurações adicionais que precisam ser executadas para sucesso na reprodução do trabalho. Essas configurações constam nas páginas da web referenciadas e devem ser seguidas conforme a recomendação dos autores. 
O parâmetro "filename" indica o nome do arquivo ".off" que será processado. O parâmetro "coeficientes"indica o máximo de coeficientes significativos que deve ser utilizado naquele experimento.

Também deve ser criada uma pasta chamada "Resultados", onde serão gravados os gráficos resultantes do processamento.

Ajuda adicional pode ser obtida através do e-mail josepaulolima@gmail.com. 


\section{Referências}

ALLIEZ, P.; DESBRUN, M. Progressive compression for lossless transmission of triangle meshes. In: Proceedings of the 28th annual conference on Computer graphics and interactive techniques. New York, NY, USA: ACM, 2001. (SIGGRAPH '01), p. 195-202. ISBN 1-58113-374-X. Disponível em: http://doi.acm.org/10.1145/383259.383281.

BAUDRIER, E.; MILLON, F. N. G.; RUAN, S. A new similarity measure using hausdorff distance map. In: Image Processing, 2004. ICIP '04. 2004 International Conference on. [S.l.: s.n.], 2004. v. 1, p. 669 - 672 Vol. 1. ISSN 1522-4880.

BOUZIDI, I.; ZAID, A. O.; HACHANI, M.; PUECH, W. Joint watermarking and progressive geometric compression of $3 \mathrm{~d}$ meshes. In: Proceedings of the First ACM Workshop on Information Hiding and Multimedia Security. New York, NY, USA: ACM, 2013. (IH\&\#38;MMSec '13), p. 209-214. ISBN 978-1-4503-2081-8. Disponível em: http: //doi.acm.org/10.1145/2482513.2482530.

BROOKS, J. P.; DULá, J. H.; BOONE, E. L. A pure 11-norm principal component analysis. Comput. Stat. Data Anal., Elsevier Science Publishers B. V., Amsterdam, The Netherlands, The Netherlands, v. 61, p. 83-98, maio 2013. ISSN 0167-9473. Disponível em: http://dx.doi.org/10.1016/j.csda.2012.11.007.

CANDÈS, E.; ROMBERG, J. L1-magic : Recovery of sparse signals via convex programming. 2005. Disponível em: http://users.ece.gatech.edu/ justin/11magic/.

CANDÈS, E.; ROMBERG, J. Sparsity and incoherence in compressive sampling. Inverse Problems, v. 23, p. 969-985, 2007.

CANDÈS, E. J.; PLAN, Y. A probabilistic and ripless theory of compressed sensing. CoRR, abs/1011.3854, 2010. Disponível em: http://arxiv.org/abs/1011.3854.

CANDèS, E. J.; ROMBERG, J.; TAO, T. Robust uncertainty principles: Exact signal reconstruction from highly incomplete frequency information. IEEE Trans. Inform. Theory, v. 52, n. 2, p. 489-509, 2006.

CANDÈS, E. J.; WAKIN, M. An introduction to compressive sampling [a sensing/sampling paradigm that goes against the common knowledge in data acquisition]. IEEE Signal Processing Magazine, v. 25, n. 2, p. 21-30, 2007. ISSN 1053-5888.

CHAUFFERT, N.; CIUCIU, P.; WEISS, P. Variable density compressed sensing in mri. theoretical vs heuristic sampling strategies. In: Biomedical Imaging (ISBI), 2013 IEEE 10th International Symposium on. [S.l.: s.n.], 2013. p. 298-301. ISSN 1945-7928.

CHEN, D.; CHIANG, Y.-J.; MEMON, N.; WU, X. Optimized prediction for geometry compression of triangle meshes. In: Data Compression Conference, 2005. Proceedings. DCC 2005. [S.l.: s.n.], 2005. p. 83-92. ISSN 1068-0314. 
CHOW, M. M. Optimized geometry compression for real-time rendering. In: Visualization '97., Proceedings. [S.l.: s.n.], 1997. p. 347-354. ISSN 1.

COHEN-OR, D.; LEVIN, D.; REMEZ, O. Progressive compression of arbitrary triangular meshes. VIS '99 Proceedings of the conference on Visualization '99: celebrating ten years, p. 67-72, 1999.

COIFMAN, R.; GESHWIND, F.; MEYER, Y. Noiselets. Applied and Computational Harmonic Analysis, v. 10, p. 27-44, 2001.

DANIELS, J. FEATURE-ALIGNED, SEMIREGULAR, QUAD-ONLY MESH GENERATION. Tese (Doutorado) — Universidade de Utah, Agosto 2010.

DAVENPORT, M. A.; DUARTE, M. F.; ELDAR, Y. C.; KUTYNIOK, G. Introduction to Compressed Sensing in Compressed Sensing: Theory and Applications. [S.1.]: Cambridge University Press, 2011.

DEFRAENE, B.; MANSOUR, N.; HERTOGH, S. D.; WATERSCHOOT, T. van; DIEHL, M.; MOONEN, M. Declipping of audio signals using perceptual compressed sensing. Audio, Speech, and Language Processing, IEEE Transactions on, v. 21, n. 12, p. 2627-2637, 2013. ISSN 1558-7916.

DU, Z.-M.; GENG, G.-H. 3-d geometric signal compression method based on compressed sensing. In: Image Analysis and Signal Processing (IASP), 2011 International Conference on. [S.l.: s.n.], 2011. p. 62-66.

DUARTE, M.; ELDAR, Y. Structured compressed sensing: From theory to applications. Signal Processing, IEEE Transactions on, v. 59, n. 9, p. 4053-4085, 2011. ISSN 1053-587X.

ENDER, J. A brief review of compressive sensing applied to radar. In: Radar Symposium (IRS), 201314 th International. [S.l.: s.n.], 2013. v. 1, p. 3-16.

FALKOWSKI, B.; RAHARDJA, S. Walsh-like functions and their relations. Vision, Image and Signal Processing, IEE Proceedings -, v. 143, n. 5, p. 279-284, 1996. ISSN 1350-245X.

GAO, Y.; WANG, M.; JI, R.; WU, X.; DAI, Q. 3d object retrieval with hausdorff distance learning. Industrial Electronics, IEEE Transactions on, PP, n. 99, p. 1-1, 2013. ISSN 0278-0046.

GRAY, A. Modern Differential Geometry Of Curves And Surfaces With Mathematica. Boca Raton: CRC Press, 1998. ISBN 9780849371646. Disponível em: http://isbnplus. org/9780849371646.

HA, P. H.; PATANAVIJIT, V. Performance evaluation of 11, 12 and sl0 on compressive sensing based on stochastic estimation technique. In: Electrical Engineering/Electronics Computer Telecommunications and Information Technology (ECTI-CON), 2010 International Conference on. [S.l.: s.n.], 2010. p. 688-692.

HAO, L.; WEIBING, L.; JIACHEN, W. Data compression based on compressed sensing and wavelet transform. In: Computer Science and Information Technology (ICCSIT), 2010 3rd IEEE International Conference on. [S.1.: s.n.], 2010. v. 8, p. 537-542. 
HONGNIAN, L.; BO, L.; HONGBIN, Z. Progressive geometry-driven compression for triangle mesh based on binary tree. In: Visualisation, 2009. VIZ '09. Second International Conference in. [S.l.: s.n.], 2009. p. 229-234.

HORN, R. A.; JOHNSON, C. R. Matrix Analysis. Cambridge University Press, 1990. ISBN 0521386322. Disponível em: http://www.amazon. com/Matrix-Analysis-Roger-Horn/dp/0521386322\%3FSubscriptionId\% 3D192BW6DQ43CK9FN0ZGG2\%26tag\%3Dws\%26linkCode\%3Dxm2\%26camp\%3D2025\% 26 creative $\% 3$ D $165953 \% 26$ creativeASIN $\% 3 D 0521386322$.

JONG, B.-S.; YANG, W.-H.; TSENG, J.-L.; LIN, T.-W. An efficient connectivity compression for triangular meshes. In: Proceedings of the Fourth Annual ACIS International Conference on Computer and Information Science. Washington, DC, USA: IEEE Computer Society, 2005. (ICIS '05), p. 583-588. ISBN 0-7695-2296-3. Disponível em: http://dx.doi.org/10.1109/ICIS.2005.29.

KARNI, Z.; GOTSMAN, C. Spectral compression of mesh geometry. SIGGRAPH '00 Proceedings of the 27th annual conference on Computer graphics and interactive techniques, p. 279-286, 2000.

KARNI, Z.; GOTSMAN, C. 3d mesh compression using fixed spectral bases. Proc.Graphics Interface, p. 1-8, 2001.

KHODAKOVSKY, A.; SCHRÖDER, P.; SWELDENS, W. Progressive geometry compression. SIGGRAPH '00 Proceedings of the 27th annual conference on Computer graphics and interactive techniques, p. 271-278, 2000.

LEE, J.; CHOE, S.; LEE, S. Compression of 3d mesh geometry and vertex attributes for mobile graphics. JCSE, v. 4, n. 3, p. 207-224, 2010. Disponível em: http://dblp. uni-trier.de/db/journals/jcse/jcse4.html\#LeeCL10.

LEWINER, T. Mesh Compression from Geometry. Tese (Doutorado) — Université Pierre et Marie Curie, 2005.

LIU, Y.; LI, M.; PADOS, D. Motion-aware decoding of compressed-sensed video. Circuits and Systems for Video Technology, IEEE Transactions on, v. 23, n. 3, p. 438-444, 2013. ISSN 1051-8215.

LUFFEL, M.; GURUNG, T.; LINDSTROM, P.; ROSSIGNAC, J. Grouper: A compact, streamable triangle mesh data structure. Visualization and Computer Graphics, IEEE Transactions on, PP, n. 99, p. 1-1, 2013. ISSN 1077-2626.

MAMOU, K.; DEHAIS, C.; CHAIEB, F.; GHORBEL, F. Shape approximation for efficient progressive mesh compression. In: Image Processing (ICIP), 2010 17th IEEE International Conference on. [S.l.: s.n.], 2010. p. 3425-3428. ISSN 1522-4880.

MATLAB. version 7.10.0 (R2010a). Natick, Massachusetts: The MathWorks Inc., 2010.

NEEDELL, D.; WARD, R. Near-optimal compressed sensing guarantees for total variation minimization. Image Processing, IEEE Transactions on, v. 22, n. 10, p. 3941-3949, 2013. ISSN 1057-7149. 
PENG, J.; KIM, C.-S.; KUO, C.-C. J. Technologies for 3d mesh compression: A survey. Journal of Visual Communication and Image Representation, v. 16, p. 688-733, 2005.

PEREIRA, M. P. Efeitos da Quantização em Compressive Sensing de Imagens com Matrizes de Amostragem Determinísticas. Dissertação (Mestrado) - Universidade Federal do Rio de Janeiro, 2010.

PEYRÉ, G. Fourier on Meshes. 2008. Acesso em Novembro de 2013. Disponível em: https://www.ceremade.dauphine.fr/ peyre/numerical-tour/tours/ meshproc_4_fourier/.

PEYRÉ, G. Toolbox Graph. Julho 2009. A toolbox to perform computations on graph. Disponível em: http://www.mathworks.com/matlabcentral/fileexchange/ 5355-toolbox-graph.

PEYRÉ, G. Best basis compressed sensing. IEEE Transactions on Signal Processing, v. 58, p. 2613-2622, 2010.

PEYRÉ, G. The numerical tours of signal processing - advanced computational signal and image processing. IEEE Computing in Science and Engineering, v. 13(4), p. 9497, 2011. Disponível em: http://www.mathworks.fr/matlabcentral/fileexchange/ 9554-a-numerical-tour-of-signal-processing.

PRUGOVECKI, E. Quantum Mechanics in Hilbert Space. 2. ed. [S.l.]: Academic Press, 1981. 20 p.

REINHARDT, C. Taxi cab geometry: History and applications. The Montana Mathematics Enthusiast, v. 2, p. 38, 2005.

ROSSIGNAC, J. Edgebreaker: Connectivity compression for triangle meshes. [S.1.], Julho 1998.

RUDIN, L. I.; OSHER, S.; FATEMI, E. Nonlinear total variation based noise removal algorithms. Phys. D, Nonlinear Phenomena, v. 60, n. 1-4, p. 259-268, 1992. ISSN 0167-2789. Disponível em: http://wWw.sciencedirect.com/science/article/ pii/016727899290242F.

SALOMON, D. Data Compression: The Complete Reference. [S.1.]: Springer, 2007. With contributions by Giovanni Motta and David Bryant. ISBN 1-84628-602-6.

SCHRÖDER, P.; SWELDENS, W. Spherical wavelets: Efficiently representing functions on the sphere. SIGGRAPH '95 Proceedings of the 22nd annual conference on Computer graphics and interactive techniques, p. 161-172, 1995.

SCHULZ, A. Compressive Sensing: Novos Paradigmas para Aquisição e Compressão de Imagens. Dissertação (Mestrado) — Universidade Federal do Rio de Janeiro, 2008.

SCHUlZ, A.; SILVA, E. da; VELHO, L. Compressive Sensing. 1. ed. [S.l.]: 27 Coloquio Brasileiro de Matematica - SBM, 2009.

SCHULZ, A.; VELHO, L.; SILVA, E. A. B. da. On the Empirical Rate-Distortion Performance of Compressive Sensing. Novembro 2009. Acesso em Fevereiro de 2014. Disponível em: http://w3.impa.br/ aschulz/CS/paper.html. 
SCHULZ, A.; VELHO, L.; SILVA, E. A. B. da. Uma investigação empírica do desempenho da amostragem compressiva em codificação de imagens. XXVII SIMPÓSIO BRASILEIRO DE TELECOMUNICAÇÕES, 2009.

TAUBIN, G.; ROSSIGNAC, J. Geometric compression through topological surgery. ACM Transactions on Graphics (TOG), v. 17, p. 84-115, 1998.

TOUMA, C.; GOTSMAN, C. Triangle mesh compression. In: Proceedings of Graphics Interface. [S.l.: s.n.], 1998. p. 26-34.

VALETTE, S.; PROST, R. Wavelet-based multiresolution analysis of irregular surface meshes. Visualization and Computer Graphics, IEEE Transactions on, v. 10, n. 2, p. 113-122, 2004. ISSN 1077-2626.

VALETTE, S.; PROST, R. Wavelet-based progressive compression scheme for triangle meshes: wavemesh. Visualization and Computer Graphics, IEEE Transactions on, v. 10, n. 2, p. 123-129, 2004. ISSN 1077-2626.

WANG, H.; LIANG, J.; PAN, J.; LI, G.; DONG, G. A method of similarity of logging curves based on the improved lts hausdorff distance. In: Image and Signal Processing (CISP), 2011 4th International Congress on. [S.l.: s.n.], 2011. v. 1, p. 26-30.

YANG, A.; SASTRY, S.; GANESH, A.; MA, Y. Fast 11-minimization algorithms and an application in robust face recognition: A review. In: Image Processing (ICIP), 2010 17th IEEE International Conference on. [S.l.: s.n.], 2010. p. 1849-1852. ISSN 1522-4880.

YOON, S. M.; KUIJPER, A. View-based 3d model retrieval using compressive sensing based classification. In: Image and Signal Processing and Analysis (ISPA), 2011 7th International Symposium on. [S.1.: s.n.], 2011. p. 437 -442. ISSN 1845-5921.

YU, H.; CHEN, J.; WAN, W.; WANG, R.; YU, X. A segmentation progressive mesh compression method. In: Audio, Language and Image Processing (ICALIP), 2012 International Conference on. [S.l.: s.n.], 2012. p. 1163-1166.

ZHANG, J.; LAI, R.; KUO, C.-C. Latent fingerprint segmentation with adaptive total variation model. In: Biometrics (ICB), 2012 5th IAPR International Conference on. [S.l.: s.n.], 2012. p. 189-195. 